\title{
ALTERATION OF ORAL MICROBIOME IN CHILDREN AFTER USING MISWAK (SALVADORA PERSICA L.) MADE FROM ARAK AS A NATURAL TOOTHPASTE
}

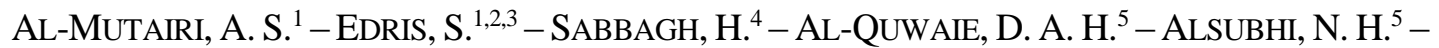 \\ ABULfarAJ, A. A. ${ }^{5}$ - AlghAMDI, R. A. ${ }^{6}-$ Al-GARNI, S. M. S. ${ }^{1}$ - BAHIELDIN, A. ${ }^{1,3^{*}}-$ KABLI, S. A. ${ }^{1}$ \\ ${ }^{1}$ Department of Biological Sciences, Faculty of Science, King Abdulaziz University, Jeddah, \\ Saudi Arabia \\ ${ }^{2}$ Princess Al Jawhara Albrahim Centre of Excellence in Research of Hereditary Disorders \\ (PACER-HD), King Abdulaziz University, Jeddah, Saudi Arabia \\ ${ }^{3}$ Department of Genetics, Faculty of Agriculture, Ain Shams University, Cairo, Egypt \\ ${ }^{4}$ Pediatric Dentistry Department, Faculty of Dentistry, King Abdulaziz University, Jeddah, \\ Saudi Arabia \\ ${ }^{5}$ Department of Biological Sciences, Science and Arts College, Rabigh Campus, King Abdulaziz. \\ University (KAU), Jeddah, Saudi Arabia \\ ${ }^{6}$ Department of Chemistry, Science and Arts College, Rabigh Campus, King Abdulaziz \\ University (KAU), Jeddah, Saudi Arabia \\ *Corresponding author \\ e-mail: abmahmed@kau.edu.sa; phone: +966-506-329-922 \\ (Received $6^{\text {th }}$ Mar 2020; accepted $2^{\text {nd }}$ Jul 2020)
}

\begin{abstract}
The influence of Miswak (Salvadora persica L.) that is made from arak on the oral microbiome signatures of 6- to 12-year-old Saudi children was studied. Deep sequencing was done for the V3-V4 regions of bacterial 16S rRNA. Sequence tags were assigned to 291 OTUs (operational taxonomic units) across samples with $\geq 97 \%$ similarity. The results indicated that factors like ethnic background and/or geographic origin can influence differences in healthy oral microbiome signatures. The results indicated some changes in the overall structure and diversity of oral microbiome. At genera level, there are five abundant phyla. At the species level, there are two opportunistic pathogens and the unassigned species as well as bacteria of the Proteobacteria family significantly decreased, the unassigned species belonging to the two genera increased due to swaking. The high abundance of Streptococcus and Megasphaera genera and low abundance of Veillonella genus are biomarkers of good oral hygiene as the first two genera (producer) can catabolize carbohydrates to the useful short-chain organic acids in biofilm formation, while the third (consumer) relies mainly on the fermentation of organic acids. These results shed light on the possible anti-microbial and antiinflammatory properties of Miswak in addition to the role in removing plaque. In summary, we claim that Miswak is an excellent natural toothpaste for maintaining good oral hygiene, especially for children.

Keywords: oral microflora, dysbiosis, Streptococcus, Megasphaera, Veillonella, organic acids
\end{abstract}

\section{Introduction}

The human body contains $\sim 100$ trillion bacterial cells representing 1000 bacterial species or more. This bacteriome influences important parameters in human health including immune response, nutrient absorption, body weight, etc. (Gill et al., 2006; Pflughoeft and Versalovic, 2012). Although most of these bacterial species promote human health, others contribute to human illness (Greenblum et al., 2012; Ley, 2010). Other reports indicate that 
the type of bacteria is not the only factor affecting human health, but the global microbiome balance was proved to have influence on human health (Huttenhower et al., 2012; Methé et al., 2012). Therefore, it is important to detect the normal symbiotic bacterial community that holds the healthy performance in human and how dysbiosis of this community encounters for diseases (Costello et al., 2009; Qin et al., 2010; Turnbaugh et al., 2009).

The mouth cavity is the major gateway to the human body, which influences the gastrointestinal microbiome and subsequent status of human health (Meurman, 2010). Dysbiosis of oral bacteriome has been linked with several life-threatening disorders including cardiovascular disease, stroke, pneumonia, etc. (Awano et al., 2008; Beck and Offenbacher, 2005; Joshipura et al., 1996, 2003; Offenbacher et al., 1998; Seymour et al., 2007). Simon-Soro et al. (2018) indicated that combined assessment of host response along with host oral microbiome can reveal clusters of health and disease. This indicates that oral microbiome can offer biomarkers of oral health (Alcaraz et al., 2012) and disease (Gomez and Nelson, 2017). Simon-Soro and colleagues also indicated that susceptibility to oral disease can be influenced by host immune factors, with emphasis to those existing in saliva. The latter contains a complex mixture of innate anti-microbial proteins and adaptive immune mediators with a significant impact on the microbial colonization of the oral cavity (Hancock et al., 2016; Mookherjee and Hancock, 2007). Previous reports indicate the high diversity among oral microbiomes of healthy individuals (inter-individual variation) (Aas et al., 2005; Nasidze et al., 2009), but little is known about the link between the structure and diversity of the oral microbiomes of healthy individuals in different ethnics/geographic regions (Mason et al., 2013). Interestingly, Nasidze and colleagues (Nasidze et al., 2009) indicated that normal saliva microbiome differs as we go further from the equator. In addition, saliva microbiome differs due to the human lifestyle and diet (Nasidze et al., 2011).

Salvadora persica L., also known as Miswak, is a tooth (or chewing) stick that is recommended by Prophet "Muhammad". Salvadora persica belongs to the family Salvadoraceae and order Brassicales (Table 1). This plant is a well-branched evergreen tree, with soft yellow wood, that is capable to tolerate severe abiotic stresses (Haque and Alsareii, 2015; Khatak et al., 2010). The World Health Organization (WHO) has recommended the use of this stick as a natural toothbrush for healthy oral hygiene (WHO, 1984). The plant is known to contain important chemical constituents such as vitamin C, alkaloids, trimethylamine, tannins, saponins, organic sulphur compounds, lignan glycosides, etc. (Ohtani et al., 1992). Besides, the plant possesses a number of bioactive compounds with important pharmacological properties (Aumeeruddy et al., 2018). These properties include anti-microbial, anti-oxidant, anti-ulcer, anti-inflammatory, and anti-tumor activities besides being recently feasible in several biotechnological applications (Lebda et al., 2018).

Table 1. The taxonomic classification of Salvadora persica

\begin{tabular}{c|c}
\hline Kingdom & Plantae \\
Division & Magnoliphyta \\
Class & Magnoliopsida \\
Order & Brassicales \\
Family & Salvadoraceae \\
Genus & Salvadora \\
Species & Persica oleoides \\
Binomial name & Salvadora persica \\
\hline
\end{tabular}


The present study aims at detecting the influence of swaking with Salvadora persica L. (Miswak) for one month on maintaining or restoring healthy oral microbiome in Saudi children and assessing the possible protective effects against human opportunistic pathogens.

\section{Materials and methods}

\section{Recruitment of participants and sample collection}

The study was approved by the Ethics Committee of King Abdulaziz University Hospital (KAUH, Jeddah, Saudi Arabia) under number 066-16 in 2018 and written informed consent was obtained from parents of all participant children. All participant children received oral examination and those with a history of immunosuppression or systemic diseases, use of medications that reduce saliva flow, or exposure to antimicrobials in the previous three months were excluded from the study. A total of 10 Saudi children were selected based on the pervious criteria with age ranging from 6 to 12 years old. Children have used Miswak once a day for one month. The saliva samples were collected before (BEF) and after (AF) swaking in Oragene-DNA (OG-500) SelfCollection kit (DNA Genotek Inc., Canada) and mixed with stabilizing reagent in the collection tubes per manufacturer's instructions and stored at $4{ }^{\circ} \mathrm{C}$.

\section{DNA extraction and partial 16S rRNA gene sequencing}

Genomic DNA was extracted using the QIAamp® DNA Mini kit (Qiagen ${ }^{\circledR} 51306$; Hilden, North Rhine-Westphalia, Germany) according to the manufacturer's instructions. DNA purity was evaluated via A260/A280 ratio using NanoDrop 7000 Spectrophotometer (Thermo Fisher Scientific, Waltham, MA, USA), and DNA integrity was checked by $1 \%$ agarose gel electrophoresis. PCR amplification of the V3-V4 regions of bacterial $16 \mathrm{~S}$ rRNA was performed using the universal primers 338F $\left(5^{\prime}\right.$ ACTCCTACGGGAGGCAGCA-3') and 806R (5'-GGACTACHVGGGTWTCTAAT$\left.3^{\prime}\right)$. PCR program was the following: initial denaturation at $95^{\circ} \mathrm{C}$ for $5 \mathrm{~min} ; 25$ cycles of denaturation at $95{ }^{\circ} \mathrm{C}$ for $30 \mathrm{~s}$, annealing at $56^{\circ} \mathrm{C}$ for $30 \mathrm{~s}$, and extension at $72{ }^{\circ} \mathrm{C}$ for 40 $\mathrm{s}$; and final extension of $72{ }^{\circ} \mathrm{C}$ for $10 \mathrm{~min}$. Amplicons were run on agarose gel $(1.2 \%)$, then gel-purified using DNA Gel Extraction kit (Qiagen, Hilden, Germany) according to the manufacturer's instructions. Amplicons were, then, shipped to Beijing Genome Institute (BGI) in China for library construction and deep sequencing on Illumina Miseq platform to recover $\sim 300$ bp pair-end reads of the V3 and V4 regions. The ends of each read were overlapped to generate high-quality, full-length reads. The resulted sequencing data has been deposited in the European Nucleotide Archive (ENA) (https://www.ebi.ac.uk/ena/submit/sra/\#studies) under the project number PRJEB27276.

\section{$16 S$ dataset processing and statistical analysis}

Sample size estimation was performed to determine the probability that the samples are representative (Motulsky, 2010). The raw sequencing data were analyzed using the Quantitative Insights Into Microbial Ecology 2 (QIIME2) package v.2018.11; (https://qiime2.org) (Bokulich et al., 2018; Bolyen et al., 2019). V3-V4 16S rRNA sequence reads were trimmed using trimmomatic software (Version 0.33) and merged into single sequences using FLASH (Version 1.2.10). Merged sequences were filtered to remove the low-quality sequences. The latter are the reads shorter than 110 
nucleotides, reads truncated at any site with an average quality score of $<20$ over a 50 bp sliding window, or the truncated reads that were shorter than $50 \mathrm{bp}$. Only sequences that overlapped for more than $10 \mathrm{bp}$ were assembled. The unique sequence set was linked to tags and classified into operational taxonomic units (OTUs) with a cutoff of $97 \%$ identity using the de novo OTU selection strategy. We retained only OTUs with at least $0.01 \%$ mean relative abundance, as predominant. OTUs were ranked by the relative abundance values as $\mathrm{x}$ - and $\mathrm{y}$-axis, then the rank curve was drawn by software $\mathrm{R}$ (Version 3.1.1). Taxonomies were assigned by the RDP classifier (Version 2.2) (Cole et al., 2013) against the Human Oral Microbiome Database (Chen et al., 2010) (HOMD RefSeq, Version 13.2) and the Greengenes database (version 13.8: 16S rDNA database, http://qiime.org/home_static/dataFiles.html) with a confidence threshold of 0.7 . Chimeric sequences were removed using Usearch (Version 8.0).

Alpha diversity was assessed by Shannon and Simpson indices that were calculated by Mothur (v1.31.2), and the corresponding boxplot of alpha diversity and rarefaction curve were drawn by software $\mathrm{R}$ (Version 3.1.1). Drawing rarefaction curve was based on calculating OTU numbers of the extracted tags (in multiples of 500) and detecting the maximum depth (no. reads) permitted to retain all samples in the dataset. Sequences were extracted randomly according to the minimum sequence number for all samples, and the extracted sequences formed a new 'OTU table biom' file. To detect the beta diversity within and between groups, the weighted and unweighted UniFrac distances were calculated (Lozupone et al., 2011) and plotted via principal coordinate analysis (PCoA) using package 'ade4' of software R (Version 3.1.1). UniFrac uses the system evolution information to compare the composition of community species between samples. The results can be used as a measure of beta diversity. It takes into account the distance of evolution between species, and the bigger the index, the greater the differences between samples. The UniFrac is divided into weighted UniFrac and unweighted UniFrac of which the weighted UniFrac considers the abundance of sequences, while unweighted UniFrac gives more weight on species presence/absence.

Heat maps were generated using the package 'gplots' of software R (Version 3.0.3) (https://github.com/talgalili/gplots). At phylum level, all species were used to draw the heat map and taxa of which abundance was less than $0.5 \%$ in all samples were classified as 'others'. To minimize the differences degree of the relative abundance value, the values were all $\log$ transformed. The representative sequences were aligned against the Silva core set. Representative OTU phylogenetic tree was constructed using the QIIME 2 (v.2018.11) built-in scripts including the fast-tree method for tree construction. The tags with the highest abundance of each genus was chosen as the corresponding genus representative sequences, and genus level phylogenetic tree was obtained by the same way as the OTU phylogenetic tree. Then, the phylogeny tree was imaged by $\mathrm{R}$ phylogenetics packages. Venn diagram was drawn by Venny (http://bioinfogp.cnb.csic.es/tools/venny/), while differences in the relative abundances of taxa at the phylum, genus and species levels were analyzed using Metastats (Paulson et al., 2011). PERMANOVA was used to test significance among values. All statistical tests were two-sided, and $\mathrm{P}$ value $\leq 0.05$ was considered significant. BenjaminiHochberg false discovery rate (FDR) correction was used to correct for multiple hypothesis testing where applicable. A GitHub repository link (https://github.com/shandley/Microbiome-Analysis-Using-R.git) providing the applied codes was added. 


\section{Results}

\section{Statistics of oral $16 \mathrm{~S}$ rRNA sequence datasets}

In the present study, the oral microbiome was detected for a group of 10 Saudi children (subjects) who used Miswak as a natural toothpaste. Illumina MiSeq was used in analyzing 20 salivary samples based on the $16 \mathrm{~S}$ rRNA. Statistics of the raw data description and its processing is shown in Table 2. The average sequence length per read was $297 \mathrm{bp}$ across different samples ranging from 293 to $300 \mathrm{bp}$. A total of 2,305,029 clean sequence reads were generated across subjects before and after swaking with average read numbers of 116,476 and 114,027 per subject, respectively (Fig. 1). A total of 2,241,369 tag-linked sequences were generated across subjects before and after swaking with average read numbers of 113,346 and 110,791 per subject, respectively. While, a total of 1,700,687 sequence tags were generated across subjects before and after swaking with average read numbers of 86,072 and 83,995 per subject, respectively (Fig. 1). These sequence tags were assigned to 291 OTUs (operational taxonomic units) across samples with $\geq 97 \%$ similarity. A summation of 4,147 OTUs for the 20 samples were generated with an average of 207 OTUs per sample ranging from 146 to 257 OTUs and averages of 206 and 208 OTUs per subject before and after swaking (Figs. 2 and $A 1$ ). The overall number of OTUs before swaking (BEF) was 289, while 282 after swaking (AF). The results for the number of observed species (number of OTUs) per subject indicated increases in four subjects, while resulted in decreases in five subjects and no change in one subject (Fig. 2).

Table 2. Statistics of data generated from deep sequencing for 10 Saudi children before $(B E F)$ and after $(A F)$ swaking for one month

\begin{tabular}{|c|c|c|c|c|c|c|c|c|c|}
\hline $\begin{array}{c}\text { Sample } \\
\text { ID }\end{array}$ & $\begin{array}{c}\text { Reads } \\
\text { length (bp) }\end{array}$ & $\begin{array}{c}\text { Raw data } \\
\text { (Mbp) }\end{array}$ & $\begin{array}{c}\text { N base } \\
(\%)\end{array}$ & $\begin{array}{c}\text { Low } \\
\text { quality }(\%)\end{array}$ & $\begin{array}{c}\text { Clean data } \\
\text { (Mbp) }\end{array}$ & $\begin{array}{c}\text { Data } \\
\text { utilization }(\%)\end{array}$ & $\begin{array}{l}\text { Raw } \\
\text { reads }\end{array}$ & $\begin{array}{l}\text { Clean } \\
\text { reads }\end{array}$ & $\begin{array}{c}\text { Read } \\
\text { utilization }(\%)\end{array}$ \\
\hline $\mathrm{BEF} 2$ & $300: 295$ & 89.24 & 0.002 & 7.765 & 73.06 & 81.87 & 149,985 & 130,663 & 87.12 \\
\hline BEF6 & 299:295 & 79.81 & 0.001 & 6.864 & 66.83 & 83.74 & 134,352 & 119,170 & 88.70 \\
\hline BEF8 & 298:295 & 73.22 & 0.001 & 7.257 & 60.23 & 82.26 & 123,481 & 108,164 & 87.60 \\
\hline BEF9 & $296: 295$ & 84.64 & 0.001 & 7.787 & 69.78 & 82.44 & 143,209 & 125,526 & 87.65 \\
\hline BEF10 & $297: 294$ & 70.10 & 0.001 & 7.719 & 57.33 & 81.79 & 118,613 & 103,360 & 87.14 \\
\hline BEF12 & 296:294 & 65.60 & 0.000 & 7.847 & 53.49 & 81.55 & 111,179 & 96,635 & 86.92 \\
\hline BEF14 & 294:294 & 79.26 & 0.001 & 7.752 & 64.36 & 81.21 & 134,790 & 117,250 & 86.99 \\
\hline BEF15 & 293:294 & 70.97 & 0.002 & 7.396 & 57.99 & 81.71 & 120,904 & 105,761 & 87.48 \\
\hline BEF19 & $300: 294$ & 92.49 & 0.001 & 7.376 & 76.47 & 82.69 & 155,701 & 136,473 & 87.65 \\
\hline BEF20 & 299:294 & 82.00 & 0.001 & 7.163 & 67.93 & 82.84 & 138,284 & 121,761 & 88.05 \\
\hline $\mathrm{AF} 2$ & $294: 296$ & 74.17 & 0.002 & 6.002 & 62.50 & 84.27 & 125,711 & 113,133 & 89.99 \\
\hline AF6 & 293:296 & 64.83 & 0.001 & 6.418 & 54.24 & 83.67 & 110,064 & 98,130 & 89.16 \\
\hline AF8 & $300: 296$ & 83.51 & 0.001 & 6.229 & 70.41 & 84.32 & 140,110 & 125,524 & 89.59 \\
\hline AF9 & 299:296 & 88.14 & 0.003 & 5.953 & 74.70 & 84.76 & 148,127 & 133,382 & 90.05 \\
\hline AF10 & $298: 296$ & 65.37 & 0.001 & 6.203 & 54.80 & 83.82 & 110,056 & 98,229 & 89.25 \\
\hline AF12 & $296: 296$ & 80.26 & 0.001 & 6.397 & 67.79 & 84.46 & 135,575 & 121,608 & 89.70 \\
\hline $\mathrm{AF} 14$ & $297: 295$ & 88.56 & 0.002 & 7.310 & 73.27 & 82.74 & 149,588 & 131,711 & 88.05 \\
\hline AF15 & $296: 295$ & 69.51 & 0.003 & 7.725 & 57.17 & 82.25 & 117,610 & 102,860 & 87.46 \\
\hline AF19 & 294:295 & 64.55 & 0.001 & 7.524 & 52.85 & 81.87 & 109,588 & 95,807 & 87.42 \\
\hline AF20 & 293:295 & 80.93 & 0.001 & 7.712 & 66.05 & 81.62 & 137,635 & 119,882 & 87.10 \\
\hline
\end{tabular}



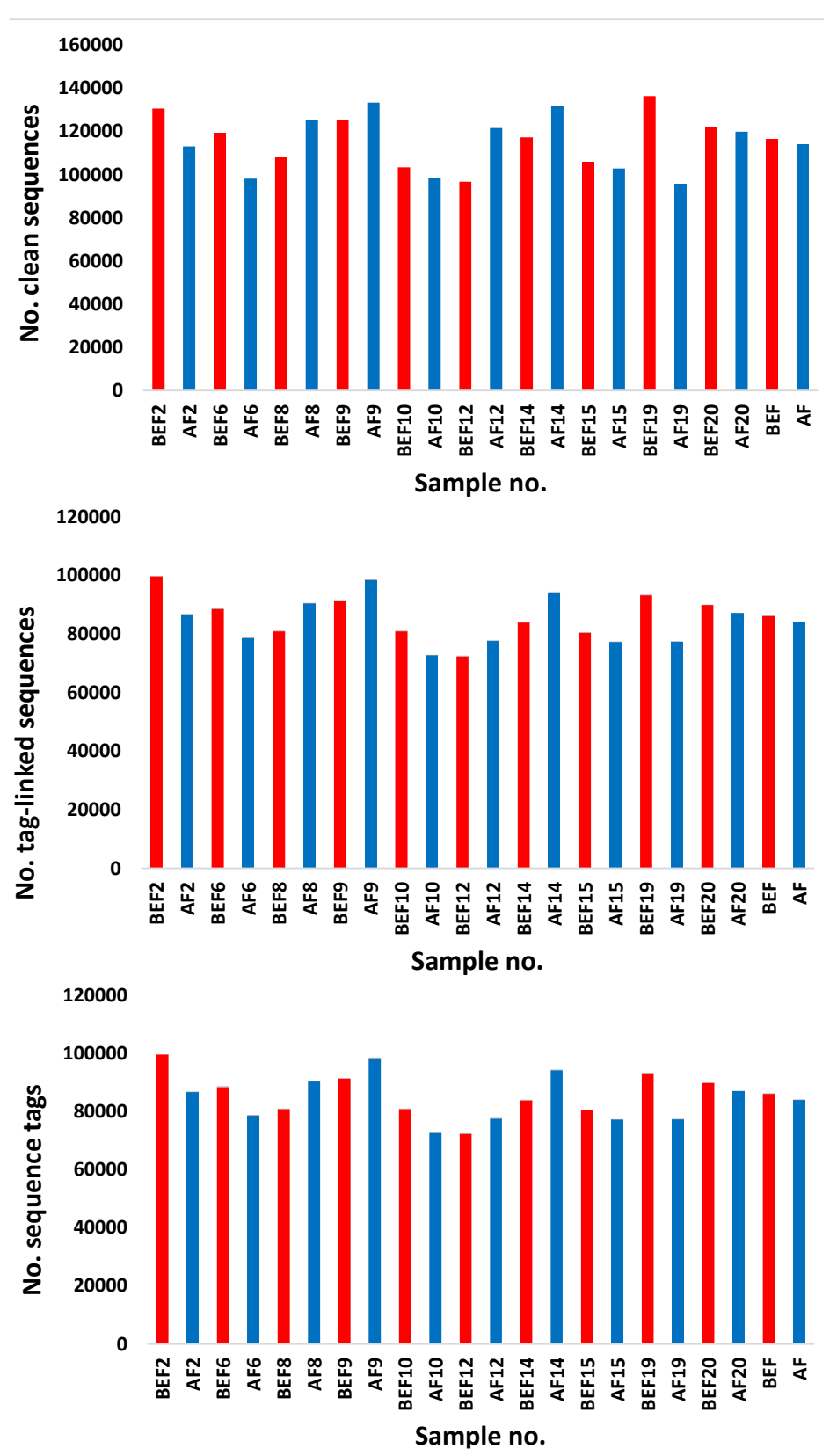

Figure 1. Comparison among numbers of clean and tagged sequences along with the recovered sequence tags at the sample and group levels before (red) and after (blue) swaking for one month to sequences statistics. BEF = before swaking, AF = after swaking

\section{Diversity and rarefaction curve analysis}

Description of observed species detected from OTU annotation is shown in Table Al. Alpha diversity was applied to analyze complexity of species. Shannon and Simpson indices as alpha diversity measures indicated no significance between BEF and AF groups (Fig. 2). Shannon and Simpson values reflect the species diversity of the community at both species' richness and evenness levels. But Shannon index comprises more weight on sequence richness, while Simpson index comprises more weight on evenness. With the same species richness, the greater the species evenness, the greater the community diversity. Alpha diversity per subject indicated increases in six subjects 
due to swaking for one month in terms of Shannon measures (Fig. 2). Almost opposite results were detected in terms of Simpson measures (Fig. 2). These results indicated that the use of Miswak has resulted in increased microbial species richness and decreased species evenness. In other words, Miswak likely changed the overall structure of oral microbiome during such a short period of treatment. Alpha diversity at the group level showed much higher diversity in AF group due to swaking than BEF group (Fig. 3). However, further prolonged studies might be required to prove whether salivary bacterial diversity is related to oral hygiene status, especially after swaking, or not.
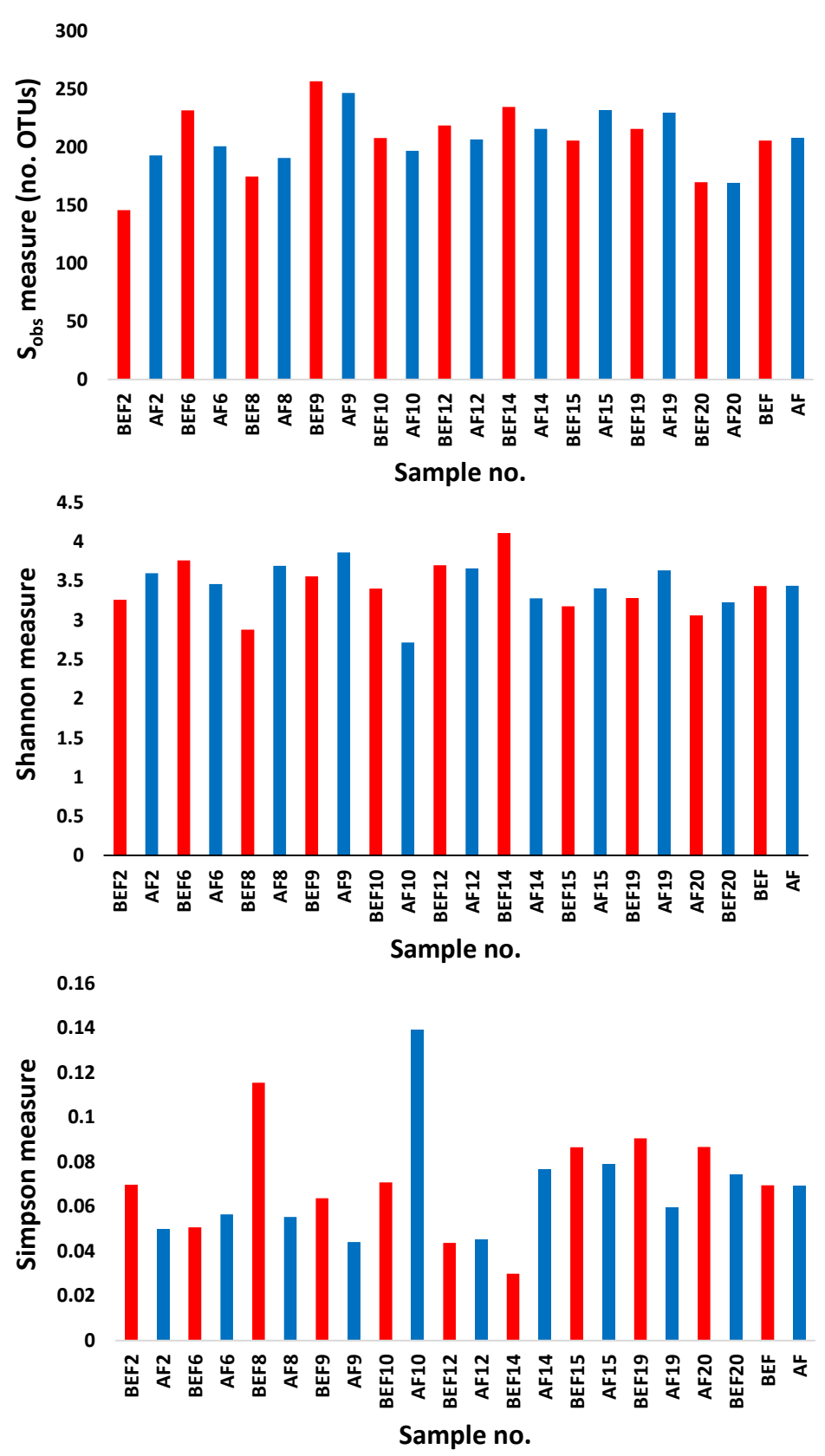

Figure 2. Alpha diversity measures at the sample and group levels before (red) and after (blue) swaking for one month to describe number of species (OTUs) per sample or group, sample or group richness (Shannon index) and evenness (Simpson index). BEF = before swaking,

$$
\text { AF }=\text { after swaking }
$$



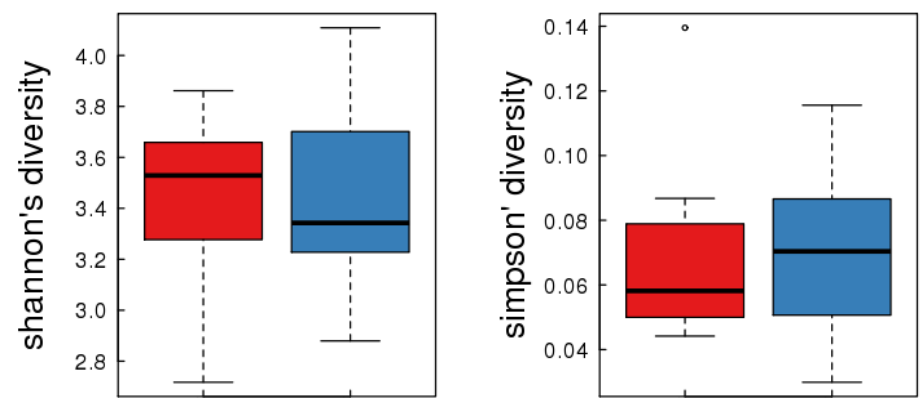

Figure 3. Alpha diversity indices as boxplots to describe richness and evenness at the group level of the samples before (red) and after (blue) swaking for one month

Rarefaction curves based on stacked number of OTUs (Fig. 4) were analyzed in order to describe the maximum depth permitted to retain all samples in the dataset for studying taxonomic relative abundance and to evaluate if produced data is enough to cover all species in the microbial community. When the curve tends to drop (Fig. 4) or no longer climbs, this indicates that the produced data is enough for further analysis. The more the curve continues to climb with increasing sequencing reads, the higher the complexity will be in samples, i.e., there will still be species uncovered by the sequencing data. The two rarefaction measures indicated that the maximum number of sequences reads to be used for further analysis of taxonomy abundance is 72,000 (Fig. 4).

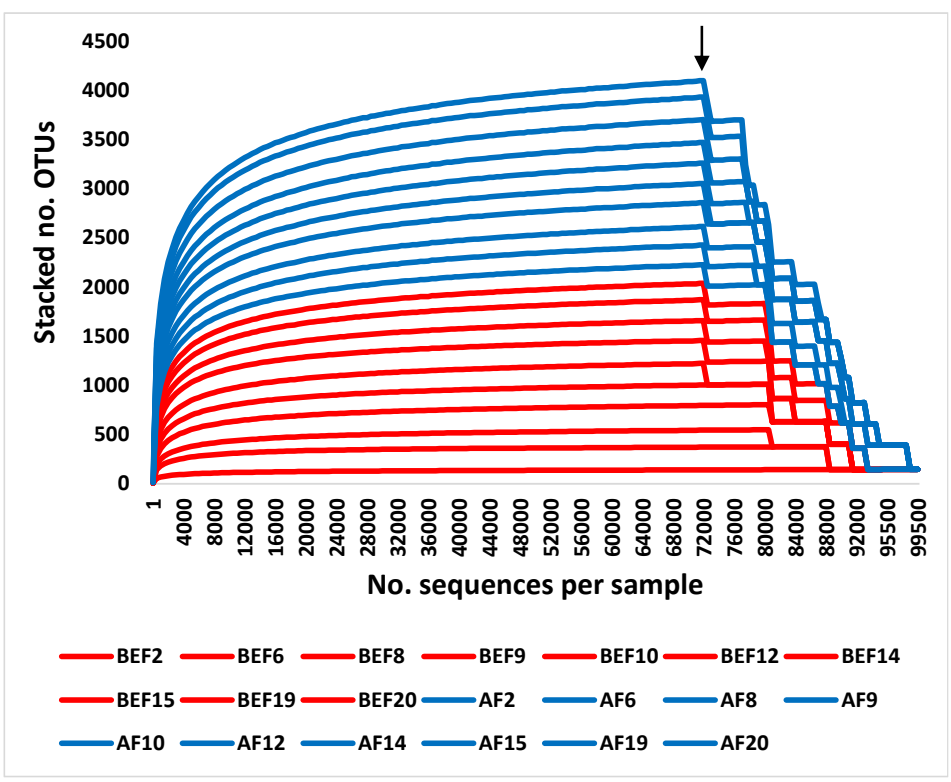

Figure 4. Stacked number of OTUs as rarefaction measures to describe the maximum depth permitted to retain all samples in the dataset for studying taxonomic relative abundance. The arrows indicate the suitable sample size for analyzing taxonomy abundance (72,000 sequence reads). $B E F=$ before swaking, $A F=$ after swaking

In order to display the diversity and differences of OTU composition in different samples and groups, principal coordinate analysis (PCoA) was used (Fig. 5). PCoA summarizes factors mainly responsible for this difference. When similarity is high, the two groups are closely located. Based on the OTU abundance information, the relative 
abundance of each OTU in each sample and group was calculated, thus the PCoA of OTUs was plotted (Fig. 5). The PCoA plot partially showed a similar tendency in the distances within and between groups. The diversity of BEF subjects was higher towards PCoA 2 direction (PC2), while diversity of AF subjects was higher towards PCoA 1 direction (PC1). Overall, the diagram showed that mean value of BEF group was localized in the positive directions of PCoA 1 and PCoA 2 (PC1 and PC2), while that of AF group was localized in the negative directions (Fig. 5). These results indicated that the microbiome signatures of the two groups differed due to swaking, while holding relatively similar microbiome compositions as the swaking time of the experiment was short.

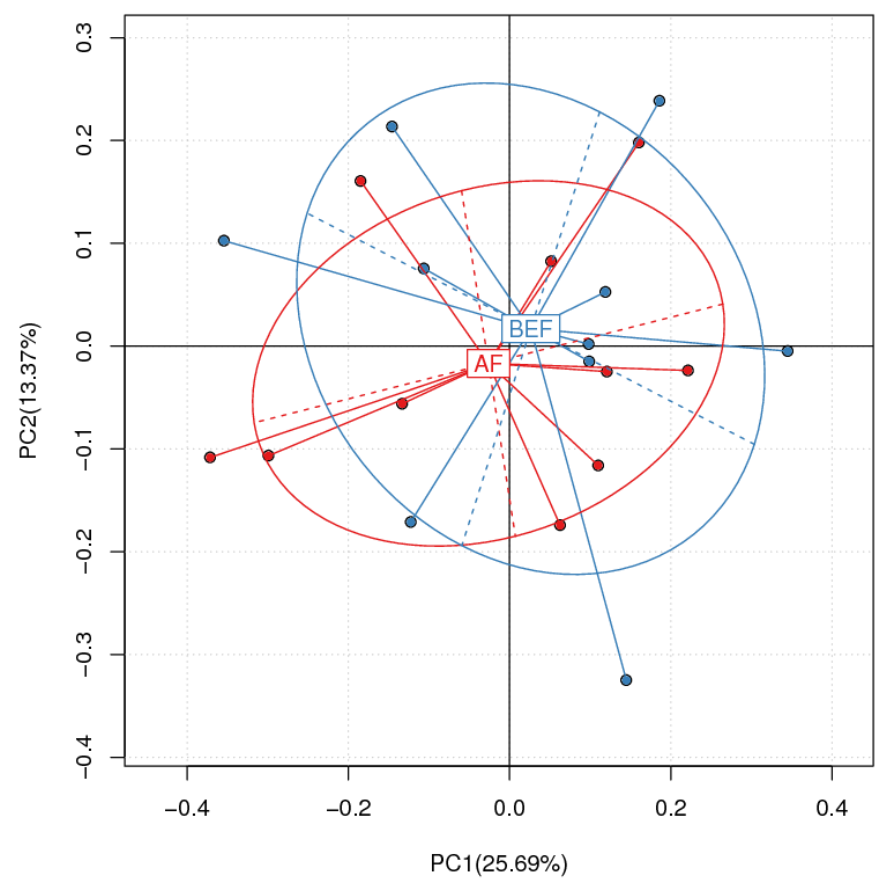

Figure 5. PCOA based on OTU abundance of different samples. Blue box indicate sample mean before swaking. Red box indicate sample mean after swaking for one month. $X$-axis is the first principal coordinate and $Y$-axis is the second. Numbers in brackets represent contributions of

PCoAs to differences among samples. A dot represents each sample, and different colors represent different groups

\section{Oral microbiomes at phylum and genus levels}

Phylogenetic tree describing taxonomic groups of oral microbiomes at phylum and genus levels are shown in Figure 6. A phylogenetic tree is a branching diagram showing the inferred evolutionary relationships among various biological taxa based upon similarities and differences in their physical or genetic characteristics. The evolutionary distance between taxa is closer if the branch length is shorter. Besides the taxa composition and abundance analysis, phylogenetic tree could clarify the species evolutionary relationship further. The results indicated that the most common phyla are Actinobacteria (seven genera), Bacteroidetes (six genera), Firmicutes (28 genera), Fusobacteria (two genera), Proteobacteria (11 genera), Sphirochaetes (one genus), Synergistetes (two genera) and Tenericutes (two genera) (Fig. 6). 


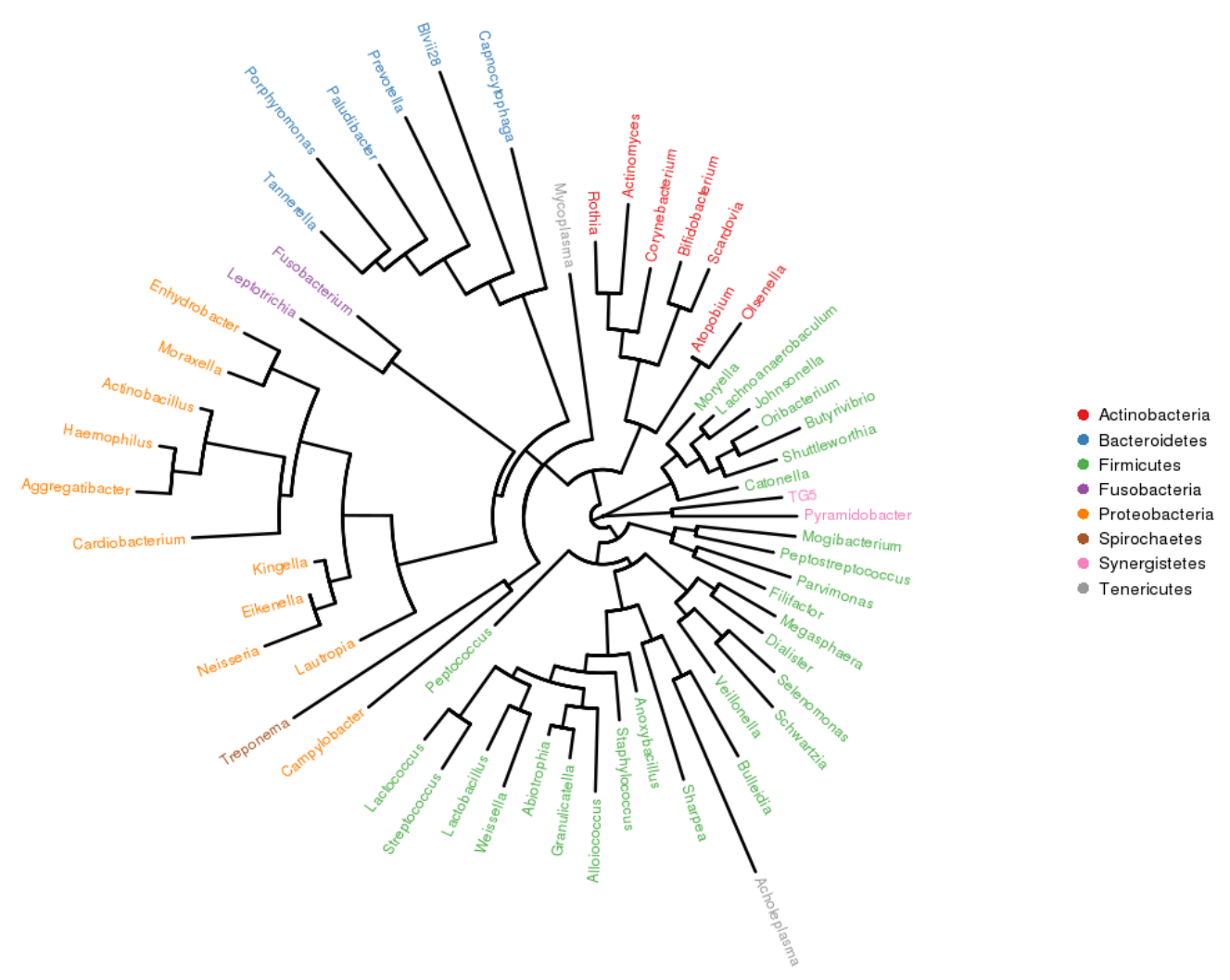

Figure 6. Genus level phylogenetic tree of oral microbiome. Genera with the same color belong to the same phylum

Abundance of individual OTUs across samples was also studied in which OTUs with number of sequences over 10,000 were considered highly abundant (Fig. 7). This criterion was met by a number of 29 out of the 219 OTUs (Table A2). These selected OTUs are OTU1-OTU12, OTU14, OTU15, OTU17, OTU20, OTU21, OTU23, OTU25OTU29, OTU32, OTU33, OTU37, OTU40, OTU193 and OTU261. Table A2 also indicates richness of these OTUs for different samples before and after swaking. Description of these selected highly abundant OTUs in terms of taxonomy of their phyla, genera and/or species is shown in Table A3. The results of Table A3 indicate that the highly abundant OTUs belong to five of the previously mentioned phyla (e.g., Bacteroidetes, Firmicutes, Proteobacteria, Fusobacteria, Actinobacteria) in addition to the recently discovered phylum of Saccharibacteria, previously known as TM7. These results are consistent with those of log-scaled percentage heat map at the phylum level (Fig. A2). A heat map is a graphical representation of data where the individual values contained in a matrix are represented as colors.

The five highly abundant phyla included a number of 25 genera/species (Table A3). The latter include assigned and unassigned species of genera Prevotella and Porphyromonas of Bacteroidetes; Streptococcus, Veillonella, Gemella, Megasphaera, Clostridium and Granulicatella of Firmicutes; Haemophilus, Campylobacter, Neisseria, Moraxella and Pasteurella of Proteobacteria; Fusobacterium and Leptotrichia of Fusobacteria; while Rothia of Actinobacteria. However, no genus/species information is available for the new phyla Saccharibacteria TM7-3 because, up to date, these bacteria is culture-independent. 


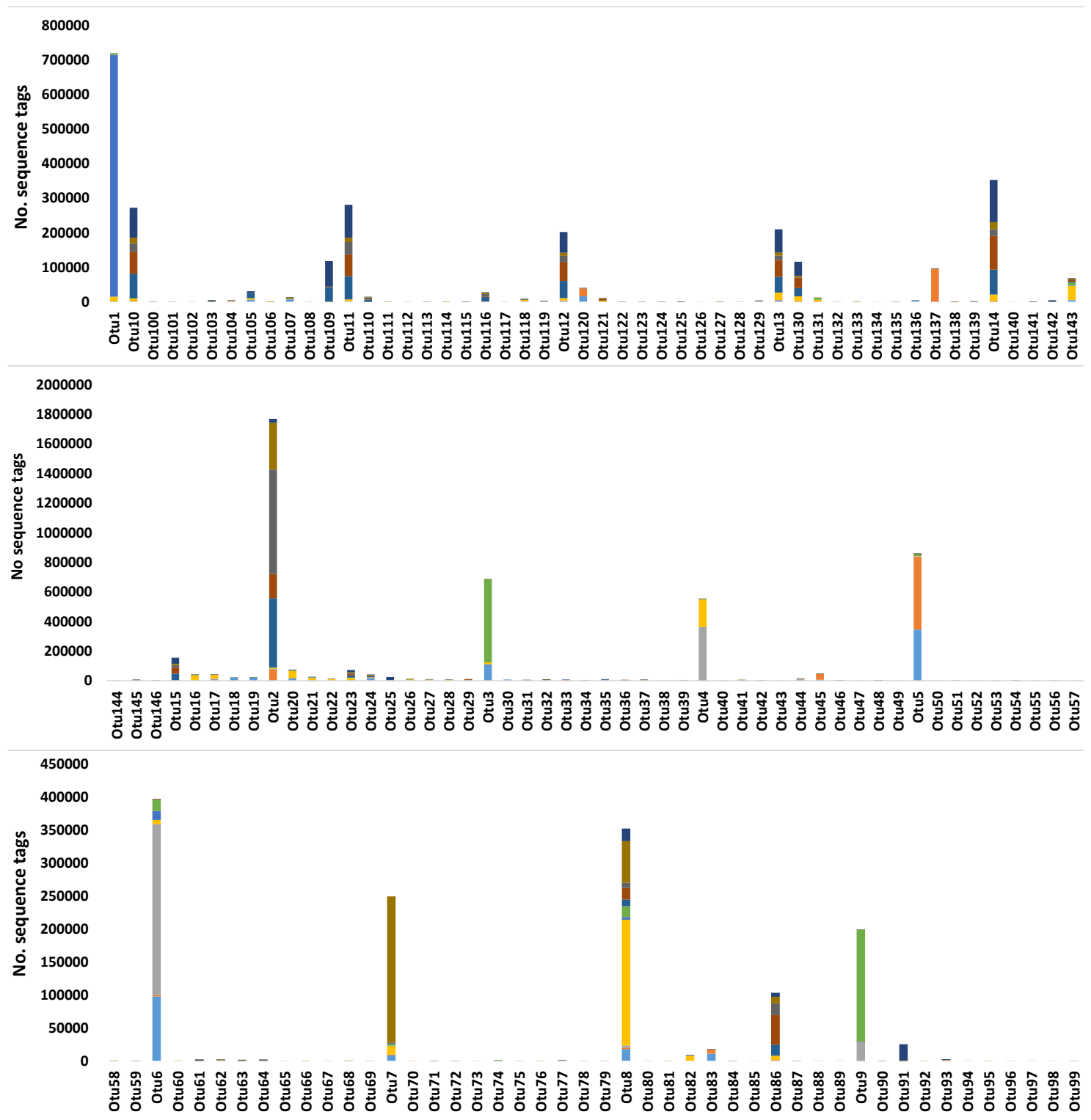

Figure 7. OTU abundances across samples

At the genus level, Streptococcus was the most abundant genus, with $S$. infantis as the most abundant species, followed by Veillonella (mainly $V$. dispar), Prevotella (mainly P. melaninogenica), Haemophilus (mainly H. parainfluenzae), Rothia (mainly R. mucilaginosa), Neisseria (mainly N. subflava), Fusobacterium, Campylobacter and the candidate phyla Saccharibacteria (Table A3). These results are consistent with those of log-scaled percentage heat maps at genus and species levels (Figs. A3 and A4). Many of the highly abundant genera (e.g., Veillonella, Campylobacter, Clostridium, Prevotella, etc.) and species (e.g., V. dispar, H. parainfluenzae, $R$. mucilaginosa, etc.) are opportunistic pathogens and reflect the lack or the poor hygiene that requires attention, especially at childhood period.

Venn diagram indicated the existence of 280 common OTUs in both the BEF and AF groups (Fig. 8). The number of OTUs uniquely found in BEF group was nine representing the taxonomic groups Streptococcus spp., Aggregatibacter, 
Veillonellaceae, Prevotella spp., Pyramidobacter piscolens, Bifidobacterium spp., Bulleidia spp., Prevotella spp. and Streptophyta I), while two (Actinobacillus spp. and Kingella spp.) in AF group. Each of these taxonomic groups were present in only 1-2 samples, while only Streptococcus spp. was present in five BEF samples. However, this result was not considered affective because the number of sequences for the specific OTU of this taxa (e.g., OTU138) is as little as 72. Thus, the 11 group-specific OTUs were not considered effective in distinguishing between the two groups or in detecting the influence of swaking for one month on children oral microbiomes (Fig. 8).

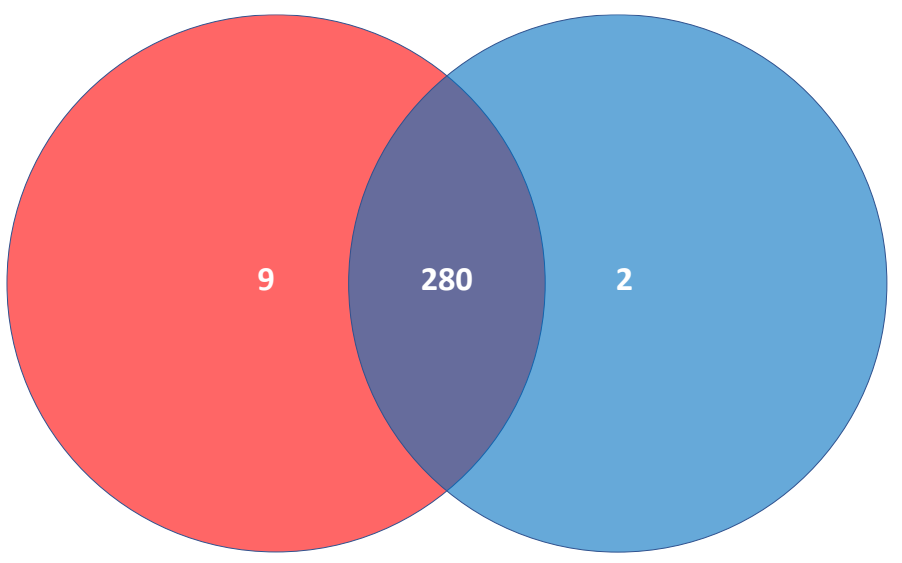

Figure 8. Venn diagram describing the unique (nine for BEF and two for AF) and shared OTUs (280) between the two groups of samples before (red) and after (blue) swaking for one month. $B E F=$ before swaking, $A F=$ after swaking. The nine BEF OTUs involve OTU138, OTU181, OTU224, OTU232, OTU243, OTU257, OTU260, OTU266 and OTU 267. The two AF OTUs involve OTU127 and OTU269. The other OTUs (280) are shared between the two groups with different relative abundances

\section{Differential abundance of microbes due to swaking for one month}

Differential abundance of microbes of different subjects before and after swaking for one month was studied at phylum, genus and species levels (Figs. 9, 10 and 11, respectively). Weighted Unifrac diversity distances within subjects indicated major changes in microbiome signature due to swaking in six out of the ten subjects, while unweighted Unifrac diversity distances within subjects indicated major changes in only two subjects. We did not consider the unweighted Unifrac results as the number of diverged subjects is less than four. As indicated earlier, prolonged swaking time might result in higher distances at the weighted and unweighted Unifrac levels. A number of 12 phyla, 27 genera and 21 species showed considerable changes within each subject's microbiome due to swaking (Figs. 9, 10 and 11, respectively). Overall, phyla Actinobacteria and Bacteroidetes decreased, while Firmicutes increased due to swaking for one month.

Statistical analysis for the highly abundant OTUs recovered from oral microbiomes with number of sequences over 10,000 indicated significant increases due to swaking across subjects in two OTUs referring to unassigned species of the genera Streptococcus and Megasphaera (Fig. 12; Table A4), while significant decreases in five OTUs referring to opportunistic pathogens Veillonella dispar and Rothia mucilaginosa; unassigned species of genera Campylobacter and Prevotella as well as bacteria of the family Pasteurellaceae (Fig. 13; Table A4). 


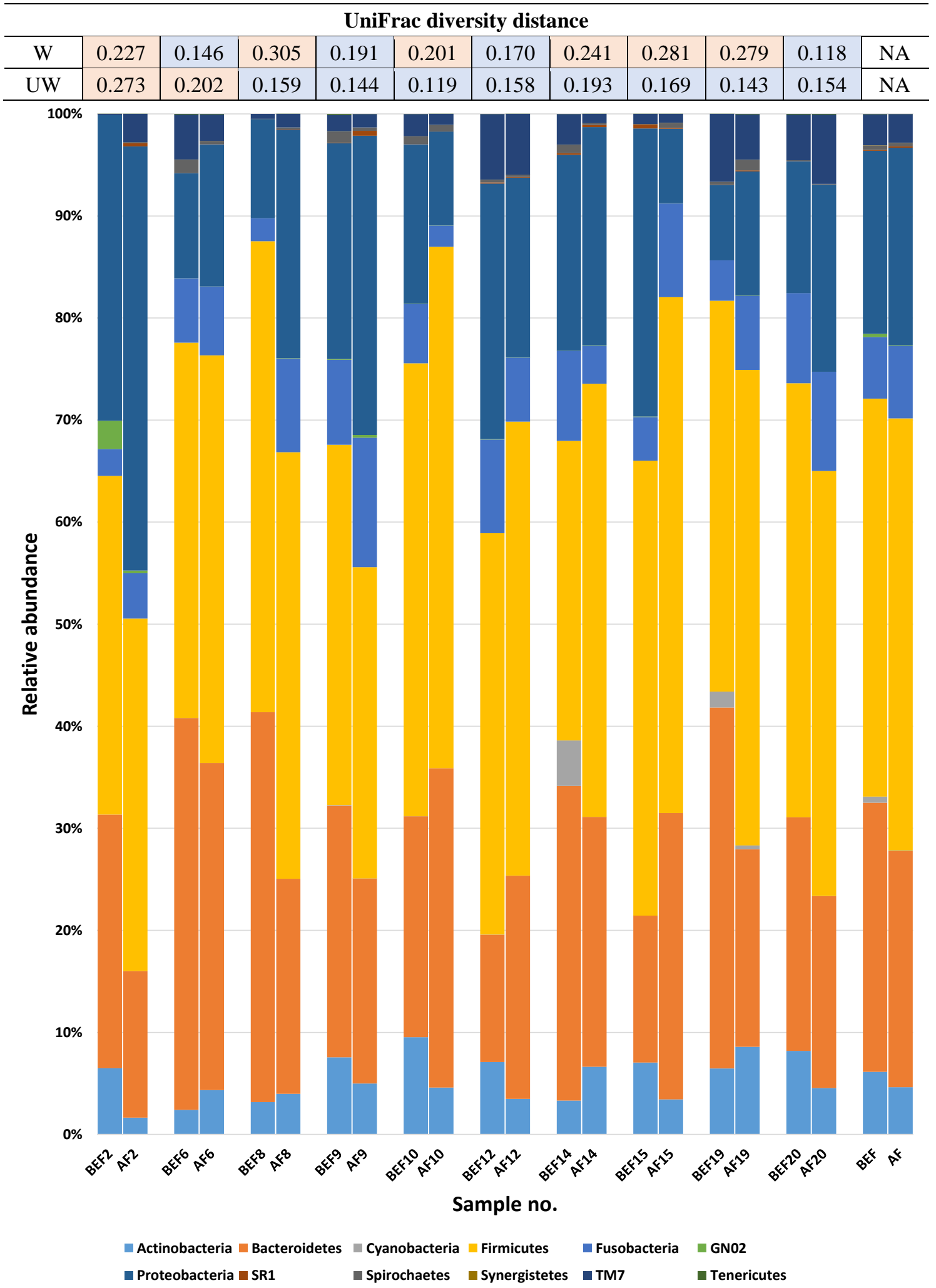

Figure 9. Relative abundance at phylum level as measured by Metastats at sample and group levels before (red) and after (blue) swaking for one month. BEF = before swaking, AF = after swaking. On top of the figure: pink box $=$ distance of $\geq 2$, while blue box $=$ distance of $<2$ to describe both weighted_Unifrac $(W)$ and unweighted_Unifrac $(U W)$ diversity distances between sample pairs of each subject (beforelafter) 


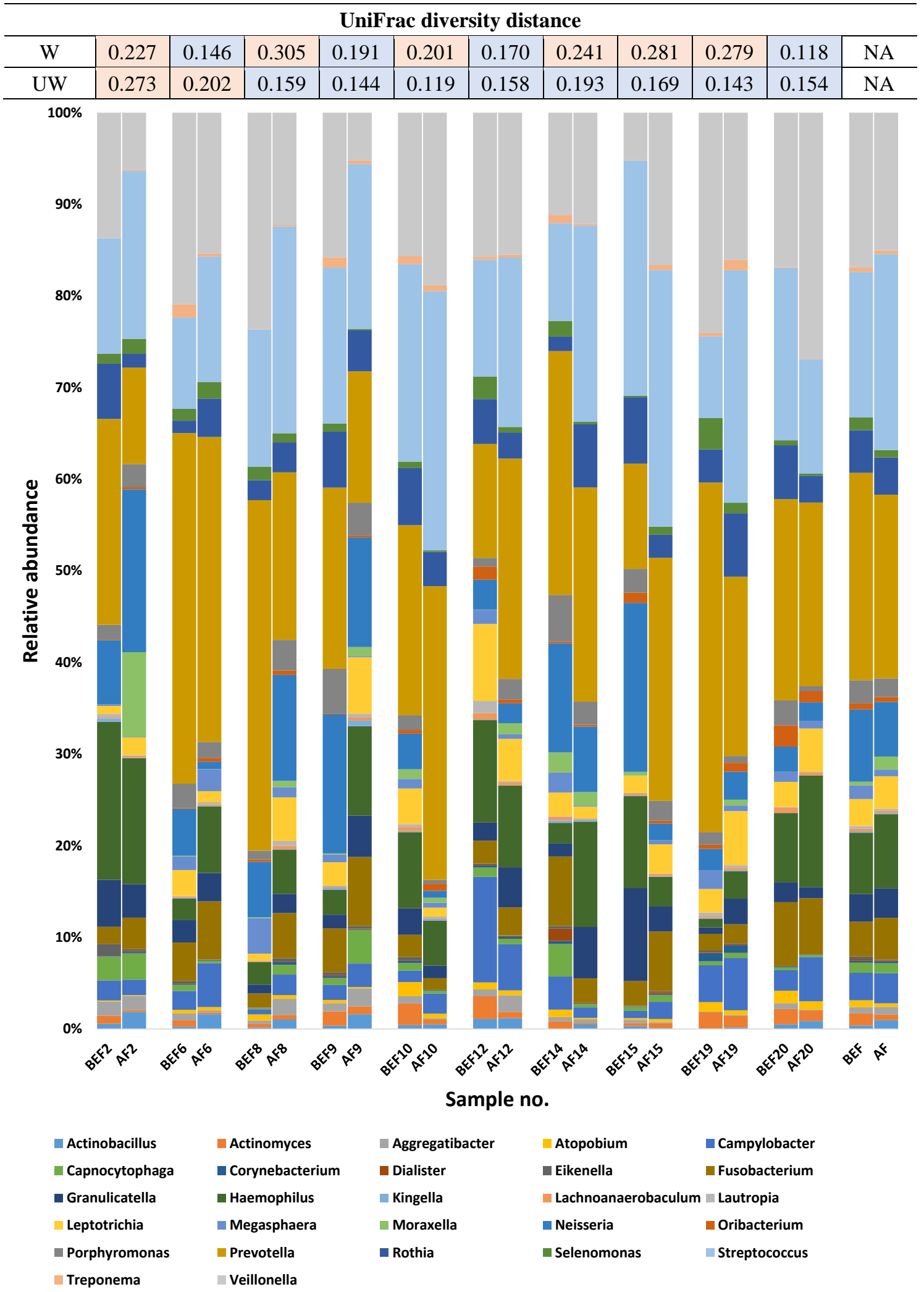

Figure 10. Relative abundance at genus level as measured by Metastats at sample and group levels before (red) and after (blue) swaking for one month. $B E F=$ before swaking, $A F=$ after swaking. On top of the figure: pink box $=$ distance of $\geq 2$, while blue box $=$ distance of $<2$ to describe both weighted_Unifrac $(W)$ and unweighted_Unifrac $(U W)$ diversity distances between sample pairs of each subject (before/after) 


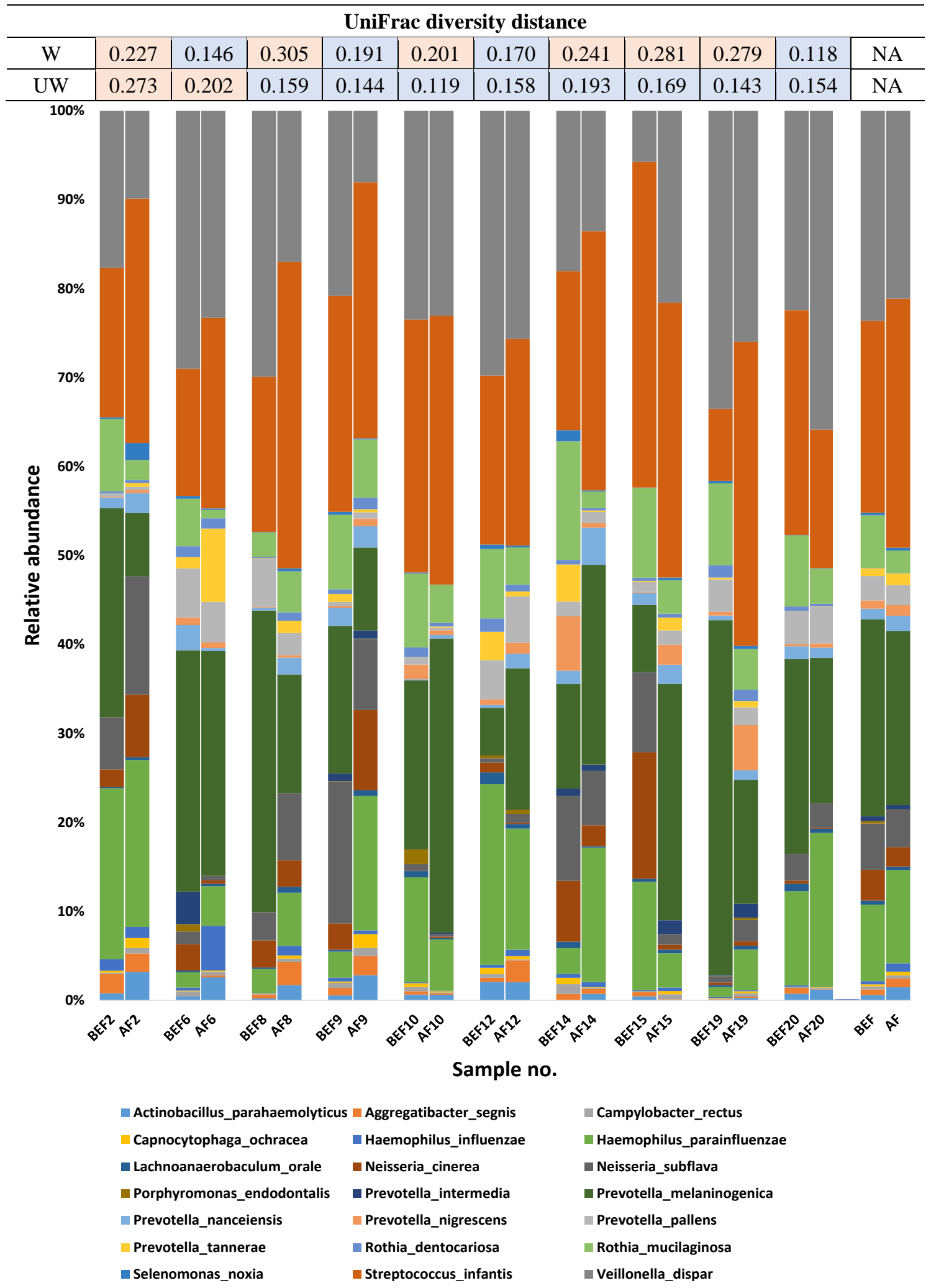

Figure 11. Relative abundance at species level as measured by Metastats at sample and group levels before (red) and after (blue) swaking for one month. BEF = before swaking, $A F=$ after swaking. On top of the figure: pink box $=$ distance of $\geq 2$, while blue box $=$ distance of $<2$ to describe both weighted_Unifrac $(W)$ and unweighted_Unifrac $(U W)$ diversity distances between sample pairs of each subject (beforelafter) 


\section{Streptococcus spp.}

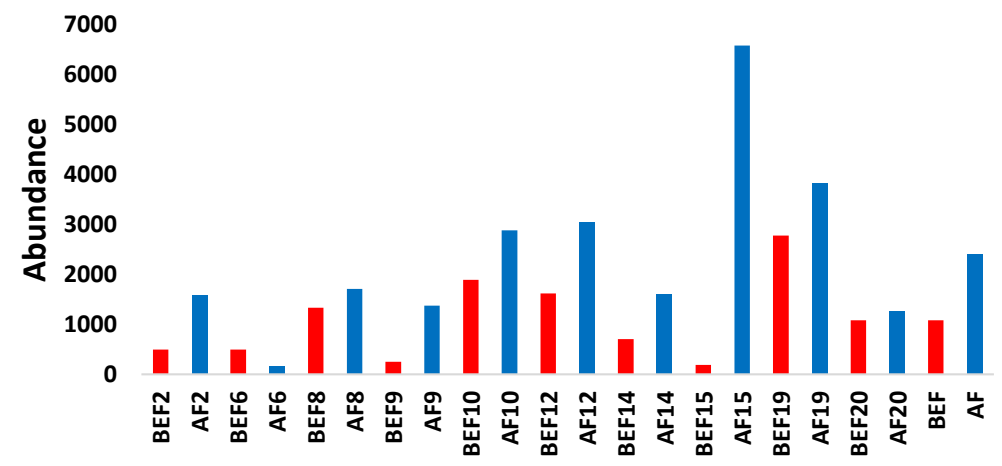

Sample no.

Megasphaera spp.

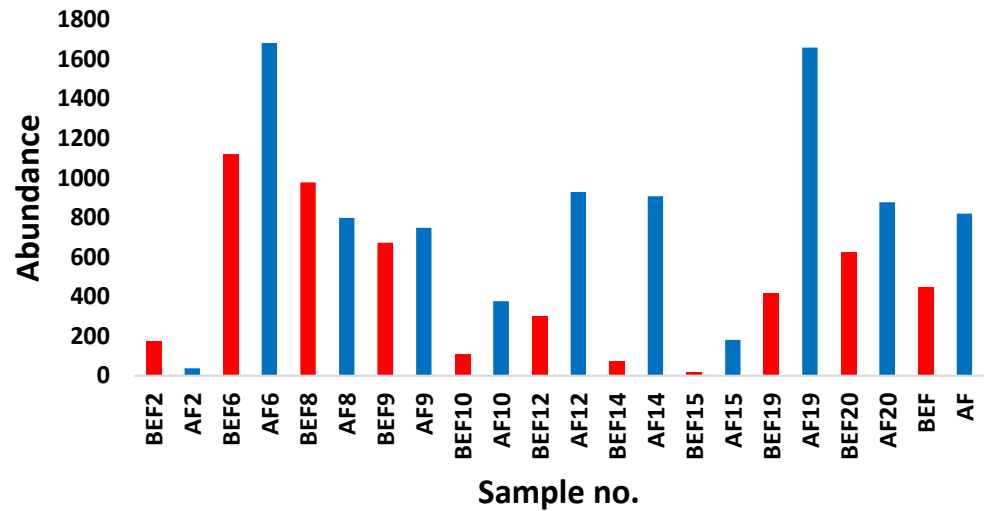

Figure 12. High abundance of the unassigned species of the genera Streptococcus and Megasphaera due to swaking for one month. BEF = before swaking, $A F=$ after swaking

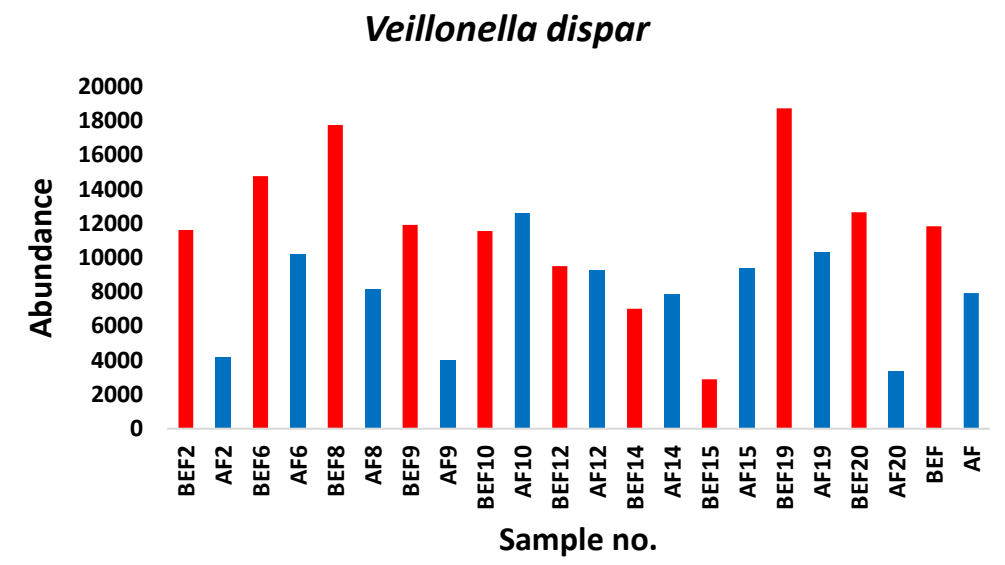

Figure 13. Low abundance of Veillonella dispar, Rothia mucilaginosa, unassigned species of the genera Campylobacter and Prevotella as well as bacteria of the family Pasteurellaceae due to swaking for one month. $B E F=$ before swaking, $A F=$ after swaking 


\section{Rothia mucilaginosa}

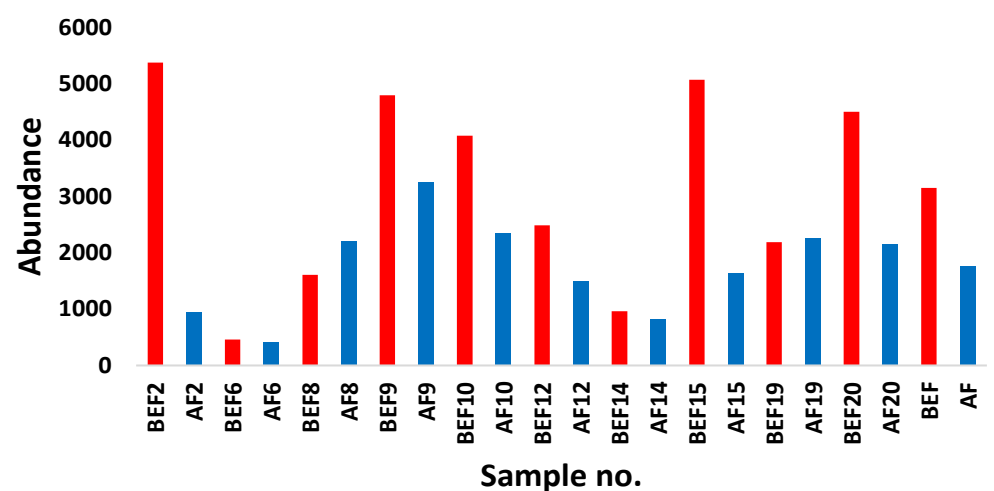

Campylobacter spp.

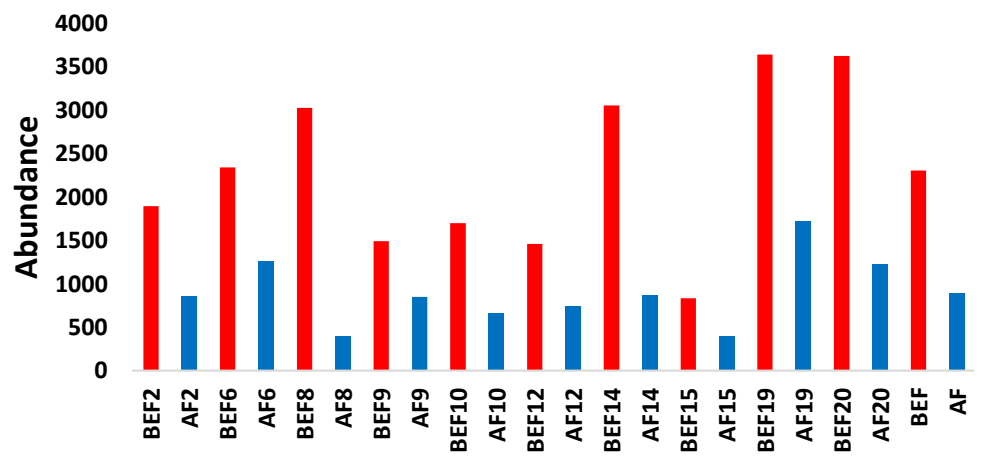

Sample no.

Prevotella spp.

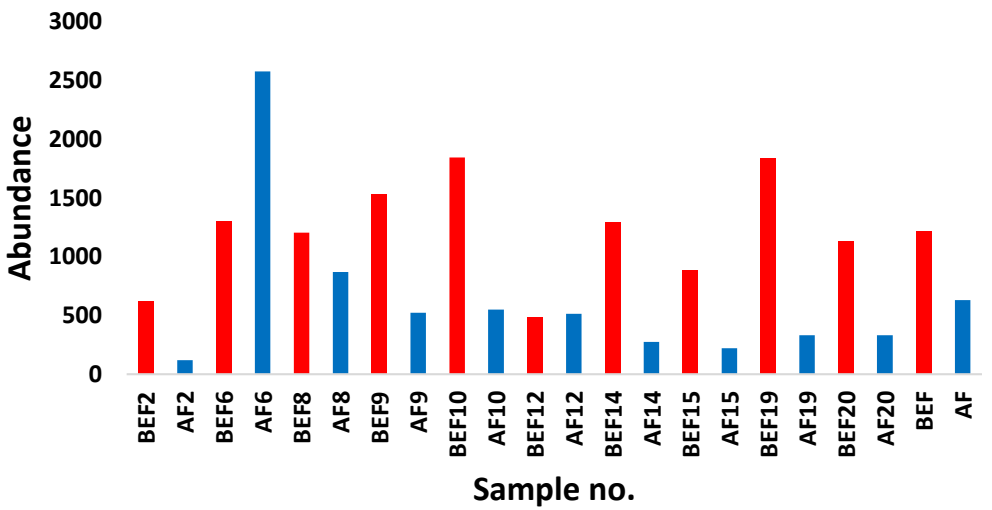

\section{Pasteurellaceae}

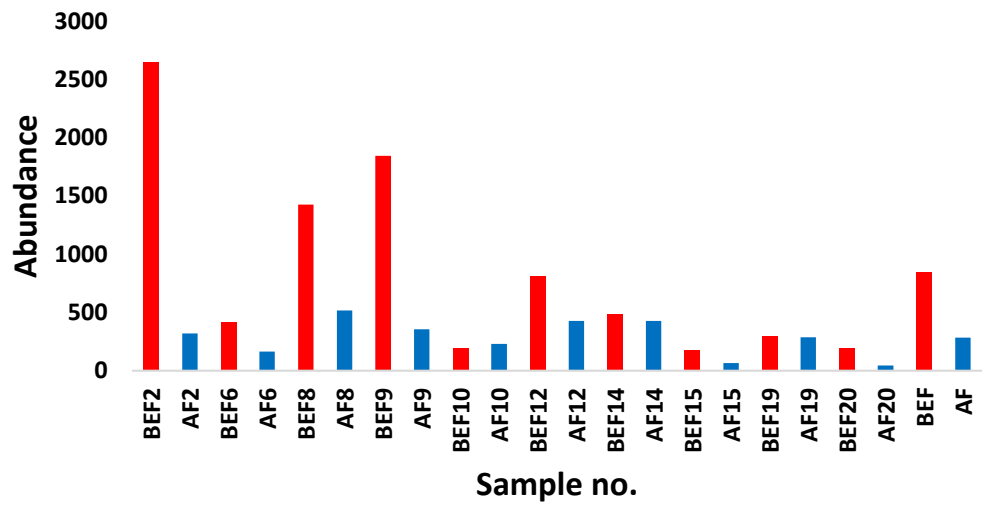

Figure 13. Contiued 


\section{Discussion}

Oral microbiome significantly affects overall human health. It is organized as biofilms adapted to every niche within the mouth. This biofilm has fundamental role in host homeostasis and the protection against oral as well as gastric diseases (Ismail et al., 2009; Kau et al., 2011).

Normally, the predominant bacteria in saliva are commensal and produce enzymes that degrade biofilm matrix polymers (Kaplan et al., 2004; Pereira et al., 2012) Poor oral hygiene can lead to changes in microbial communities and cause dental caries and periodontal disease that seriously affect children's overall life-time health status (Marsh, 2003; Prabhu and John, 2015). Therefore, it is important to detect oral microbe biofilm signatures in healthy and infected individuals in order to develop preventive strategies, especially in childhood.

Earlier studies indicated that changes in the microbiome balance might have a more important influence on human health than a distinct microbial species being either beneficial or harmful (Huttenhower et al., 2012; Methé et al., 2012). Although a distinct microbial species might not be harmful in its primary habitat, oral bacteria were linked with systemic, life-threatening disorders including cardiovascular disease, pneumonia and stroke (Awano et al., 2008; Beck and Offenbacher, 2005; Joshipura et al., 2003; Joshipura et al., 1996; Seymour et al., 2007). Oral microbiome is highly divergent among healthy individuals as several ecological factors, such as life style, external environment and oral hygiene, can contribute to this divergence (Aas et al., 2005; Crielaard et al., 2011; Nasidze et al., 2009; Sheiham and Watt, 2000).

Other factors include ethnic background and/or geographic origin (Aas et al., 2005; Ledder et al., 2007). Several bacterial genera/phyla fundamentally influence human oral health/disease status. They include Actinomyces spp., Gemella spp., Granulicatella spp., Veillonella spp., Haemophilus spp., Capnocytophaga spp. and TM7. For example, early colonization of Veillonella spp. and existence of phylum TM7 guide the development of microbial biofilm communities (Liu et al., 2012; Periasamy and Kolenbrander, 2010). As indicated earlier, Streptococcus was the most abundant genus in oral micrbiomes of Saudi children regardless of swaking, followed by Veillonella, Prevotella, Haemophilus, Fusobacterium, Rothia, Neisseria, Campylobacter and the candidate phyla Saccharibacteria (Table A3). These results are consistent with previous studies of the human oral microbiota (Hoffman et al., 2018; Li et al., 2014; Takeshita et al., 2014).

High-throughput technologies are employed in detecting microbiome signatures in different human organs and their relation to disease risk/status (Gao et al., 2017; Jo et al., 2017). The approach of the cost-efficient, high-throughput characterization of the human microbiome relies on the use of microbial 16S ribosomal RNA (rRNA) gene sequence that is considered as a barcode of microbes, either culturable or unculturable (Ahn et al., 2011). Such an approach can provide new insights into the diversity, normal microbial signatures and health/disease status (Ahn et al., 2011; Belda-Ferre et al., 2012; Johansson et al., 2016; Zhou et al., 2016). Many problems raised when isolating oral bacterial DNA from clinical samples due to the lack of bacterial lysis uniformity, particularly for gram-positive bacteria (Lazarevic et al., 2013). Although Vesty et al. (2017) recommended the use of enzymatic lysis method for bacterial DNA extractions, Garbieri et al. (2017) recommended the use of commercial DNA extraction kits. We have chosen the QIAamp ${ }^{\circledR}$ DNA Mini kit (Qiagen ${ }^{\circledR} 51306$; Hilden, North RhineWestphalia, Germany) for extracting high-quality oral bacterial DNA. Another problem lies in the choice of the hypervariable regions (V1-V9) of 16S rRNA gene that 
adequately and reliably detect oral microbiome signatures. Besides, it is important to know the proper database for OTU annotation. Based on the most recent studies, the $16 \mathrm{~S} \mathrm{V3-V4} \mathrm{regions} \mathrm{of} \mathrm{oral} \mathrm{microbiome} \mathrm{were} \mathrm{successful} \mathrm{in} \mathrm{detecting} \mathrm{accurate} \mathrm{microbial}$ signatures and in providing adequate phylogenetic assignment (Furquim et al., 2017; Jiang et al., 2016; Yu et al., 2017). Accordingly, we have chosen the V3-V4 regions for analyzing the oral microbiome. We have also chosen the Greengenes (version 13_8: 16S rDNA database, http://qiime.org/home_static/dataFiles.html) (DeSantis et al., 2006) and Human Oral Microbiome (HOMD, http://www.homd.org/) (Chen et al., 2010) databases for annotating the oral microbiome sequences.

The influence of swaking on human oral microbiome was statistically studied on the 29 most abundant families, genera and species (Table A4). The overall results indicated that swaking for one month resulted in the significant increases of the unassigned species of the genera Streptococcus and Megasphaera (Table A4; Fig. 12) and the significant decreases of the bacteria Veillonella dispar and Rothia mucilaginosa; unassigned species of genera Campylobacter and Prevotella as well as bacteria of the family Pasteurellaceae (Table A4; Fig. 13). Although extremely abundant, Streptococcus anginosus (previously known as Streptococcus milleri) and S. infantis showed insignificant increases due to swaking (Table A4). Otherwise, the influence of Miswak was arbitrary for the other highly abundant taxa with no specific pattern across subjects. Although it resides in normal flora of the oral cavity, Streptococcus anginosus is considered as a strong virulent pathogen (Liu et al., 2018). It is speculated that the significant increase of oral Streptococcus anginosus associates with periodontal diseases (Drucker and Green, 1977; Liu et al., 2018; Rawlinson et al., 1993). Streptococcus infantis is a microbe that lives mainly in the human upper respiratory tract and usually found in healthy mouths, e.g., free of or are at low risk of tooth decay (http://www.ncbi.nlm.nih.gov/pmc/articles/PMC2444020/, http://www.ncbi.nlm.nih.gov/pmc/articles/PMC3472979/).

Miller et al. (2017) showed an increased evidence that the commensal acetaldehydogenic microorganism Rothia mucilaginosa can be an opportunistic pathogen in immune-compromised hosts, while Amer et al. (2017) indicated that the increased abundance of $R$. mucilaginosa is linked to oral leukoplakias from lingual sites. Elevated levels of $R$. mucilaginosa was also shown to be associated with human endocarditis, meningitis and peritonitis (https://en.wikipedia.org/wiki/Rothia). Amer et al. (2017) also indicated that the increased levels of Campylobacter concisus is associated with severe dysplasia. Campylobacter spp. is the main cause of food poisoning (campylobacteriosis) affecting up to $1 \%$ of the world (https://en.wikipedia.org/wiki/Campylobacter). Recently, Liu et al. (2018) detected high abundance of Prevotella intermedia in saliva of gout and hyperuricemia (HUA) patients and suggested that abundance of this bacterial species is linked with gum inflammation and the progression of periodontitis. This conclusion complements a previous one made by Kamma et al. (1994). As for the bacteria of the family Pasteurellaceae, it was recently reported to be associated with caries in young children living in a rural province in China (Xu et al., 2018). The significant decreases of Rothia mucilaginosa, Campylobacter spp., Prevotella and Pasteurellaceae due to swaking in the present study (Fig. 13) can be considered as biomarkers of good hygiene in children.

Most of the normal commensal oral bacteria benefit the host through the production of various metabolites. They mostly include short chain fatty acids, vitamins, co-factors and other metabolites (Nallabelli et al., 2016). However, there is a strong reverse action 
of the two colonizers, e.g., Streptococcus and Veillonella in oral cavity bacteria (Hoffman et al., 2018). Mashima et al. (2017) indicated that unassigned species of Streptococcus spp. decreased, while Veillonella dispar, V. parvula and unassigned species of Veillonella spp. increased with poor oral hygiene status. Streptococcus, a facultative anaerobe and an initial colonizer, is able to catabolize (and transport) carbohydrates to short-chain organic acids, e.g., lactic acid and pyruvic acid (Cotter and Hill, 2003). On the other hand, Veillonella, an obligate anaerobe and subsequent colonizer, is unable to catabolize sugars, thus, it relies mainly on the fermentation of organic acids to propionic and acetic acids, carbon dioxide, and hydrogen (Delwiche et al., 1985). It is reported that oral Veillonella depends on organic acids produced by oral Streptococcus (Mashima and Nakazawa, 2014; Palmer et al., 2006). The proximity of the producer/consumer shuttle is important in such metabolite transfers (Mashima and Nakazawa, 2014; Palmer et al., 2006). Organic acids participate mainly in biofilm formation due to the action of Streptococcus (Periasamy and Kolenbrander, 2010). Anaerobic environment promotes growth of Veillonella due to the prior growth of aerobic and facultative organisms that results in an increased plaque thickness to yield conditions suitable for anaerobic growth (Ritz, 1967). The growth of Streptococcus may be inhibited by anaerobic conditions that favor the growth of Veillonella. Therefore, the high abundance of Veillonella in salivary microbiome is considered as a biomarker of poor oral hygiene and occurrence of caries in children (Fig. 14). Pharmacological studies indicated that Miswak possesses anti-microbial, anti-plaque and antiinflammatory activities that makes it useful in defeating plaque (Lebda et al., 2018). The latter potential activities align with our results in terms of the decrease of Veillonella spp., the bacteria that favors the accumulation of plaque. Veillonella was also found in higher proportion in caries or periodontal subjects (Zhang et al., 2015; Zhou et al., 2016).

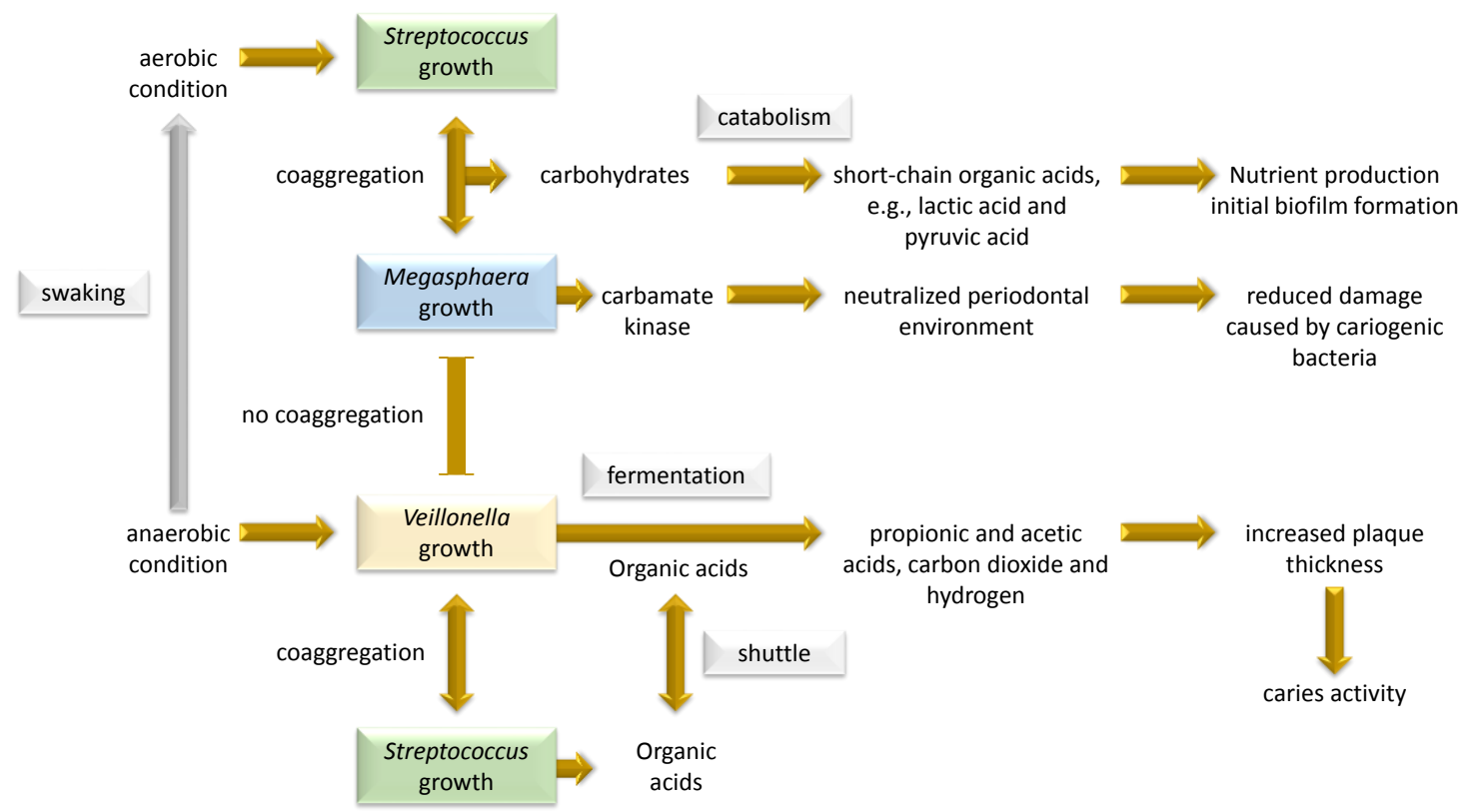

Figure 14. Roles of the three genera Streptococcus, Veillonella and Megasphaera and possible influence of swaking on oral hygiene 


\section{Conclusion}

In general, we claim that swaking hinders the anaerobic condition required for Veillonella growth, thus favors the aerobic condition that promote Streptococcus growth. Our results also indicate parallel significant increases of the unassigned species of the genera Streptococcus and Megasphaera (Fig. 12; Table A4). Interestingly, Megasphaera spp. strain DISK18, a nonpathogenic species, was recently reported to coaggregate with Streptococcus during oral early colonization but not with Veillonella (Nallabelli et al., 2016). It is speculated that genera Megasphaera and Veillonella compete for coaggregating with Streptococcus due to homology of surface receptors of these two genera (Kreth et al., 2009; Nallabelli et al., 2016). Whole genome sequencing of the Megasphaera strain showed a lack of virulence genes, that are associated with oral pathogenesis, or genes encoding collagenase or gelatinase. The latter indicates that Megasphaera unlikely participates in periodontal disease. Instead, this bacteria harbors carbamate kinase that participate in neutralizing the periodontal environment, thus, reduce the damage caused by cariogenic bacteria (Fig. 14). In summary, we consider Miswak as an excellent natural toothpaste with differential influence on oral microbiome that makes it feasibly useful for maintaining good oral hygiene, especially for children. Future studies on the new selected species are still required in order to support the results of the present research.

Acknowledgments. The authors Acknowledge Prof. Khalid M. Al-Ghamdi, the head of Department of Biological Sciences, Faculty of Science, King Abdulaziz University, Jeddah, KSA, for providing physical and logistic support for this study.

\section{REFERENCES}

[1] Aas, J. A., Paster, B. J., Stokes, L. N., Olsen, I., Dewhirst, F. E. (2005): Defining the normal bacterial flora of the oral cavity. - Journal of Clinical Microbiology 43(11): 5721-5732.

[2] Ahn, J., Yang, L., Paster, B. J., Ganly, I., Morris, L., Pei, Z., Hayes, R. B. (2011): Oral microbiome profiles: $16 \mathrm{~S}$ rRNA pyrosequencing and microarray assay comparison. - PloS ONE 6(7): e22788.

[3] Alcaraz, L., Belda-Ferre, P., Cabrera-Rubio, R., Romero, H., Simón-Soro, Á., Pignatelli, M., Mira, A. (2012): Identifying a healthy oral microbiome through metagenomics. - Clinical Microbiology and Infection 18: 54-57.

[4] Amer, A., Galvin, S., Healy, C. M., Moran, G. P. (2017): The microbiome of potentially malignant oral leukoplakia exhibits enrichment for Fusobacterium, Leptotrichia, Campylobacter, and Rothia species. - Frontiers in Microbiology 8: 2391.

[5] Aumeeruddy, M. Z., Zengin, G., Mahomoodally, M. F. (2018): A review of the traditional and modern uses of Salvadora persica L. (Miswak): toothbrush tree of Prophet Muhammad. - Journal of Ethnopharmacology 213: 409-444.

[6] Awano, S., Ansai, T., Takata, Y., Soh, I., Akifusa, S., Hamasaki, T., Yoshida, A., Sonoki, K., Fujisawa, K., Takehara, T. (2008): Oral health and mortality risk from pneumonia in the elderly. - Journal of Dental Research 87(4): 334-339.

[7] Beck, J. D., Offenbacher, S. (2005): Systemic effects of periodontitis: epidemiology of periodontal disease and cardiovascular disease. - Journal of Periodontology 76: 2089-2100. 
[8] Belda-Ferre, P., Alcaraz, L. D., Cabrera-Rubio, R., Romero, H., Simon-Soro, A., Pignatelli, M., Mira, A. (2012): The oral metagenome in health and disease. - The ISME Journal 6(1): 46.

[9] Bokulich, N. A., Kaehler, B. D., Rideout, J. R., Dillon, M., Bolyen, E., Knight, R., Huttley, G. A., Caporaso, J. G. (2018): Optimizing taxonomic classification of marker gene amplicon sequences with QIIME 2's q2-feature-classifier plugin. - Microbiome 6: Article 90.

[10] Bolyen, E., Rideout, J. R., Dillon, M. R., Bokulich, N. A., Abnet, C., Al-Ghalith, G. A., Alexander, H., Alm, E. J., Arumugam, M., Asnicar, F., et al. (2019): QIIME 2: Reproducible, interactive, scalable, and extensible microbiome data science. - Nature Biotechnology 37(8): 852-857.

[11] Chen, T., Yu, W.-H., Izard, J., Baranova, O. V., Lakshmanan, A., Dewhirst, F. E. (2010): The Human Oral Microbiome Database: a web accessible resource for investigating oral microbe taxonomic and genomic information. - Database 2010.

[12] Cole, J. R., Wang, Q., Fish, J. A., Chai, B., McGarrell, D. M., Sun, Y., Brown, C. T., Porras-Alfaro, A., Kuske, C. R., Tiedje, J. M. (2013): Ribosomal Database Project: data and tools for high throughput rRNA analysis. - Nucleic Acids Research 42(D1): D633-D642.

[13] Costello, E. K., Lauber, C. L., Hamady, M., Fierer, N., Gordon, J. I., Knight, R. (2009): Bacterial community variation in human body habitats across space and time. - Science 326(5960): 1694-1697.

[14] Cotter, P. D., Hill, C. (2003): Surviving the acid test: responses of gram-positive bacteria to low pH. - Microbiol. Mol. Biol. Rev. 67(3): 429-453.

[15] Crielaard, W., Zaura, E., Schuller, A. A., Huse, S. M., Montijn, R. C., Keijser, B. J. (2011): Exploring the oral microbiota of children at various developmental stages of their dentition in the relation to their oral health. - BMC Medical Genomics 4(1): 22.

[16] Delwiche, E., Pestka, J., Tortorello, M. (1985): The Veillonellae: gram-negative cocci with a unique physiology. - Annual Reviews in Microbiology 39(1): 175-193.

[17] DeSantis, T. Z., Hugenholtz, P., Larsen, N., Rojas, M., Brodie, E. L., Keller, K., Huber, T., Dalevi, D., Hu, P., Andersen, G. L. (2006): Greengenes, a chimerachecked 16S rRNA gene database and workbench compatible with ARB. - Appl. Environ. Microbiol. 72(7): 5069-5072.

[18] Drucker, D., Green, R. (1977): Dental caries induced by Streptococcus milleri. Journal of Dental Research 56(9): 1062-1062.

[19] Furquim, C., Soares, G., Ribeiro, L., Azcarate-Peril, M., Butz, N., Roach, J., Moss, K., Bonfim, C., Torres-Pereira, C., Teles, F. (2017): The salivary microbiome and oral cancer risk: a pilot study in Fanconi anemia. - Journal of Dental Research 96(3): 292-299.

[20] Gao, R., Gao, Z., Huang, L., Qin, H. (2017): Gut microbiota and colorectal cancer. European Journal of Clinical Microbiology \& Infectious Diseases 36(5): 757-769.

[21] Garbieri, T. F., Brozoski, D. T., Dionisio, T. J., Santos, C. F., Neves, L. T. d. (2017): Human DNA extraction from whole saliva that was fresh or stored for 3, 6 or 12 months using five different protocols. - Journal of Applied Oral Science 25(2): 147 158.

[22] Gill, S. R., Pop, M., DeBoy, R. T., Eckburg, P. B., Turnbaugh, P. J., Samuel, B. S., Gordon, J. I., Relman, D. A., Fraser-Liggett, C. M., Nelson, K. E. (2006): Metagenomic analysis of the human distal gut microbiome. - Science 312(5778): 1355-1359.

[23] Gomez, A., Nelson, K. E. (2017): The oral microbiome of children: development, disease, and implications beyond oral health. - Microbial Ecology 73(2): 492-503.

[24] Greenblum, S., Turnbaugh, P. J., Borenstein, E. (2012): Metagenomic systems biology of the human gut microbiome reveals topological shifts associated with 
obesity and inflammatory bowel disease. - Proceedings of the National Academy of Sciences 109(2): 594-599.

[25] Hancock, R. E., Haney, E. F., Gill, E. E. (2016): The immunology of host defence peptides: beyond antimicrobial activity. - Nature Reviews Immunology 16(5): 321.

[26] Haque, M. M., Alsareii, S. A. (2015): A review of the therapeutic effects of using miswak (Salvadora persica) on oral health. - Saudi Medical Journal 36(5): 530.

[27] Hoffman, K. L., Hutchinson, D. S., Fowler, J., Smith, D. P., Ajami, N. J., Zhao, H., Scheet, P., Chow, W.-H., Petrosino, J. F., Daniel, C. R. (2018): Oral microbiota reveals signs of acculturation in Mexican American women. - PloS One 13(4): e0194100.

[28] Huttenhower, C., Gevers, D., Knight, R., Abubucker, S., Badger, J. H., Chinwalla, A. T., Creasy, H. H., Earl, A. M., FitzGerald, M. G., Fulton, R. S. (2012): Structure, function and diversity of the healthy human microbiome. - Nature 486(7402): 207.

[29] Ismail, A. S., Behrendt, C. L., Hooper, L. V. (2009): Reciprocal interactions between commensal bacteria and $\gamma \delta$ intraepithelial lymphocytes during mucosal injury. - The Journal of Immunology 182(5): 3047-3054.

[30] Jiang, S., Gao, X., Jin, L., Lo, E. (2016): Salivary microbiome diversity in caries -free and caries-affected children. - International Journal of Molecular Sciences 17(12): 1978.

[31] Jo, J.-H., Kennedy, E. A., Kong, H. H. (2017): Topographical and physiological differences of the skin mycobiome in health and disease. - Virulence 8(3): 324-333.

[32] Johansson, I., Witkowska, E., Kaveh, B., Lif Holgerson, P., Tanner, A. (2016): The microbiome in populations with a low and high prevalence of caries. - Journal of Dental Research 95(1): 80-86.

[33] Joshipura, K. J., Rimm, E., Douglass, C., Trichopoulos, D., Ascherio, A., Willett, W. (1996): Poor oral health and coronary heart disease. - Journal of Dental Research 75(9): 1631-1636.

[34] Joshipura, K. J., Hung, H.-C., Rimm, E. B., Willett, W. C., Ascherio, A. (2003): Periodontal disease, tooth loss, and incidence of ischemic stroke. - Stroke 34(1): 4752.

[35] Kamma, J. J., Nakou, M., Manti, F. A. (1994): Microbiota of rapidly progressive periodontitis lesions in association with clinical parameters. - Journal of Periodontology 65(11): 1073-1078.

[36] Kaplan, J. B., Ragunath, C., Velliyagounder, K., Fine, D. H., Ramasubbu, N. (2004): Enzymatic detachment of Staphylococcus epidermidis biofilms. - Antimicrobial Agents and Chemotherapy 48(7): 2633-2636.

[37] Kau, A. L., Ahern, P. P., Griffin, N. W., Goodman, A. L., Gordon, J. I. (2011): Human nutrition, the gut microbiome and the immune system. - Nature 474(7351): 327.

[38] Khatak, M., Khatak, S., Siddqui, A., Vasudeva, N., Aggarwal, A., Aggarwal, P. (2010): Salvadora persica. - Pharmacognosy Reviews 4(8): 209.

[39] Kreth, J., Merritt, J., Qi, F. (2009): Bacterial and host interactions of oral streptococci. - DNA and Cell Biology 28(8): 397-403.

[40] Lazarevic, V., Gaïa, N., Girard, M., François, P., Schrenzel, J. (2013): Comparison of DNA extraction methods in analysis of salivary bacterial communities. - PloS One 8(7): e67699.

[41] Lebda, M. A., El-Far, A. H., Noreldin, A. E., Elewa, Y. H., Al Jaouni, S. K., Mousa, S. A. (2018): Protective effects of Miswak (Salvadora persica) against experimentally induced gastric ulcers in rats. - Oxidative Medicine and Cellular Longevity 2018.

[42] Ledder, R. G., Gilbert, P., Huws, S. A., Aarons, L., Ashley, M. P., Hull, P. S., McBain, A. J. (2007): Molecular analysis of the subgingival microbiota in health and disease. - Appl. Environ. Microbiol. 73(2): 516-523. 
[43] Ley, R. E. (2010): Obesity and the human microbiome. - Current Opinion in Gastroenterology 26(1): 5-11.

[44] Li, J., Quinque, D., Horz, H.-P., Li, M., Rzhetskaya, M., Raff, J. A., Hayes, M. G., Stoneking, M. (2014): Comparative analysis of the human saliva microbiome from different climate zones: Alaska, Germany, and Africa. - BMC Microbiology 14(1): 316.

[45] Liu, B., Faller, L. L., Klitgord, N., Mazumdar, V., Ghodsi, M., Sommer, D. D., Gibbons, T. R., Treangen, T. J., Chang, Y.-C., Li, S. (2012): Deep sequencing of the oral microbiome reveals signatures of periodontal disease. - PloS ONE 7(6): e37919.

[46] Liu, J., Cui, L., Yan, X., Zhao, X., Cheng, J., Zhou, L., Gao, J., Cao, Z., Ye, X., Hu, S. (2018): Analysis of oral microbiota revealed high abundance of Prevotella Intermedia in gout patients. - Cellular Physiology and Biochemistry 49(5): 18041812.

[47] Lozupone, C., Lladser, M. E., Knights, D., Stombaugh, J., Knight, R. (2011): UniFrac: an effective distance metric for microbial community comparison. - The ISME Journal 5(2): 169.

[48] Marsh, P. D. (2003): Are dental diseases examples of ecological catastrophes? Microbiology 149(2): 279-294.

[49] Mashima, I., Nakazawa, F. (2014): The influence of oral Veillonella species on biofilms formed by Streptococcus species. - Anaerobe 28: 54-61.

[50] Mashima, I., Theodorea, C. F., Thaweboon, B., Thaweboon, S., Scannapieco, F. A., Nakazawa, F. (2017): Exploring the salivary microbiome of children stratified by the oral hygiene index. - PloS ONE 12(9): e0185274.

[51] Mason, M. R., Nagaraja, H. N., Camerlengo, T., Joshi, V., Kumar, P. S. (2013): Deep sequencing identifies ethnicity-specific bacterial signatures in the oral microbiome. PloS ONE 8(10): e77287.

[52] Methé, B. A., Nelson, K. E., Pop, M., Creasy, H. H., Giglio, M. G., Huttenhower, C., Gevers, D., Petrosino, J. F., Abubucker, S., Badger, J. H. (2012): A framework for human microbiome research. - Nature 486(7402): 215.

[53] Meurman, J. H. (2010): Oral microbiota and cancer. - Journal of Oral Microbiology 2(1): 5195.

[54] Miller, C., Tichindelean, C., Blanchette, L. (2017): Rothia mucilaginosa bacteremia associated with HIV and non-Hodgkin's lymphoma: a case report and brief review of literature. - J. Microbiol. Infect. Dis. 7: 148-150.

[55] Mookherjee, N., Hancock, R. (2007): Cationic host defence peptides: innate immune regulatory peptides as a novel approach for treating infections. - Cellular and Molecular life Sciences 64(7-8): 922.

[56] Nallabelli, N., Patil, P. P., Pal, V. K., Singh, N., Jain, A., Patil, P. B., Grover, V., Korpole, S. (2016): Biochemical and genome sequence analyses of Megas phaera sp. strain DISK18 from dental plaque of a healthy individual reveals commensal lifestyle. - Scientific Reports 6: 33665.

[57] Nasidze, I., Li, J., Quinque, D., Tang, K., Stoneking, M. (2009): Global diversity in the human salivary microbiome. - Genome Research 19(4): 636-643.

[58] Nasidze, I., Li, J., Schroeder, R., Creasey, J. L., Li, M., Stoneking, M. (2011): High diversity of the saliva microbiome in Batwa Pygmies. - PloS ONE 6(8): e23352.

[59] Offenbacher, S., Jared, H., O'reilly, P., Wells, S., Salvi, G., Lawrence, H., Socransky, S., Beck, J. (1998): Potential pathogenic mechanisms of periodontitis-associated pregnancy complications. - Annals of Periodontology 3(1): 233-250.

[60] Ohtani, K., Kasai, R., Yamasaki, K., Tanaka, O., Kamel, M., Assaf, M., ElShanawani, M., Ali, A. (1992): Lignan glycosides from stems of Salvadora persica. Phytochemistry 31(7): 2469-2471.

[61] WHO (1984): Prevention methods and programmes for oral diseases. - Report of a WHO Expert Committee. Meeting Held in Geneva from 12 to 16 September 1983. 
[62] Palmer, R. J., Diaz, P. I., Kolenbrander, P. E. (2006): Rapid succession within the Veillonella population of a developing human oral biofilm in situ. - Journal of Bacteriology 188(11): 4117-4124.

[63] Paulson, J. N., Pop, M., Bravo, H. C. (2011): Metastats: an improved statistical method for analysis of metagenomic data. - Genome Biology 12(1): P17.

[64] Pereira, J. V., Leomil, L., Rodrigues-Albuquerque, F., Pereira, J. O., Astolfi-Filho, S. (2012): Bacterial diversity in the saliva of patients with different oral hygiene indexes. - Brazilian Dental Journal 23(4): 409-416.

[65] Periasamy, S., Kolenbrander, P. E. (2010): Central role of the early colonizer Veillonella sp. in establishing multispecies biofilm communities with initial, middle, and late colonizers of enamel. - Journal of Bacteriology 192(12): 2965-2972.

[66] Pflughoeft, K. J., Versalovic, J. (2012): Human microbiome in health and disease. Annual Review of Pathology: Mechanisms of Disease 7: 99-122.

[67] Prabhu, S., John, J. (2015): Oral health education for improving oral health status of school children - a systematic review. - J. Dent. Med. Sci. 14(2): 101-106.

[68] Qin, J., Li, R., Raes, J., Arumugam, M., Burgdorf, K. S., Manichanh, C., Nielsen, T., Pons, N., Levenez, F., Yamada, T., Mende, D. R., Li, J., Xu, J., Li, S., Li, D., Cao, J., Wang, B., Liang, H., Zheng, H., Xie, Y., Tap, J., Lepage, P., Bertalan, M., Batto, J. M., Hansen, T., Le Paslier, D., Linneberg, A., Nielsen, H. B., Pelletier, E., Renault, P., Sicheritz-Ponten, T., Turner, K., Zhu, H., Yu, C., Li, S., Jian, M., Zhou, Y., Li, Y., Zhang, X., Li, S., Qin, N., Yang, H., Wang, J., Brunak, S., Dore, J., Guarner, F., Kristiansen, K., Pedersen, O., Parkhill, J., Weissenbach, J., Meta, H. I. T. C., Bork, P., Ehrlich, S. D., Wang, J. (2010): A human gut microbial gene catalogue established by metagenomic sequencing. - Nature 464(7285): 59-65.

[69] Rawlinson, A., Duerden, B., Goodwin, L. (1993): New findings on the microbial flora associated with adult periodontitis. - Journal of Dentistry 21(3): 179-184.

[70] Ritz, H. L. (1967): Microbial population shifts in developing human dental plaque. Archives of Oral Biology 12(12): 1561-1568.

[71] Seymour, G., Ford, P., Cullinan, M., Leishman, S., Yamazaki, K. (2007): Relationship between periodontal infections and systemic disease. - Clinical Microbiology and Infection 13: 3-10.

[72] Sheiham, A., Watt, R. G. (2000): The common risk factor approach: a rational basis for promoting oral health. - Community Dentistry and Oral Epidemiology: Commentary 28(6): 399-406.

[73] Simon-Soro, A., Sherriff, A., Sadique, S., Ramage, G., Macpherson, L., Mira, A., Culshaw, S., Malcolm, J. (2018): Combined analysis of the salivary microbiome and host defence peptides predicts dental disease. - Scientific Reports 8(1): 1484.

[74] Takeshita, T., Matsuo, K., Furuta, M., Shibata, Y., Fukami, K., Shimazaki, Y., Akifusa, S., Han, D.-H., Kim, H.-D., Yokoyama, T. (2014): Distinct composition of the oral indigenous microbiota in South Korean and Japanese adults. - Scientific Reports 4: 6990.

[75] Turnbaugh, P. J., Hamady, M., Yatsunenko, T., Cantarel, B. L., Duncan, A., Ley, R. E., Sogin, M. L., Jones, W. J., Roe, B. A., Affourtit, J. P., Egholm, M., Henrissat, B., Heath, A. C., Knight, R., Gordon, J. I. (2009): A core gut microbiome in obese and lean twins. - Nature 457(7228): 480-484.

[76] Vesty, A., Biswas, K., Taylor, M. W., Gear, K., Douglas, R. G. (2017): Evaluating the impact of DNA extraction method on the representation of human oral bacterial and fungal communities. - PloS ONE 12(1): e0169877.

[77] Xu, Y., Jia, Y., Chen, L., Huang, W., Yang, D. (2018): Metagenomic analysis of oral microbiome in young children aged 6-8 years living in a rural isolated Chinese province. - Oral Diseases 24(6): 1115-1125. 
[78] Yu, G., Phillips, S., Gail, M. H., Goedert, J. J., Humphrys, M. S., Ravel, J., Ren, Y., Caporaso, N. E. (2017): The effect of cigarette smoking on the oral and nasal microbiota. - Microbiome 5(1): 3.

[79] Zhang, M., Chen, Y., Xie, L., Li, Y., Jiang, H., Du, M. (2015): Pyrosequencing of plaque microflora in twin children with discordant caries phenotypes. - PLoS ONE 10(11): e0141310.

[80] Zhou, J., Jiang, N., Wang, S., Hu, X., Jiao, K., He, X., Li, Z., Wang, J. (2016): Exploration of human salivary microbiomes-insights into the novel characteristics of microbial community structure in caries and caries-free subjects. - PloS ONE 11(1): e0147039. 


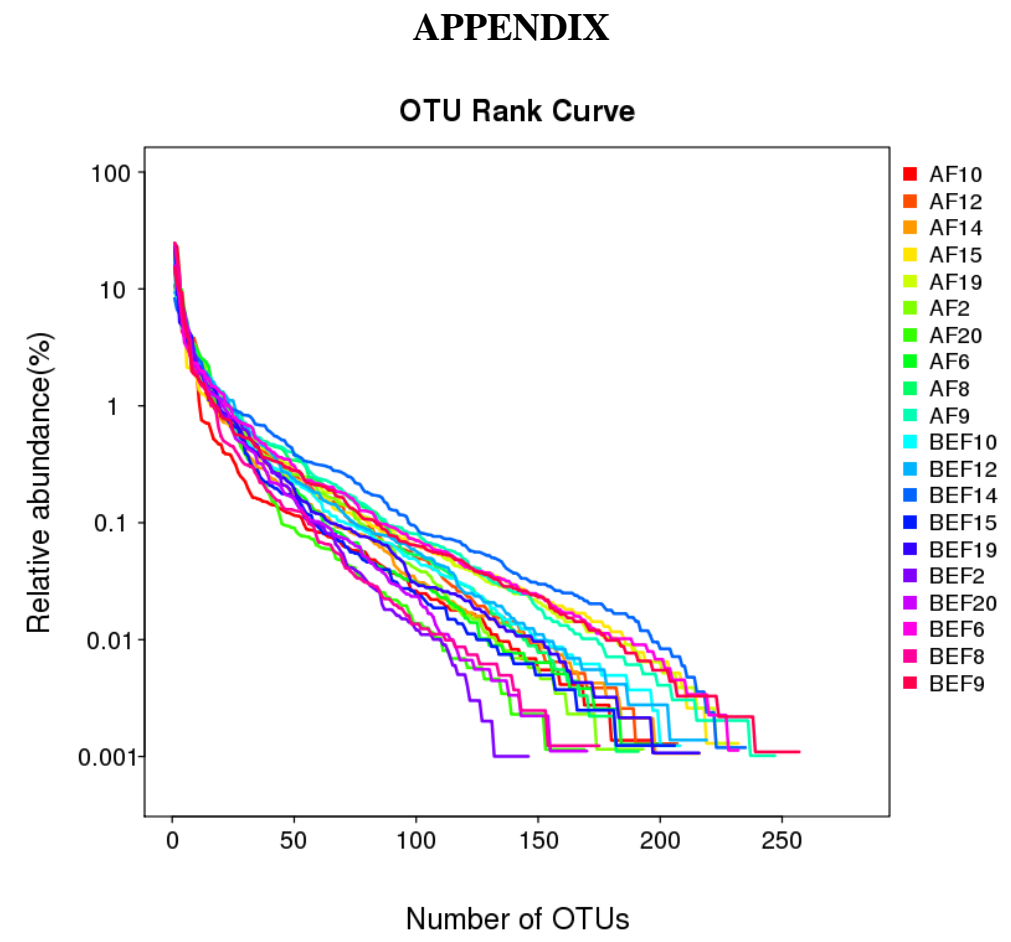

Figure A1. Number and relative abundance of OTUs of different samples. BEF = before swaking, AF = after swaking

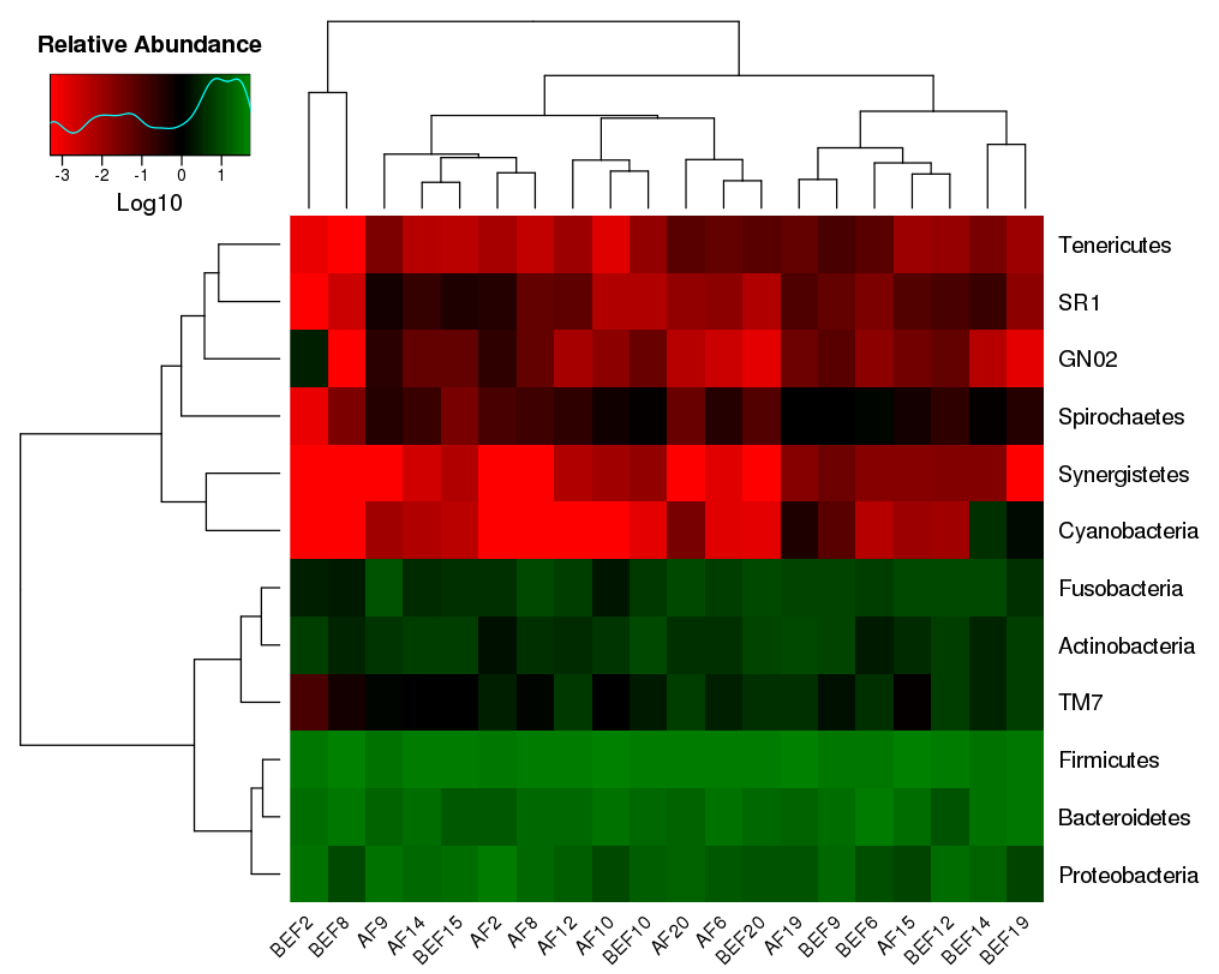

Figure A2. Log-scaled percentage heat map at phylum level. BEF = before swaking, AF = after swaking 


$$
-7116-
$$

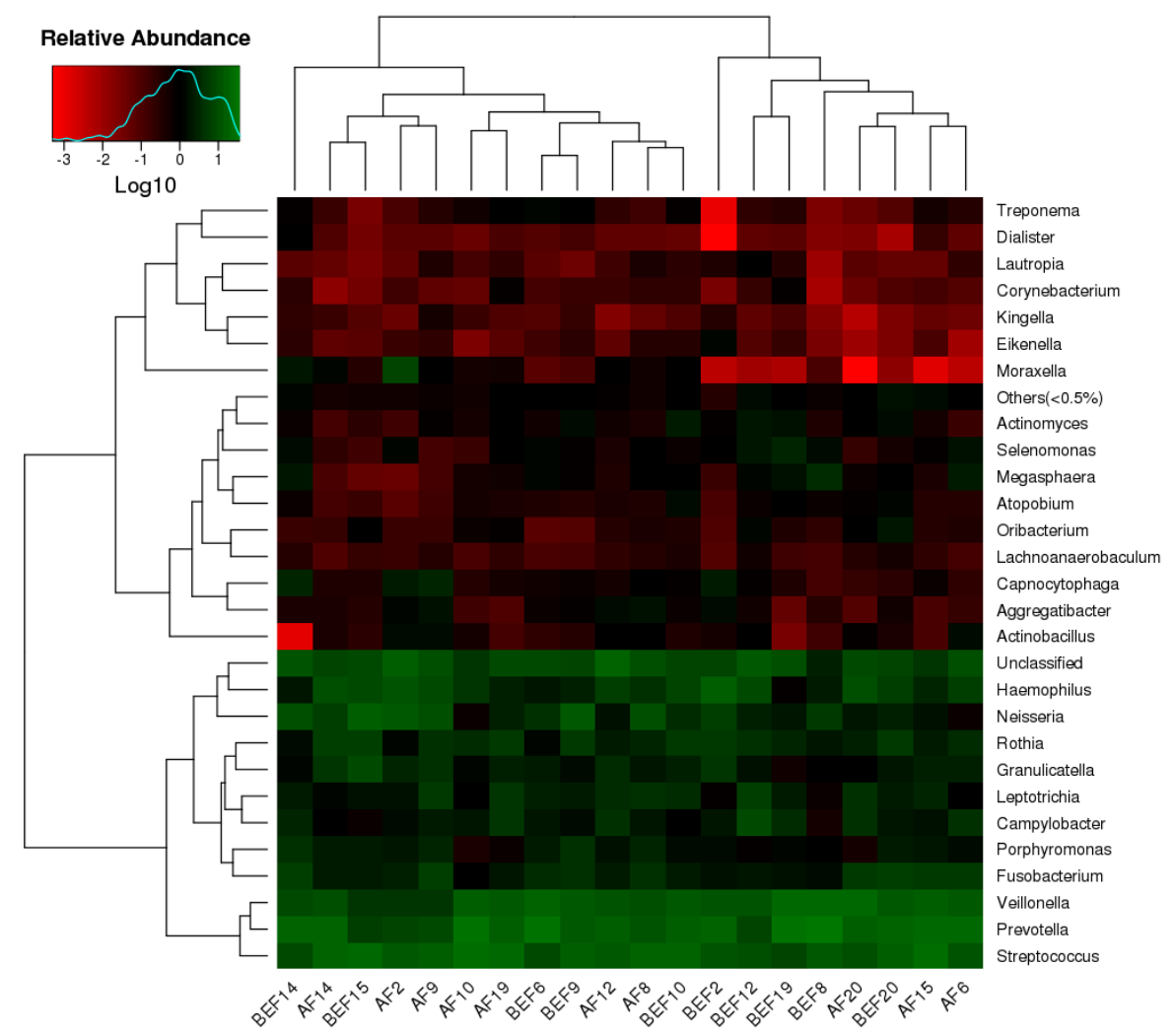

Figure A3. Log-scaled percentage heat map at genus level. BEF = before swaking, AF = after swaking

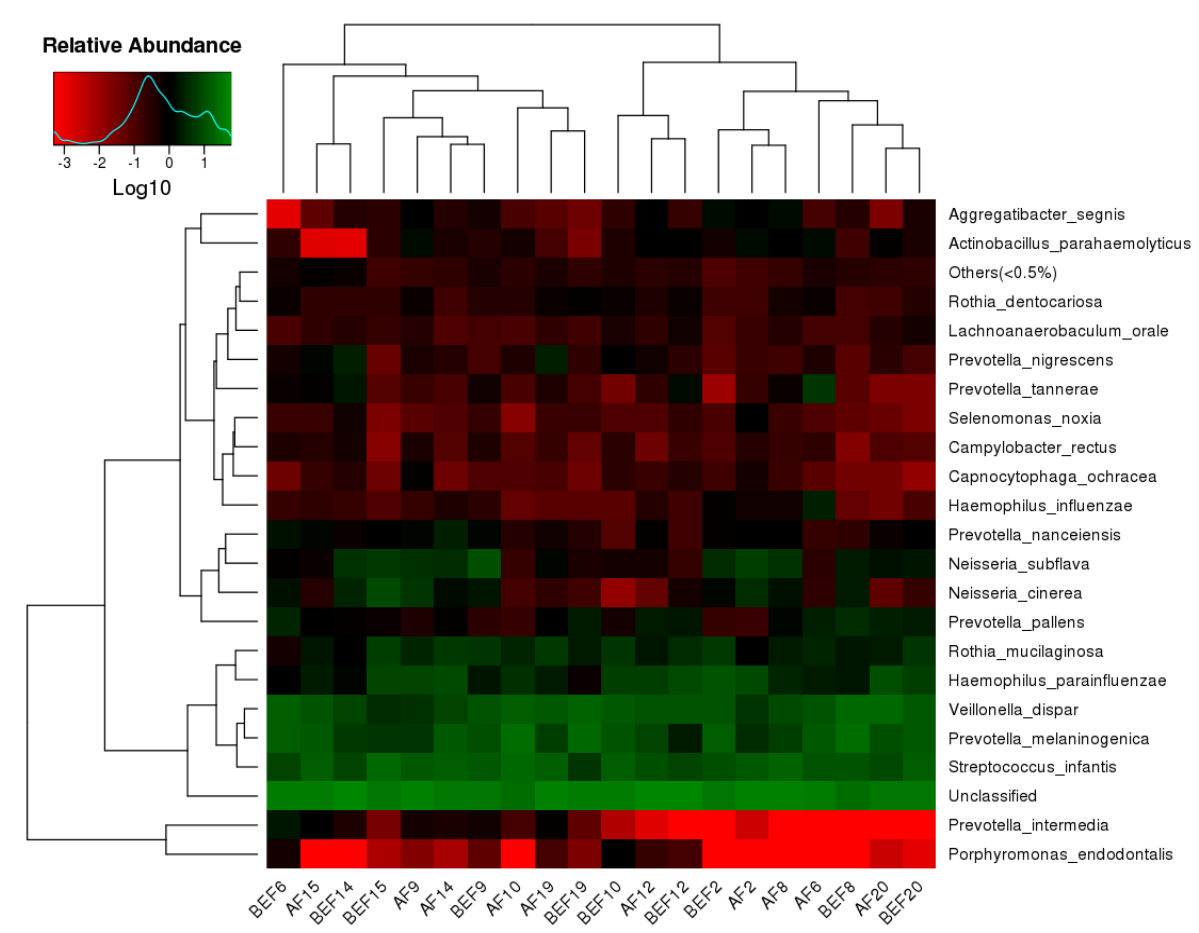

Figure A4. Log-scaled percentage heat map at species level. BEF = before swaking, $A F=$ after swaking 
Table A1. Description of observed species detected from OTU annotation across subjects and swaking

\begin{tabular}{|c|c|c|}
\hline OTU no. & OTU abundance & Taxonomy \\
\hline Otu2 & 235993 & Bacteria; Firmicutes; Bacilli; Lactobacillales; Streptococcaceae; Streptococcus; Streptococcus_infantis \\
\hline Otu1 & 195394 & Bacteria; Bacteroidetes; Bacteroidia; Bacteroidales; Prevotellaceae; Prevotella; Prevotella_melaninogenica \\
\hline Otu3 & 163677 & Bacteria; Firmicutes; Clostridia; Clostridiales; Veillonellaceae; Veillonella; Veillonella_dispar \\
\hline Otu4 & 92051 & Bacteria; Proteobacteria; Gammaproteobacteria; Pasteurellales; Pasteurellaceae; Haemophilus; Haemophilus_parainfluenzae \\
\hline Otu11 & 58531 & Bacteria; Fusobacteria; Fusobacteriia; Fusobacteriales; Fusobacteriaceae; Fusobacterium \\
\hline Otu8 & 58093 & Bacteria; Actinobacteria; Actinobacteria; Actinomycetales; Micrococcaceae; Rothia; Rothia_mucilaginosa \\
\hline Otu32 & 50183 & Bacteria; Firmicutes; Clostridia; Clostridiales; Veillonellaceae; Veillonella; Veillonella_dispar \\
\hline Otu14 & 46624 & Bacteria; Firmicutes; Bacilli; Gemellales; Gemellaceae \\
\hline Otu6 & 40872 & Bacteria; Proteobacteria; Betaproteobacteria; Neisseriales; Neisseriaceae; Neisseria; Neisseria_subflava \\
\hline Otu5 & 39815 & Bacteria; Proteobacteria; Epsilonproteobacteria; Campylobacterales; Campylobacteraceae; Campylobacter \\
\hline Otu12 & 34029 & Bacteria; Firmicutes; Bacilli; Lactobacillales; Streptococcaceae; Streptococcus \\
\hline Otu10 & 33068 & Bacteria; TM7; TM7-3 \\
\hline Otu7 & 32641 & Bacteria; Firmicutes; Bacilli; Lactobacillales; Carnobacteriaceae; Granulicatella \\
\hline Otu29 & 29782 & Bacteria; Proteobacteria; Betaproteobacteria; Neisseriales; Neisseriaceae; Neisseria \\
\hline Otu261 & 27911 & Bacteria; Proteobacteria; Betaproteobacteria; Neisseriales; Neisseriaceae; Neisseria; Neisseria_cinerea \\
\hline Otu17 & 23783 & Bacteria; Bacteroidetes; Bacteroidia; Bacteroidales; Prevotellaceae; Prevotella; Prevotella_pallens \\
\hline Otu15 & 22697 & Bacteria; Bacteroidetes; Bacteroidia; Bacteroidales; Prevotellaceae; Prevotella \\
\hline Otu25 & 20994 & Bacteria; Bacteroidetes; Bacteroidia; Bacteroidales; Porphyromonadaceae; Porphyromonas \\
\hline Otu21 & 18426 & Bacteria; Bacteroidetes; Bacteroidia; Bacteroidales; Paraprevotellaceae; Prevotella \\
\hline Otu20 & 17155 & Bacteria; Fusobacteria; Fusobacteriia; Fusobacteriales; Leptotrichiaceae; Leptotrichia \\
\hline Otu37 & 14672 & Bacteria; Firmicutes; Clostridia; Clostridiales; Veillonellaceae; Megasphaera \\
\hline Otu27 & 13910 & Bacteria; Firmicutes; Bacilli; Lactobacillales; Carnobacteriaceae; Granulicatella \\
\hline Otu26 & 13468 & Bacteria; Bacteroidetes; Bacteroidia; Bacteroidales; Prevotellaceae; Prevotella; Prevotella_nanceiensis \\
\hline Otu9 & 13242 & Bacteria; Proteobacteria; Gammaproteobacteria; Pseudomonadales; Moraxellaceae; Moraxella \\
\hline Otu40 & 13051 & Bacteria; Firmicutes; Clostridia; Clostridiales; Veillonellaceae; Veillonella \\
\hline Otu33 & 12906 & Bacteria; Bacteroidetes; Bacteroidia; Bacteroidales; Paraprevotellaceae; Prevotella \\
\hline Otu193 & 12432 & Bacteria; Proteobacteria; Gammaproteobacteria; Pasteurellales; Pasteurellaceae \\
\hline Otu23 & 11707 & Bacteria; Firmicutes; Clostridia; Clostridiales \\
\hline Otu28 & 10024 & Bacteria; Bacteroidetes; Bacteroidia; Bacteroidales; Paraprevotellaceae; Prevotella; Prevotella_tannerae \\
\hline Otu109 & 9878 & Bacteria; Proteobacteria; Gammaproteobacteria; Pasteurellales; Pasteurellaceae; Haemophilus \\
\hline Otu49 & 9750 & Bacteria; Proteobacteria; Gammaproteobacteria; Pasteurellales; Pasteurellaceae; Actinobacillus; Actinobacillus_parahaemolyticus \\
\hline Otu18 & 9704 & Bacteria; Bacteroidetes; Bacteroidia; Bacteroidales; Prevotellaceae; Prevotella; Prevotella_nigrescens \\
\hline
\end{tabular}




\begin{tabular}{|c|c|c|}
\hline OTU no. & OTU abundance & Taxonomy \\
\hline Otu55 & 8814 & Bacteria; Fusobacteria; Fusobacteriia; Fusobacteriales; Leptotrichiaceae; Leptotrichia \\
\hline Otu24 & 8592 & Bacteria; Firmicutes; Clostridia; Clostridiales; Lachnospiraceae; Oribacterium \\
\hline Otu38 & 8380 & Bacteria; Actinobacteria; Coriobacteriia; Coriobacteriales; Coriobacteriaceae; Atopobium \\
\hline Otu42 & 8302 & Bacteria; Firmicutes; Clostridia; Clostridiales; Veillonellaceae; Selenomonas \\
\hline Otu68 & 8159 & Bacteria; Bacteroidetes; Bacteroidia; Bacteroidales; Prevotellaceae; Prevotella \\
\hline Otu53 & 8127 & Bacteria; Proteobacteria; Gammaproteobacteria; Pasteurellales; Pasteurellaceae; Aggregatibacter; Aggregatibacter_segnis \\
\hline Otu245 & 7056 & Bacteria; Firmicutes; Clostridia; Clostridiales; Veillonellaceae; Veillonella \\
\hline Otu51 & 6869 & Bacteria; Actinobacteria; Actinobacteria; Actinomycetales; Micrococcaceae; Rothia; Rothia_dentocariosa \\
\hline Otu41 & 6741 & Bacteria; Firmicutes; Clostridia; Clostridiales; Mogibacteriaceae \\
\hline Otu50 & 6255 & Bacteria; Actinobacteria; Actinobacteria; Actinomycetales; Actinomycetaceae; Actinomyces \\
\hline Otu19 & 6183 & Bacteria; Proteobacteria; Gammaproteobacteria; Pasteurellales; Pasteurellaceae; Haemophilus; Haemophilus_influenzae \\
\hline Otu39 & 6124 & Bacteria; TM7; TM7-3; CW040 \\
\hline Otu277 & 5959 & Bacteria; Proteobacteria; Betaproteobacteria; Neisseriales; Neisseriaceae; Neisseria; Neisseria_subflava \\
\hline Otu65 & 5820 & Bacteria; Bacteroidetes; Bacteroidia; Bacteroidales; Porphyromonadaceae; Porphyromonas \\
\hline Otu31 & 5140 & Bacteria; Bacteroidetes; Bacteroidia; Bacteroidales; Prevotellaceae; Prevotella \\
\hline Otu35 & 5103 & Bacteria; Fusobacteria; Fusobacteriia; Fusobacteriales; Leptotrichiaceae; Leptotrichia \\
\hline Otu22 & 5023 & Bacteria; Bacteroidetes; Bacteroidia; Bacteroidales; Prevotellaceae; Prevotella; Prevotella_intermedia \\
\hline Otu13 & 4905 & Bacteria; Cyanobacteria; Chloroplast; Streptophyta \\
\hline Otu88 & 4889 & Bacteria; Fusobacteria; Fusobacteriia; Fusobacteriales; Leptotrichiaceae; Leptotrichia \\
\hline Otu155 & 4814 & Bacteria; Fusobacteria; Fusobacteriia; Fusobacteriales; Leptotrichiaceae; Leptotrichia \\
\hline Otu61 & 4797 & Bacteria; Bacteroidetes; Bacteroidia; Bacteroidales; Prevotellaceae; Prevotella \\
\hline Otu70 & 4788 & Bacteria; Bacteroidetes; Bacteroidia; Bacteroidales; Porphyromonadaceae; Porphyromonas \\
\hline Otu34 & 4397 & Bacteria; Bacteroidetes; Flavobacteriia; Flavobacteriales; Flavobacteriaceae; Capnocytophaga \\
\hline Otu52 & 4247 & Bacteria; Firmicutes; Clostridia; Clostridiales \\
\hline Otu66 & 4201 & Bacteria; TM7; TM7-3; CW040; F16 \\
\hline Otu76 & 4044 & Bacteria; Firmicutes; Clostridia; Clostridiales; Lachnospiraceae; Lachnoanaerobaculum; Lachnoanaerobaculum_orale \\
\hline Otu69 & 3903 & Bacteria; Bacteroidetes; Flavobacteriia; Flavobacteriales; Flavobacteriaceae; Capnocytophaga \\
\hline Otu57 & 3763 & Bacteria; TM7; TM7-3 \\
\hline Otu36 & 3476 & Bacteria; Proteobacteria; Betaproteobacteria; Neisseriales; Neisseriaceae; Eikenella \\
\hline Otu48 & 3440 & Bacteria; Proteobacteria; Betaproteobacteria; Burkholderiales; Burkholderiaceae; Lautropia \\
\hline Otu16 & 3440 & Bacteria; GN02; BD1-5 \\
\hline Otu64 & 3415 & Bacteria; Bacteroidetes; Bacteroidia; Bacteroidales; Paraprevotellaceae; Prevotella \\
\hline Otu84 & 3406 & Bacteria; Proteobacteria; Epsilonproteobacteria; Campylobacterales; Campylobacteraceae; Campylobacter; Campylobacter_rectus \\
\hline Otu47 & 3381 & Bacteria; Bacteroidetes; Flavobacteriia; Flavobacteriales; Weeksellaceae \\
\hline
\end{tabular}




\begin{tabular}{|c|c|c|}
\hline OTU no. & OTU abundance & Taxonomy \\
\hline Otu93 & 3367 & Bacteria; Proteobacteria; Gammaproteobacteria; Pasteurellales; Pasteurellaceae; Aggregatibacter \\
\hline Otu126 & 3331 & Bacteria; Bacteroidetes; Bacteroidia; Bacteroidales; Prevotellaceae; Prevotella \\
\hline Otu87 & 3074 & Bacteria; Bacteroidetes; Flavobacteriia; Flavobacteriales; Flavobacteriaceae; Capnocytophaga \\
\hline Otu77 & 2993 & Bacteria; Firmicutes; Clostridia; Clostridiales; Veillonellaceae; Selenomonas; Selenomonas_noxia \\
\hline Otu271 & 2986 & Bacteria; Bacteroidetes; Bacteroidia; Bacteroidales; Prevotellaceae; Prevotella; Prevotella_melaninogenica \\
\hline Otu75 & 2939 & Bacteria; Actinobacteria; Actinobacteria; Actinomycetales; Corynebacteriaceae; Corynebacterium \\
\hline Otu98 & 2827 & Bacteria; Bacteroidetes; Bacteroidia; Bacteroidales; Prevotellaceae; Prevotella \\
\hline Otu59 & 2750 & Bacteria; Actinobacteria; Actinobacteria; Actinomycetales; Actinomycetaceae; Actinomyces \\
\hline Otu80 & 2727 & Bacteria; Fusobacteria; Fusobacteriia; Fusobacteriales; Leptotrichiaceae; Leptotrichia \\
\hline Otu86 & 2462 & Bacteria; Bacteroidetes; Bacteroidia; Bacteroidales; Prevotellaceae; Prevotella \\
\hline Otu81 & 2433 & Bacteria; Actinobacteria; Actinobacteria; Actinomycetales; Actinomycetaceae; Actinomyces \\
\hline Otu206 & 2425 & Bacteria; Actinobacteria; Actinobacteria; Actinomycetales; Actinomycetaceae; Actinomyces \\
\hline Otu137 & 2241 & Bacteria; Firmicutes; Clostridia; Clostridiales; Veillonellaceae; Selenomonas \\
\hline Otu62 & 2126 & Bacteria; Firmicutes; Clostridia; Clostridiales; Lachnospiraceae; Catonella \\
\hline Otu67 & 2056 & Bacteria; Fusobacteria; Fusobacteriia; Fusobacteriales; Leptotrichiaceae; Leptotrichia \\
\hline Otu71 & 2001 & Bacteria; Bacteroidetes; Bacteroidia; Bacteroidales; Prevotellaceae; Prevotella \\
\hline Otu45 & 1972 & Bacteria; Bacteroidetes; Bacteroidia; Bacteroidales; Prevotellaceae; Prevotella; Prevotella_melaninogenica \\
\hline Otu280 & 1908 & Bacteria; Proteobacteria; Gammaproteobacteria; Pasteurellales; Pasteurellaceae; Haemophilus \\
\hline Otu274 & 1904 & Bacteria; Proteobacteria; Betaproteobacteria; Neisseriales; Neisseriaceae \\
\hline Otu108 & 1902 & Bacteria; Fusobacteria; Fusobacteriia; Fusobacteriales; Fusobacteriaceae; Fusobacterium \\
\hline Otu117 & 1867 & Bacteria; Spirochaetes; Spirochaetes; Spirochaetales; Spirochaetaceae; Treponema \\
\hline Otu90 & 1864 & Bacteria; Firmicutes; Erysipelotrichi; Erysipelotrichales; Erysipelotrichaceae; Bulleidia; Bulleidia_moorei \\
\hline Otu72 & 1834 & Bacteria; Bacteroidetes; Flavobacteriia; Flavobacteriales; Weeksellaceae \\
\hline Otu100 & 1827 & Bacteria; Bacteroidetes; Bacteroidia; Bacteroidales; Prevotellaceae; Prevotella \\
\hline Otu78 & 1823 & Bacteria; SR1 \\
\hline Otu146 & 1794 & Bacteria; Proteobacteria; Epsilonproteobacteria; Campylobacterales; Campylobacteraceae; Campylobacter \\
\hline Otu44 & 1788 & Bacteria; Firmicutes; Clostridia; Clostridiales; Lachnospiraceae \\
\hline Otu46 & 1702 & Bacteria; Bacteroidetes; Bacteroidia; Bacteroidales; Porphyromonadaceae; Porphyromonas; Porphyromonas_endodontalis \\
\hline Otu105 & 1665 & Bacteria; Fusobacteria; Fusobacteriia; Fusobacteriales; Leptotrichiaceae; Leptotrichia \\
\hline Otu58 & 1645 & Bacteria; Bacteroidetes; Flavobacteriia; Flavobacteriales; Flavobacteriaceae; Capnocytophaga; Capnocytophaga_ochracea \\
\hline Otu30 & 1638 & Bacteria; Fusobacteria; Fusobacteriia; Fusobacteriales; Leptotrichiaceae \\
\hline Otu79 & 1577 & Bacteria; Fusobacteria; Fusobacteriia; Fusobacteriales; Leptotrichiaceae \\
\hline Otu56 & 1534 & Bacteria; Firmicutes; Clostridia; Clostridiales; Veillonellaceae; Dialister \\
\hline Otu124 & 1505 & Bacteria; Firmicutes; Clostridia; Clostridiales; Veillonellaceae; Selenomonas \\
\hline & & $\begin{array}{c}\text { APPLIED ECOLOGY AND ENVIRONMENTAL RESEARCH 18(5):7089-7138. } \\
\text { http://www.aloki.hu } \bullet \text { ISSN } 15891623 \text { (Print) } \bullet \text { ISSN } 17850037 \text { (Online) } \\
\text { DOI: http://dx.doi.org/10.15666/aeer/1805_70897138 } \\
\text { (c) 2020, ALÖKI Kft., Budapest, Hungary }\end{array}$ \\
\hline
\end{tabular}




\begin{tabular}{|c|c|c|}
\hline OTU no. & OTU abundance & Taxonomy \\
\hline Otu140 & 1498 & Bacteria; Bacteroidetes; Bacteroidia; Bacteroidales; Paraprevotellaceae; Prevotella \\
\hline Otu115 & 1295 & Bacteria; Firmicutes; Bacilli; Lactobacillales; Aerococcaceae; Abiotrophia \\
\hline Otu43 & 1184 & Bacteria; Firmicutes; Clostridia; Clostridiales \\
\hline Otu125 & 1134 & Bacteria; Fusobacteria; Fusobacteriia; Fusobacteriales; Fusobacteriaceae; Fusobacterium \\
\hline Otu114 & 1133 & Bacteria; Bacteroidetes; Bacteroidia; Bacteroidales; Prevotellaceae; Prevotella \\
\hline Otu103 & 1108 & Bacteria; Bacteroidetes; Bacteroidia; Bacteroidales; Prevotellaceae; Prevotella; Prevotella_nanceiensis \\
\hline Otu82 & 1104 & Bacteria; Firmicutes; Clostridia; Clostridiales; Lachnospiraceae; Butyrivibrio \\
\hline Otu144 & 1087 & Bacteria; Spirochaetes; Spirochaetes; Spirochaetales; Spirochaetaceae; Treponema \\
\hline Otu134 & 1077 & Bacteria; Firmicutes; Bacilli; Lactobacillales; Streptococcaceae; Streptococcus; Streptococcus_anginosus \\
\hline Otu106 & 1067 & Bacteria; Firmicutes; Clostridia; Clostridiales; Peptostreptococcaceae; Peptostreptococcus \\
\hline Otu151 & 964 & Bacteria; Firmicutes; Clostridia; Clostridiales; Lachnospiraceae; Moryella \\
\hline Otu85 & 953 & Bacteria; Proteobacteria; Betaproteobacteria; Neisseriales; Neisseriaceae \\
\hline Otu92 & 952 & Bacteria; Proteobacteria; Betaproteobacteria; Neisseriales; Neisseriaceae; Kingella \\
\hline Otu54 & 939 & Bacteria; Firmicutes; Clostridia; Clostridiales; Veillonellaceae; Megasphaera \\
\hline Otu97 & 904 & Bacteria; Bacteroidetes; Bacteroidia; Bacteroidales; Prevotellaceae; Prevotella \\
\hline Otu63 & 884 & Bacteria; Bacteroidetes; Bacteroidia; Bacteroidales; Porphyromonadaceae; Porphyromonas \\
\hline Otu239 & 826 & Bacteria; Proteobacteria; Gammaproteobacteria; Pasteurellales; Pasteurellaceae; Haemophilus; Haemophilus_parainfluenzae \\
\hline Otu91 & 824 & Bacteria; Firmicutes; Clostridia; Clostridiales; Mogibacteriaceae; Mogibacterium \\
\hline Otu219 & 807 & Bacteria; Bacteroidetes; Flavobacteriia; Flavobacteriales; Flavobacteriaceae; Capnocytophaga; Capnocytophaga_ochracea \\
\hline Otu94 & 803 & Bacteria; Bacteroidetes; Bacteroidia; Bacteroidales \\
\hline Otu276 & 776 & Bacteria; Bacteroidetes; Bacteroidia; Bacteroidales; Prevotellaceae; Prevotella \\
\hline Otu73 & 773 & Bacteria; Bacteroidetes; Bacteroidia; Bacteroidales; Prevotellaceae; Prevotella \\
\hline Otu122 & 739 & Bacteria; Bacteroidetes; Flavobacteriia; Flavobacteriales; Weeksellaceae \\
\hline Otu129 & 711 & Bacteria; Firmicutes; Bacilli; Lactobacillales; Streptococcaceae; Streptococcus \\
\hline Otu169 & 705 & Bacteria; Spirochaetes; Spirochaetes; Spirochaetales; Spirochaetaceae; Treponema \\
\hline Otu145 & 698 & Bacteria; TM7; TM7-3 \\
\hline Otu131 & 688 & Bacteria; Proteobacteria; Betaproteobacteria; Neisseriales; Neisseriaceae; Kingella \\
\hline Otu99 & 619 & Bacteria; Cyanobacteria; Chloroplast; Streptophyta \\
\hline Otu120 & 611 & Bacteria; Firmicutes; Clostridia; Clostridiales; Tissierellaceae; Parvimonas \\
\hline Otu287 & 608 & Bacteria; Bacteroidetes; Bacteroidia; Bacteroidales; Prevotellaceae; Prevotella; Prevotella_melaninogenica \\
\hline Otu154 & 607 & Bacteria; Bacteroidetes; Bacteroidia; Bacteroidales; Porphyromonadaceae; Tannerella \\
\hline Otu143 & 604 & Bacteria; Bacteroidetes; Flavobacteriia; Flavobacteriales; Flavobacteriaceae; Capnocytophaga; Capnocytophaga_ochracea \\
\hline Otu217 & 556 & Bacteria; Bacteroidetes; Flavobacteriia; Flavobacteriales; Flavobacteriaceae; Capnocytophaga \\
\hline Otu268 & 556 & Bacteria; Firmicutes; Clostridia; Clostridiales; Veillonellaceae; Selenomonas \\
\hline & & $\begin{array}{c}\text { APPLIED ECOLOGY AND ENVIRONMENTAL RESEARCH 18(5):7089-7138. } \\
\text { http://www.aloki.hu } \bullet \text { ISSN } 15891623 \text { (Print) • ISSN } 17850037 \text { (Online) } \\
\text { DOI: http://dx.doi.org/10.15666/aeer/1805_70897138 } \\
\text { (c 2020, ALÖKI Kft., Budapest, Hungary }\end{array}$ \\
\hline
\end{tabular}




\begin{tabular}{|c|c|c|}
\hline OTU no. & OTU abundance & Taxonomy \\
\hline Otu102 & 551 & Bacteria; Bacteroidetes; Bacteroidia; Bacteroidales; Prevotellaceae; Prevotella \\
\hline Otu107 & 548 & Bacteria; Spirochaetes; Spirochaetes; Spirochaetales; Spirochaetaceae; Treponema; Treponema_amylovorum \\
\hline Otu139 & 546 & Bacteria; Bacteroidetes; Bacteroidia; Bacteroidales; Porphyromonadaceae; Paludibacter \\
\hline Otu192 & 540 & Bacteria; Spirochaetes; Spirochaetes; Spirochaetales; Spirochaetaceae; Treponema; Treponema_socranskii \\
\hline Otu60 & 539 & Bacteria; Proteobacteria; Gammaproteobacteria; Pseudomonadales; Moraxellaceae; Moraxella \\
\hline Otu133 & 502 & Bacteria; Bacteroidetes; Bacteroidia; Bacteroidales; Prevotellaceae; Prevotella \\
\hline Otu74 & 491 & Bacteria; Bacteroidetes; Bacteroidia; Bacteroidales \\
\hline Otu111 & 474 & Bacteria; TM7; TM7-3; I025; Rs-045 \\
\hline Otu89 & 474 & Bacteria; Spirochaetes; Spirochaetes; Spirochaetales; Spirochaetaceae; Treponema \\
\hline Otu136 & 467 & Bacteria; Bacteroidetes; Bacteroidia; Bacteroidales; Prevotellaceae; Prevotella \\
\hline Otu194 & 452 & Bacteria; Bacteroidetes; Bacteroidia; Bacteroidales; Paraprevotellaceae; Prevotella \\
\hline Otu186 & 435 & Bacteria; Spirochaetes; Spirochaetes; Spirochaetales; Spirochaetaceae; Treponema \\
\hline Otu119 & 433 & Bacteria; Bacteroidetes; Flavobacteriia; Flavobacteriales; Weeksellaceae \\
\hline Otu104 & 419 & Bacteria; Bacteroidetes; Bacteroidia; Bacteroidales \\
\hline Otu159 & 412 & Bacteria; Bacteroidetes; Flavobacteriia; Flavobacteriales; Flavobacteriaceae; Capnocytophaga \\
\hline Otu285 & 406 & Bacteria; Bacteroidetes; Bacteroidia; Bacteroidales; Prevotellaceae; Prevotella \\
\hline Otu189 & 398 & Bacteria; Firmicutes; Clostridia; Clostridiales; Veillonellaceae \\
\hline Otu96 & 387 & Bacteria; Bacteroidetes; Bacteroidia; Bacteroidales \\
\hline Otu156 & 380 & Bacteria; Bacteroidetes; Flavobacteriia; Flavobacteriales; Flavobacteriaceae; Capnocytophaga \\
\hline Otu101 & 373 & Bacteria; Firmicutes; Clostridia; Clostridiales; Veillonellaceae; Dialister \\
\hline Otu168 & 368 & Bacteria; Proteobacteria; Betaproteobacteria; Neisseriales; Neisseriaceae; Neisseria; Neisseria_oralis \\
\hline Otu113 & 348 & Bacteria; Bacteroidetes; Flavobacteriia; Flavobacteriales; Flavobacteriaceae; Capnocytophaga \\
\hline Otu123 & 347 & Bacteria; Firmicutes; Clostridia; Clostridiales; Peptostreptococcaceae; Filifactor \\
\hline Otu118 & 323 & Bacteria; Proteobacteria; Betaproteobacteria; Neisseriales; Neisseriaceae; Kingella \\
\hline Otu110 & 321 & Bacteria; Proteobacteria; Gammaproteobacteria; Pseudomonadales; Moraxellaceae; Enhydrobacter \\
\hline Otu121 & 309 & Bacteria; Spirochaetes; Spirochaetes; Spirochaetales; Spirochaetaceae; Treponema \\
\hline Otu83 & 307 & Bacteria; Firmicutes; Clostridia; Clostridiales; Lachnospiraceae; Moryella \\
\hline Otu184 & 305 & Bacteria; Proteobacteria; Gammaproteobacteria; Cardiobacteriales; Cardiobacteriaceae; Cardiobacterium \\
\hline Otu132 & 288 & Bacteria; Firmicutes; Clostridia; Clostridiales; Peptococcaceae; Peptococcus \\
\hline Otu112 & 275 & Bacteria; Firmicutes; Clostridia \\
\hline Otu177 & 264 & Bacteria; TM7; TM7-3 \\
\hline Otu95 & 261 & Bacteria; Bacteroidetes; Flavobacteriia; Flavobacteriales; Flavobacteriaceae; Capnocytophaga \\
\hline Otu164 & 241 & Bacteria; Firmicutes; Clostridia; Clostridiales; Veillonellaceae; Schwartzia \\
\hline Otu176 & 233 & Bacteria; Firmicutes; Clostridia; Clostridiales; Peptostreptococcaceae \\
\hline
\end{tabular}




\begin{tabular}{|c|c|c|}
\hline OTU no. & OTU abundance & Taxonomy \\
\hline Otu183 & 231 & Bacteria; Firmicutes; Clostridia; Clostridiales; Veillonellaceae; Megasphaera \\
\hline Otu153 & 225 & Bacteria; Firmicutes; Clostridia; Clostridiales; Mogibacteriaceae \\
\hline Otu221 & 224 & Bacteria; Firmicutes; Clostridia; Clostridiales; Veillonellaceae; Selenomonas \\
\hline Otu170 & 218 & Bacteria; Bacteroidetes; Bacteroidia; Bacteroidales; Prevotellaceae; Prevotella \\
\hline Otu165 & 215 & Bacteria; Firmicutes; Clostridia; Clostridiales; Veillonellaceae; Selenomonas \\
\hline Otu172 & 213 & Bacteria; Bacteroidetes; Bacteroidia; Bacteroidales; Porphyromonadaceae; Tannerella \\
\hline Otu162 & 211 & Bacteria; Actinobacteria; Actinobacteria; Actinomycetales; Propionibacteriaceae \\
\hline Otu147 & 207 & Bacteria; Firmicutes; Clostridia; Clostridiales; Veillonellaceae \\
\hline Otu202 & 207 & Bacteria; Firmicutes; Clostridia; Clostridiales; Veillonellaceae; Veillonella \\
\hline Otu180 & 202 & Bacteria; Actinobacteria; Actinobacteria; Actinomycetales; Actinomycetaceae; Actinomyces \\
\hline Otu148 & 198 & Bacteria; Spirochaetes; Spirochaetes; Spirochaetales; Spirochaetaceae; Treponema; Treponema_amylovorum \\
\hline Otu187 & 189 & Bacteria; Firmicutes; Clostridia; Clostridiales; Lachnospiraceae \\
\hline Otu182 & 188 & Bacteria; Spirochaetes; Spirochaetes; Spirochaetales; Spirochaetaceae; Treponema; Treponema_amylovorum \\
\hline Otu163 & 187 & Bacteria; Actinobacteria; Actinobacteria; Actinomycetales; Actinomycetaceae; Actinomyces \\
\hline Otu141 & 184 & Bacteria; Actinobacteria; Actinobacteria; Bifidobacteriales; Bifidobacteriaceae; Bifidobacterium \\
\hline Otu130 & 183 & Bacteria; TM7; TM7-3 \\
\hline Otu149 & 178 & Bacteria; Firmicutes; Clostridia; Clostridiales; Lachnospiraceae; Shuttleworthia; Shuttleworthia_satelles \\
\hline Otu281 & 174 & Bacteria; Proteobacteria; Betaproteobacteria; Neisseriales; Neisseriaceae; Kingella \\
\hline Otu142 & 169 & Bacteria; Spirochaetes; Spirochaetes; Spirochaetales; Spirochaetaceae; Treponema \\
\hline Otu116 & 155 & Bacteria; Bacteroidetes; Bacteroidia; Bacteroidales; Porphyromonadaceae; Porphyromonas \\
\hline Otu174 & 148 & Bacteria; Bacteroidetes; Flavobacteriia; Flavobacteriales; Flavobacteriaceae; Capnocytophaga \\
\hline Otu191 & 144 & Bacteria; Spirochaetes; Spirochaetes; Spirochaetales; Spirochaetaceae; Treponema \\
\hline Otu152 & 143 & Bacteria; Fusobacteria; Fusobacteriia; Fusobacteriales; Leptotrichiaceae; Leptotrichia \\
\hline Otu150 & 143 & Bacteria; Tenericutes; Mollicutes; Mycoplasmatales; Mycoplasmataceae; Mycoplasma \\
\hline Otu179 & 140 & Bacteria; Fusobacteria; Fusobacteriia; Fusobacteriales; Leptotrichiaceae; Leptotrichia \\
\hline Otu171 & 139 & Bacteria; Tenericutes; Mollicutes; Mycoplasmatales; Mycoplasmataceae; Mycoplasma \\
\hline Otu185 & 133 & Bacteria; Firmicutes; Clostridia; Clostridiales; Veillonellaceae; Selenomonas \\
\hline Otu160 & 131 & Bacteria; Bacteroidetes; Bacteroidia; Bacteroidales; Prevotellaceae; Prevotella \\
\hline Otu196 & 128 & Bacteria; Bacteroidetes; Bacteroidia; Bacteroidales; Prevotellaceae; Prevotella \\
\hline Otu216 & 126 & Bacteria; Proteobacteria; Betaproteobacteria; Neisseriales; Neisseriaceae; Neisseria; Neisseria_bacilliformis \\
\hline Otu251 & 125 & Bacteria; Bacteroidetes; Bacteroidia; Bacteroidales \\
\hline Otu128 & 122 & Bacteria; Tenericutes; Mollicutes; RF39 \\
\hline Otu228 & 122 & Bacteria; GN02; BD1-5 \\
\hline Otu238 & 111 & Bacteria; TM7; TM7-3; CW040; F16 \\
\hline
\end{tabular}

APPLIED ECOLOGY AND ENVIRONMENTAL RESEARCH 18(5):7089-7138.

http://www.aloki.hu • ISSN 15891623 (Print) • ISSN 17850037 (Online)

DOI: http://dx.doi.org/10.15666/aeer/1805_70897138

○ 2020, ALÖKI Kft., Budapest, Hungary 


\begin{tabular}{|c|c|c|}
\hline OTU no. & OTU abundance & Taxonomy \\
\hline Otu250 & 111 & Bacteria; Spirochaetes; Spirochaetes; Spirochaetales; Spirochaetaceae; Treponema \\
\hline Otu188 & 103 & Bacteria; Bacteroidetes; Bacteroidia; Bacteroidales; Prevotellaceae; Prevotella \\
\hline Otu209 & 101 & Bacteria; Proteobacteria; Betaproteobacteria; Neisseriales; Neisseriaceae \\
\hline Otu190 & 100 & Bacteria; Actinobacteria; Actinobacteria; Actinomycetales; Corynebacteriaceae; Corynebacterium \\
\hline Otu201 & 100 & Bacteria; Fusobacteria; Fusobacteriia; Fusobacteriales; Leptotrichiaceae \\
\hline Otu207 & 99 & Bacteria; Bacteroidetes; Bacteroidia; Bacteroidales; Prevotellaceae; Prevotella \\
\hline Otu204 & 96 & Bacteria; Firmicutes; Bacilli; Lactobacillales; Lactobacillaceae; Lactobacillus; Lactobacillus_helveticus \\
\hline Otu205 & 96 & Bacteria; Actinobacteria; Actinobacteria; Actinomycetales; Propionibacteriaceae \\
\hline Otu135 & 95 & Bacteria; TM7; TM7-3; CW040 \\
\hline Otu227 & 95 & Bacteria; Firmicutes; Bacilli; Lactobacillales; Lactobacillaceae; Lactobacillus; Lactobacillus_salivarius \\
\hline Otu279 & 93 & Bacteria; Proteobacteria; Gammaproteobacteria; Pasteurellales; Pasteurellaceae; Haemophilus; Haemophilus_parainfl \\
\hline Otu167 & 93 & Bacteria; Proteobacteria; Alphaproteobacteria; Rickettsiales; mitochondria \\
\hline Otu225 & 93 & Bacteria; Firmicutes; Erysipelotrichi; Erysipelotrichales; Erysipelotrichaceae; Bulleidia \\
\hline Otu197 & 92 & Bacteria; Firmicutes; Clostridia; Clostridiales; Peptostreptococcaceae \\
\hline Otu214 & 89 & Bacteria; Actinobacteria; Actinobacteria; Bifidobacteriales; Bifidobacteriaceae; Scardovia \\
\hline Otu240 & 86 & Bacteria; Firmicutes; Bacilli; Lactobacillales; Lactobacillaceae; Lactobacillus; Lactobacillus_vaginalis \\
\hline Otu158 & 85 & Bacteria; Actinobacteria; Coriobacteriia; Coriobacteriales; Coriobacteriaceae \\
\hline Otu237 & 85 & Bacteria; Actinobacteria; Coriobacteriia; Coriobacteriales; Coriobacteriaceae \\
\hline Otu291 & 85 & Bacteria; Proteobacteria; Betaproteobacteria; Neisseriales; Neisseriaceae; Neisseria; Neisseria_subflava \\
\hline Otu223 & 84 & Bacteria; Firmicutes; Clostridia; Clostridiales; Veillonellaceae; Schwartzia \\
\hline Otu127 & 82 & Bacteria; Proteobacteria; Gammaproteobacteria; Pasteurellales; Pasteurellaceae; Actinobacillus \\
\hline Otu203 & 81 & Bacteria; Bacteroidetes; Bacteroidia; Bacteroidales; Prevotellaceae; Prevotella \\
\hline Otu226 & 80 & Bacteria; Firmicutes; Bacilli; Lactobacillales; Lactobacillaceae; Lactobacillus \\
\hline Otu233 & 75 & Bacteria; Bacteroidetes; Bacteroidia; Bacteroidales; Prevotellaceae; Prevotella \\
\hline Otu215 & 75 & Bacteria; Cyanobacteria; Chloroplast; Streptophyta \\
\hline Otu157 & 73 & Bacteria; Bacteroidetes; Bacteroidia; Bacteroidales; Prevotellaceae; Prevotella; Prevotella_nanceiensis \\
\hline Otu138 & 72 & Bacteria; Firmicutes; Bacilli; Lactobacillales; Streptococcaceae; Streptococcus \\
\hline Otu242 & 71 & Bacteria; Bacteroidetes; Bacteroidia; Bacteroidales; Prevotellaceae; Prevotella \\
\hline Otu210 & 69 & Bacteria; Bacteroidetes; Bacteroidia; Bacteroidales; Prevotellaceae; Prevotella \\
\hline Otu270 & 67 & Bacteria; Synergistetes; Synergistia; Synergistales; Dethiosulfovibrionaceae; TG5 \\
\hline Otu222 & 67 & Bacteria; Actinobacteria; Coriobacteriia; Coriobacteriales; Coriobacteriaceae; Olsenella; Olsenella_profusa \\
\hline Otu256 & 66 & Bacteria; Firmicutes; Bacilli; Bacillales; Staphylococcaceae; Staphylococcus \\
\hline Otu272 & 66 & Bacteria; Firmicutes; Clostridia; Clostridiales; Veillonellaceae; Dialister \\
\hline Otu289 & 65 & Bacteria; Firmicutes; Bacilli; Lactobacillales; Lactobacillaceae; Lactobacillus; Lactobacillus_delbrueckii \\
\hline
\end{tabular}




\begin{tabular}{|c|c|c|}
\hline OTU no. & OTU abundance & \\
\hline Otu195 & 63 & \\
\hline Otu235 & 61 & $\mathrm{Bac}$ \\
\hline Otu263 & 61 & \\
\hline Otu255 & 60 & \\
\hline Otu234 & 59 & \\
\hline Otu166 & 59 & \\
\hline Otu246 & 58 & \\
\hline Otu175 & 55 & \\
\hline Otu231 & 53 & \\
\hline Otu252 & 53 & \\
\hline Otu253 & 52 & \\
\hline Otu218 & 50 & \\
\hline Otu181 & 50 & \\
\hline Otu244 & 49 & \\
\hline Otu229 & 48 & \\
\hline Otu248 & 46 & \\
\hline Otu273 & 46 & \\
\hline Otu200 & 46 & \\
\hline Otu224 & 44 & \\
\hline Otu264 & 42 & \\
\hline Otu208 & 42 & \\
\hline Otu247 & 41 & \\
\hline Otu236 & 40 & \\
\hline Otu290 & 38 & \\
\hline Otu211 & 38 & $\mathrm{Ba}$ \\
\hline Otu220 & 35 & \\
\hline Otu265 & 35 & \\
\hline Otu178 & 35 & \\
\hline Otu212 & 35 & \\
\hline Otu230 & 34 & \\
\hline Otu199 & 32 & \\
\hline Otu198 & 31 & \\
\hline Otu241 & 31 & \\
\hline Otu288 & 30 & \\
\hline
\end{tabular}

Bacteria; Proteobacteria; Gammaproteobacteria; Cardiobacteriales; Cardiobacteriaceae; Cardiobacterium

Bacteria; Firmicutes; Clostridia; Clostridiales; Lachnospiraceae; Oribacterium

Bacteria; Synergistetes; Synergistia; Synergistales; Dethiosulfovibrionaceae; TG5

Bacteria; Firmicutes; Clostridia; Clostridiales

Bacteria; Firmicutes; Clostridia; Clostridiales; Mogibacteriaceae

Bacteria; Bacteroidetes; Flavobacteriia; Flavobacteriales; Flavobacteriaceae; Capnocytophaga

Bacteria; Firmicutes; Bacilli; Lactobacillales; Aerococcaceae; Alloiococcus

Bacteria; Actinobacteria; Actinobacteria; Actinomycetales; Actinomycetaceae; Actinomyces

Bacteria; Bacteroidetes; Bacteroidia; Bacteroidales; Prevotellaceae; Prevotella

Bacteria; Proteobacteria; Betaproteobacteria; Burkholderiales; Comamonadaceae

Bacteria; Firmicutes; Bacilli; Lactobacillales; Streptococcaceae; Lactococcus

Bacteria; Proteobacteria; Gammaproteobacteria; Pasteurellales; Pasteurellaceae; Aggregatibacter

Bacteria; Actinobacteria; Actinobacteria; Actinomycetales; Actinomycetaceae

Bacteria; Bacteroidetes; Bacteroidia; Bacteroidales; Prevotellaceae; Prevotella

Bacteria; Actinobacteria; Actinobacteria; Actinomycetales; Actinomycetaceae

Bacteria; Proteobacteria; Betaproteobacteria; Neisseriales; Neisseriaceae; Kingella

Bacteria; Bacteroidetes; Bacteroidia; Bacteroidales; BS11

Bacteria; Firmicutes; Clostridia; Clostridiales; Veillonellaceae

Bacteria; Firmicutes; Clostridia; Clostridiales; Veillonellaceae; Dialister

Bacteria; Firmicutes; Clostridia; Clostridiales; Peptostreptococcaceae

Bacteria; Bacteroidetes; Bacteroidia; Bacteroidales; Prevotellaceae; Prevotella

Bacteria; Firmicutes; Clostridia; Clostridiales; Lachnospiraceae; Johnsonella; Johnsonella_ignava

Bacteria; Firmicutes; Clostridia; Clostridiales; Mogibacteriaceae

Bacteria; Firmicutes; Bacilli; Lactobacillales; Streptococcaceae; Streptococcus; Streptococcus_sobrinus

Bacteria; Firmicutes; Clostridia; Clostridiales; Acidaminobacteraceae

Bacteria; Firmicutes; Clostridia; Clostridiales; Mogibacteriaceae

Bacteria; Proteobacteria; Gammaproteobacteria; Cardiobacteriales; Cardiobacteriaceae

Bacteria; Tenericutes; Mollicutes; RF39

Bacteria; Bacteroidetes; Bacteroidia; Bacteroidales

Bacteria; Bacteroidetes; Bacteroidia; Bacteroidales

Bacteria; Proteobacteria; Gammaproteobacteria; Cardiobacteriales; Cardiobacteriaceae

Bacteria; Firmicutes; Clostridia; Clostridiales; Lachnospiraceae

Bacteria; Bacteroidetes; Bacteroidia; Bacteroidales; Paraprevotellaceae; Prevotella

APPLIED ECOLOGY AND ENVIRONMENTAL RESEARCH 18(5):7089-7138.

http://www.aloki.hu • ISSN 15891623 (Print) • ISSN 17850037 (Online)

DOI: http://dx.doi.org/10.15666/aeer/1805 70897138

(c) 2020, ALÖKI Kft., Budapest, Hungary 


\begin{tabular}{|c|c|c|}
\hline OTU no. & OTU abundance & Taxonomy \\
\hline Otu249 & 29 & Bacteria; GN02; BD1-5 \\
\hline Otu232 & 28 & Bacteria; Bacteroidetes; Bacteroidia; Bacteroidales; Rikenellaceae; Blvii28 \\
\hline Otu173 & 28 & Bacteria; Tenericutes; Mollicutes; Acholeplasmatales; Acholeplasmataceae; Acholeplasma \\
\hline Otu213 & 26 & Bacteria; TM7; TM7-3 \\
\hline Otu286 & 25 & Bacteria; Firmicutes; Clostridia; Clostridiales; Lachnospiraceae; Catonella \\
\hline Otu258 & 21 & Bacteria; Bacteroidetes; Bacteroidia; Bacteroidales; Prevotellaceae; Prevotella \\
\hline Otu161 & 21 & Bacteria; Spirochaetes; Spirochaetes; Spirochaetales; Spirochaetaceae; Treponema \\
\hline Otu269 & 20 & Bacteria; Proteobacteria; Betaproteobacteria; Neisseriales; Neisseriaceae; Kingella \\
\hline Otu262 & 17 & Bacteria; Firmicutes; Clostridia; Clostridiales; Lachnospiraceae; Johnsonella; Johnsonella_ignava \\
\hline Otu284 & 15 & Bacteria; Actinobacteria; Actinobacteria; Actinomycetales; Corynebacteriaceae; Corynebacterium \\
\hline Otu278 & 11 & Bacteria; Firmicutes; Bacilli; Bacillales; Bacillaceae; Anoxybacillus; Anoxybacillus_kestanbolensis \\
\hline Otu259 & 11 & Bacteria; Firmicutes; Bacilli; Lactobacillales; Leuconostocaceae; Weissella; Weissella_cibaria \\
\hline Otu266 & 10 & Bacteria; Bacteroidetes; Bacteroidia; Bacteroidales; Prevotellaceae; Prevotella \\
\hline Otu243 & 9 & Bacteria; Synergistetes; Synergistia; Synergistales; Dethiosulfovibrionaceae; Pyramidobacter; Pyramidobacter_piscolens \\
\hline Otu283 & 9 & Bacteria; Fusobacteria; Fusobacteriia; Fusobacteriales; Leptotrichiaceae; Leptotrichia \\
\hline Otu282 & 9 & Bacteria; Fusobacteria; Fusobacteriia; Fusobacteriales; Leptotrichiaceae; Leptotrichia \\
\hline Otu254 & 8 & Bacteria; Bacteroidetes; Bacteroidia; Bacteroidales \\
\hline Otu275 & 7 & Bacteria; Proteobacteria; Betaproteobacteria; Burkholderiales; Comamonadaceae \\
\hline Otu260 & 5 & Bacteria; Firmicutes; Erysipelotrichi; Erysipelotrichales; Erysipelotrichaceae; Bulleidia \\
\hline Otu267 & 5 & Bacteria; Cyanobacteria; Chloroplast; Streptophyta \\
\hline Otu257 & 4 & Bacteria; Actinobacteria; Actinobacteria; Bifidobacteriales; Bifidobacteriaceae; Bifidobacterium \\
\hline
\end{tabular}

Table A2. Richness of OTUs of different samples before and after swaking

\begin{tabular}{c|c|c|c|c|c|c|c|c|c|c|c|c|c|c|c|c|c|c|c|c|c|c|c|c|c|}
\hline & BEF2 & AF2 & BEF6 & AF6 & BEF8 & AF8 & BEF9 & AF9 & BEF10 & AF10 & BEF12 & AF12 & BEF14 & AF14 & BEF15 & AF15 & BEF19 & AF19 & BEF20 & AF20 & Total \\
\hline Otu2 & 11062 & 11570 & 7278 & 9371 & 10372 & 16437 & 13938 & 14394 & 14000 & 16547 & 6064 & 8382 & 6956 & 16884 & 18405 & 13464 & 4544 & 13569 & 14256 & 8500 & 235993 \\
Otu1 & 15251 & 2972 & 12398 & 10906 & 19902 & 6250 & 8512 & 4404 & 9177 & 17991 & 1640 & 5479 & 4465 & 12883 & 3700 & 11478 & 21756 & 5495 & 12085 & 8650 & 195394 \\
Otu3 & 8044 & 3356 & 9825 & 5142 & 13444 & 5971 & 10524 & 3200 & 9441 & 9744 & 5498 & 6325 & 5589 & 6824 & 2186 & 8438 & 13926 & 7560 & 10655 & 1798 & 147490 \\
Otu4 & 12642 & 7845 & 842 & 1941 & 1587 & 2831 & 1634 & 7295 & 5771 & 3147 & 6416 & 4897 & 1116 & 8691 & 6067 & 1646 & 619 & 1804 & 5901 & 9359 & 92051 \\
Otu11 & 1690 & 2370 & 3060 & 4357 & 1089 & 3688 & 3934 & 6327 & 1752 & 793 & 1498 & 1760 & 5147 & 1874 & 1641 & 4427 & 1395 & 1329 & 5658 & 4742 & 58531 \\
Otu32 & 3563 & 802 & 4934 & 5040 & 4315 & 2150 & 1399 & 816 & 2116 & 2866 & 3997 & 2932 & 1420 & 1023 & 704 & 965 & 4818 & 2740 & 1990 & 1593 & 50183 \\
Otu8 & 5378 & 948 & 458 & 419 & 1608 & 2198 & 4793 & 3265 & 4079 & 2346 & 2484 & 1503 & 959 & 830 & 5074 & 1636 & 2190 & 2268 & 4500 & 2157 & 49093 \\
Otu14 & 2425 & 5232 & 2153 & 2774 & 803 & 3783 & 951 & 1463 & 2915 & 2086 & 2246 & 5832 & 1170 & 4094 & 3432 & 1546 & 236 & 1448 & 1352 & 683 & 46624 \\
Otu6 & 3818 & 4766 & 708 & 208 & 1158 & 3386 & 8793 & 2683 & 371 & 110 & 27 & 362 & 3432 & 2877 & 3156 & 501 & 392 & 946 & 1669 & 1509 & 40872 \\
\hline
\end{tabular}

APPLIED ECOLOGY AND ENVIRONMENTAL RESEARCH 18(5):7089-7138.

http://www.aloki.hu • ISSN 15891623 (Print) • ISSN 17850037 (Online)

DOI: http://dx.doi.org/10.15666/aeer/1805_70897138

(c) 2020, ALÖKI Kft., Budapest, Hungary 


\begin{tabular}{|c|c|c|c|c|c|c|c|c|c|c|c|c|c|c|c|c|c|c|c|c|c|}
\hline & BEF2 & AF2 & BEF6 & AF6 & BEF8 & AF8 & BEF9 & AF9 & BEF10 & AF10 & BEF12 & AF12 & BEF14 & AF14 & BEF15 & AF15 & BEF19 & AF19 & BEF20 & AF20 & Total \\
\hline Otu12 & 487 & 1567 & 468 & 130 & 1323 & 1673 & 194 & 1306 & 1862 & 2852 & 1573 & 2972 & 570 & 1585 & 179 & 6526 & 2685 & 3759 & 1072 & 1246 & 34029 \\
\hline Otu10 & 1 & 640 & 2043 & 969 & 284 & 488 & 1059 & 495 & 1233 & 517 & 3846 & 3684 & 679 & 222 & 515 & 397 & 4118 & 2307 & 3827 & 5744 & 33068 \\
\hline Otu7 & 3968 & 2096 & 1733 & 1851 & 393 & 1201 & 548 & 2721 & 284 & 438 & 385 & 2072 & 769 & 4233 & 6953 & 1337 & 133 & 844 & 534 & 148 & 32641 \\
\hline Otu5 & 1896 & 864 & 2344 & 1265 & 3027 & 405 & 1494 & 853 & 1702 & 662 & 1462 & 739 & 3057 & 873 & 835 & 396 & 3641 & 1719 & 3626 & 1232 & 32092 \\
\hline Otu261 & 1318 & 2960 & 1512 & 173 & 1817 & 1428 & 1695 & 4513 & 10 & 94 & 348 & 40 & 2661 & 1374 & 7146 & 241 & 141 & 193 & 196 & 51 & 27911 \\
\hline Otu29 & 1204 & 4196 & 1753 & 151 & 291 & 1799 & 1931 & 2459 & 276 & 1394 & 938 & 2197 & 1258 & 1718 & 495 & 1368 & 933 & 351 & 27 & 154 & 24893 \\
\hline Otu17 & 209 & 158 & 2811 & 1991 & 3170 & 1185 & 253 & 344 & 390 & 143 & 1413 & 1889 & 642 & 727 & 553 & 699 & 2042 & 790 & 2090 & 2284 & 23783 \\
\hline Otu15 & 792 & 455 & 2528 & 1294 & 3798 & 773 & 483 & 272 & 1072 & 1604 & 1043 & 2485 & 695 & 355 & 198 & 523 & 2114 & 674 & 255 & 1284 & 22697 \\
\hline Otu25 & 785 & 1237 & 597 & 596 & 331 & 1719 & 3075 & 1734 & 61 & 116 & 386 & 878 & 2679 & 1383 & 1222 & 760 & 952 & 311 & 1780 & 392 & 20994 \\
\hline Otu21 & 622 & 119 & 1301 & 2576 & 1203 & 870 & 1530 & 523 & 1843 & 548 & 485 & 513 & 1291 & 273 & 882 & 220 & 1835 & 330 & 1130 & 332 & 18426 \\
\hline Otu20 & 91 & 128 & 1132 & 460 & 105 & 1377 & 454 & 2226 & 941 & 247 & 2634 & 1290 & 584 & 277 & 166 & 373 & 1213 & 2217 & 595 & 645 & 17155 \\
\hline Otu27 & 745 & 527 & 229 & 314 & 364 & 487 & 694 & 1237 & 1869 & 513 & 809 & 661 & 251 & 619 & 413 & 638 & 442 & 1081 & 1215 & 802 & 13910 \\
\hline Otu26 & 800 & 947 & 1297 & 155 & 177 & 898 & 1172 & 1185 & 54 & 173 & 104 & 544 & 457 & 2199 & 556 & 751 & 212 & 338 & 822 & 627 & 13468 \\
\hline Otu9 & 1 & 6634 & 0 & 60 & 79 & 562 & 106 & 849 & 778 & 362 & 5 & 750 & 1575 & 1182 & 263 & 1 & 0 & 21 & 14 & 0 & 13242 \\
\hline Otu40 & 797 & 78 & 1525 & 386 & 445 & 1210 & 745 & 462 & 27 & 281 & 17 & 326 & 793 & 2069 & 718 & 1551 & 747 & 723 & 108 & 43 & 13051 \\
\hline Otu33 & 825 & 25 & 2041 & 579 & 244 & 1491 & 699 & 2294 & 0 & 43 & 63 & 283 & 390 & 574 & 1564 & 594 & 403 & 566 & 176 & 52 & 12906 \\
\hline Otu37 & 171 & 37 & 1119 & 1683 & 977 & 798 & 672 & 748 & 111 & 376 & 299 & 929 & 73 & 907 & 16 & 180 & 417 & 1659 & 623 & 877 & 12672 \\
\hline Otu23 & 201 & 2117 & 328 & 924 & 24 & 606 & 214 & 2345 & 232 & 49 & 538 & 1131 & 744 & 209 & 241 & 83 & 798 & 673 & 149 & 302 & 11908 \\
\hline Otu193 & 2650 & 318 & 416 & 163 & 1426 & 515 & 1844 & 354 & 197 & 230 & 811 & 427 & 482 & 428 & 178 & 65 & 292 & 285 & 189 & 45 & 11315 \\
\hline Otu28 & 10 & 185 & 639 & 3606 & 53 & 663 & 515 & 174 & 27 & 84 & 1015 & 193 & 1624 & 97 & 70 & 627 & 115 & 286 & 21 & 20 & 10024 \\
\hline Otu109 & 1870 & 1259 & 696 & 845 & 244 & 442 & 294 & 639 & 215 & 162 & 132 & 276 & 317 & 678 & 899 & 456 & 92 & 207 & 102 & 53 & 9878 \\
\hline Otu49 & 523 & 1345 & 204 & 1129 & 125 & 813 & 306 & 1411 & 314 & 340 & 660 & 731 & 1 & 413 & 227 & 1 & 26 & 105 & 406 & 670 & 9750 \\
\hline Otu18 & 65 & 140 & 436 & 277 & 55 & 136 & 120 & 437 & 820 & 281 & 198 & 440 & 2378 & 302 & 37 & 981 & 229 & 2004 & 120 & 248 & 9704 \\
\hline Otu55 & 264 & 153 & 309 & 101 & 178 & 476 & 1056 & 707 & 461 & 60 & 243 & 119 & 300 & 277 & 304 & 916 & 91 & 378 & 1065 & 1356 & 8814 \\
\hline Otu24 & 92 & 149 & 64 & 288 & 201 & 387 & 69 & 169 & 282 & 530 & 883 & 249 & 149 & 180 & 801 & 225 & 368 & 648 & 1902 & 956 & 8592 \\
\hline Otu38 & 106 & 63 & 321 & 261 & 527 & 315 & 297 & 140 & 1134 & 341 & 460 & 334 & 580 & 118 & 132 & 230 & 845 & 349 & 1110 & 717 & 8380 \\
\hline Otu42 & 266 & 35 & 419 & 953 & 808 & 287 & 184 & 29 & 242 & 71 & 1156 & 198 & 259 & 54 & 50 & 132 & 2355 & 396 & 288 & 120 & 8302 \\
\hline Otu68 & 738 & 501 & 886 & 618 & 89 & 369 & 408 & 351 & 131 & 103 & 556 & 876 & 377 & 191 & 96 & 197 & 700 & 414 & 194 & 364 & 8159 \\
\hline Otu53 & 1419 & 871 & 1 & 96 & 265 & 1246 & 487 & 1075 & 183 & 80 & 147 & 892 & 277 & 325 & 226 & 47 & 36 & 57 & 375 & 22 & 8127 \\
\hline Otu245 & 195 & 212 & 240 & 200 & 252 & 515 & 492 & 79 & 3 & 61 & 17 & 61 & 248 & 583 & 157 & 1055 & 225 & 60 & 986 & 1415 & 7056 \\
\hline Otu51 & 159 & 137 & 619 & 509 & 101 & 450 & 305 & 656 & 526 & 227 & 480 & 279 & 199 & 146 & 178 & 188 & 782 & 505 & 292 & 131 & 6869 \\
\hline Otu41 & 97 & 16 & 186 & 744 & 368 & 220 & 63 & 91 & 230 & 12 & 1292 & 545 & 506 & 532 & 134 & 421 & 255 & 108 & 452 & 469 & 6741 \\
\hline Otu50 & 41 & 39 & 194 & 45 & 149 & 265 & 905 & 423 & 386 & 119 & 938 & 161 & 261 & 2 & 65 & 150 & 574 & 252 & 779 & 507 & 6255 \\
\hline Otu19 & 836 & 520 & 181 & 2196 & 44 & 510 & 240 & 209 & 55 & 35 & 107 & 259 & 164 & 339 & 79 & 170 & 64 & 52 & 93 & 30 & 6183 \\
\hline
\end{tabular}

APPLIED ECOLOGY AND ENVIRONMENTAL RESEARCH 18(5):7089-7138.

http://www.aloki.hu • ISSN 15891623 (Print) • ISSN 17850037 (Online)

DOI: http://dx.doi.org/10.15666/aeer/1805_70897138

( 2020 , ALÖKI Kft., Budapest, Hungary 


\begin{tabular}{|c|c|c|c|c|c|c|c|c|c|c|c|c|c|c|c|c|c|c|c|c|c|}
\hline & BEF2 & AF2 & BEF6 & AF6 & BEF8 & AF8 & BEF9 & AF9 & BEF10 & AF10 & BEF12 & AF12 & BEF14 & AF14 & BEF15 & AF15 & BEF19 & AF19 & BEF20 & AF20 & Total \\
\hline Otu39 & 62 & 1011 & 892 & 320 & 21 & 178 & 97 & 525 & 14 & 64 & 268 & 477 & 26 & 200 & 32 & 63 & 1343 & 448 & 60 & 23 & 6124 \\
\hline Otu277 & 37 & 801 & 10 & 16 & 713 & 208 & 319 & 1298 & 8 & 41 & 130 & 9 & 276 & 652 & 1339 & 15 & 7 & 22 & 34 & 24 & 5959 \\
\hline Otu65 & 629 & 276 & 158 & 392 & 311 & 187 & 324 & 890 & 92 & 130 & 21 & 122 & 283 & 754 & 587 & 531 & 7 & 42 & 79 & 5 & 5820 \\
\hline Otu31 & 18 & 287 & 163 & 176 & 131 & 164 & 173 & 442 & 76 & 83 & 30 & 49 & 2064 & 678 & 65 & 337 & 85 & 86 & 24 & 9 & 5140 \\
\hline Otu35 & 0 & 4 & 8 & 69 & 138 & 854 & 9 & 395 & 0 & 0 & 1190 & 401 & 14 & 11 & 25 & 16 & 78 & 213 & 199 & 1479 & 5103 \\
\hline Otu22 & 0 & 2 & 1854 & 0 & 0 & 0 & 508 & 462 & 4 & 89 & 0 & 1 & 317 & 411 & 21 & 680 & 56 & 618 & 0 & 0 & 5023 \\
\hline Otu13 & 0 & 0 & 2 & 1 & 0 & 0 & 11 & 4 & 0 & 0 & 0 & 0 & 3543 & 4 & 3 & 2 & 1329 & 3 & 1 & 2 & 4905 \\
\hline Otu88 & 322 & 351 & 375 & 61 & 33 & 400 & 174 & 441 & 683 & 181 & 83 & 228 & 265 & 110 & 65 & 302 & 251 & 472 & 64 & 28 & 4889 \\
\hline Otu155 & 5 & 440 & 87 & 38 & 75 & 416 & 272 & 467 & 585 & 96 & 330 & 310 & 461 & 113 & 45 & 440 & 110 & 251 & 188 & 85 & 4814 \\
\hline Otu61 & 208 & 226 & 349 & 333 & 103 & 310 & 94 & 172 & 218 & 115 & 36 & 156 & 935 & 274 & 94 & 440 & 144 & 456 & 68 & 66 & 4797 \\
\hline Otu70 & 26 & 320 & 564 & 236 & 102 & 774 & 254 & 398 & 221 & 57 & 67 & 243 & 572 & 39 & 64 & 247 & 158 & 66 & 363 & 17 & 4788 \\
\hline Otu34 & 1344 & 485 & 86 & 12 & 9 & 178 & 112 & 548 & 35 & 8 & 53 & 72 & 737 & 163 & 139 & 56 & 180 & 57 & 87 & 36 & 4397 \\
\hline Otu52 & 57 & 174 & 85 & 323 & 105 & 404 & 48 & 239 & 25 & 13 & 326 & 1007 & 208 & 21 & 32 & 71 & 800 & 186 & 97 & 26 & 4247 \\
\hline Otu66 & 15 & 321 & 626 & 587 & 45 & 141 & 122 & 105 & 138 & 103 & 298 & 196 & 696 & 92 & 149 & 64 & 227 & 141 & 56 & 79 & 4201 \\
\hline Otu76 & 79 & 144 & 101 & 109 & 100 & 310 & 117 & 305 & 336 & 83 & 423 & 185 & 281 & 83 & 167 & 176 & 140 & 173 & 471 & 261 & 4044 \\
\hline Otu69 & 595 & 668 & 192 & 34 & 18 & 152 & 155 & 403 & 54 & 19 & 143 & 44 & 867 & 78 & 56 & 161 & 61 & 71 & 69 & 63 & 3903 \\
\hline Otu57 & 10 & 219 & 178 & 92 & 25 & 336 & 129 & 111 & 299 & 55 & 110 & 155 & 980 & 86 & 42 & 94 & 412 & 322 & 66 & 42 & 3763 \\
\hline Otu36 & 1262 & 142 & 142 & 7 & 23 & 301 & 269 & 247 & 257 & 18 & 56 & 49 & 217 & 58 & 55 & 88 & 199 & 55 & 22 & 9 & 3476 \\
\hline Otu16 & 2754 & 203 & 9 & 0 & 0 & 46 & 60 & 216 & 27 & 7 & 25 & 0 & 0 & 33 & 36 & 16 & 0 & 7 & 1 & 0 & 3440 \\
\hline Otu48 & 359 & 54 & 62 & 187 & 8 & 395 & 37 & 351 & 228 & 91 & 798 & 108 & 61 & 51 & 22 & 38 & 300 & 180 & 47 & 63 & 3440 \\
\hline Otu64 & 4 & 33 & 355 & 3 & 0 & 7 & 71 & 64 & 156 & 8 & 185 & 774 & 232 & 20 & 15 & 94 & 107 & 271 & 26 & 990 & 3415 \\
\hline Otu84 & 98 & 261 & 309 & 189 & 18 & 178 & 330 & 456 & 235 & 60 & 131 & 30 & 426 & 75 & 15 & 247 & 46 & 153 & 68 & 81 & 3406 \\
\hline Otu47 & 78 & 301 & 645 & 224 & 105 & 415 & 203 & 124 & 0 & 0 & 35 & 51 & 110 & 120 & 728 & 100 & 65 & 50 & 21 & 6 & 3381 \\
\hline Otu93 & 20 & 233 & 597 & 53 & 13 & 210 & 194 & 640 & 409 & 24 & 306 & 226 & 64 & 75 & 37 & 41 & 12 & 16 & 145 & 52 & 3367 \\
\hline Otu126 & 263 & 432 & 277 & 210 & 63 & 308 & 62 & 90 & 77 & 46 & 58 & 167 & 520 & 84 & 33 & 241 & 88 & 226 & 31 & 55 & 3331 \\
\hline Otu87 & 260 & 296 & 126 & 31 & 33 & 222 & 189 & 851 & 67 & 53 & 151 & 74 & 307 & 37 & 56 & 95 & 47 & 82 & 61 & 36 & 3074 \\
\hline Otu77 & 112 & 798 & 163 & 76 & 47 & 156 & 192 & 66 & 72 & 13 & 159 & 75 & 485 & 84 & 19 & 131 & 153 & 134 & 21 & 37 & 2993 \\
\hline Otu271 & 205 & 13 & 191 & 134 & 254 & 120 & 271 & 145 & 151 & 119 & 49 & 115 & 80 & 121 & 93 & 83 & 515 & 19 & 241 & 67 & 2986 \\
\hline Otu75 & 29 & 125 & 112 & 64 & 6 & 216 & 153 & 61 & 163 & 32 & 136 & 129 & 234 & 15 & 15 & 94 & 678 & 555 & 82 & 40 & 2939 \\
\hline Otu98 & 82 & 33 & 179 & 26 & 381 & 302 & 15 & 32 & 185 & 86 & 103 & 96 & 20 & 13 & 2 & 33 & 375 & 245 & 2 & 17 & 2227 \\
\hline Otu59 & 722 & 43 & 178 & 36 & 9 & 44 & 70 & 93 & 311 & 63 & 176 & 128 & 179 & 30 & 64 & 44 & 342 & 140 & 66 & 12 & 2750 \\
\hline Otu80 & 0 & 3 & 188 & 72 & 10 & 135 & 80 & 233 & 80 & 42 & 427 & 336 & 58 & 62 & 73 & 120 & 332 & 335 & 72 & 69 & 2727 \\
\hline Otu86 & 18 & 228 & 112 & 33 & 10 & 123 & 53 & 130 & 68 & 27 & 112 & 71 & 441 & 103 & 17 & 200 & 71 & 127 & 436 & 82 & 2462 \\
\hline Otu81 & 10 & 6 & 33 & 8 & 113 & 32 & 173 & 135 & 627 & 105 & 277 & 45 & 47 & 15 & 21 & 72 & 205 & 258 & 119 & 132 & 2433 \\
\hline
\end{tabular}

APPLIED ECOLOGY AND ENVIRONMENTAL RESEARCH 18(5):7089-7138.

http://www.aloki.hu • ISSN 15891623 (Print) • ISSN 17850037 (Online)

DOI: http://dx.doi.org/10.15666/aeer/1805_70897138

(c) 2020, ALÖKI Kft., Budapest, Hungary 


\begin{tabular}{|c|c|c|c|c|c|c|c|c|c|c|c|c|c|c|c|c|c|c|c|c|c|}
\hline & BEF2 & AF2 & BEF6 & AF6 & BEF8 & AF8 & BEF9 & AF9 & BEF10 & AF10 & \begin{tabular}{|l|} 
BEF12 \\
\end{tabular} & AF12 & BEF14 & AF14 & BEF15 & AF15 & BEF19 & AF19 & BEF20 & AF20 & Total \\
\hline Otu206 & 15 & 6 & 51 & 30 & 37 & 38 & 150 & 83 & 397 & 59 & 92 & 70 & 64 & 62 & 77 & 66 & 314 & 186 & 387 & 241 & 2425 \\
\hline Otu137 & 397 & 224 & 248 & 53 & 78 & 166 & 312 & 25 & 101 & 18 & 43 & 38 & 141 & 33 & 32 & 131 & 96 & 86 & 17 & 2 & 2241 \\
\hline Otu62 & 41 & 50 & 150 & 70 & 52 & 76 & 38 & 67 & 102 & 88 & 172 & 74 & 98 & 53 & 32 & 103 & 116 & 142 & 438 & 164 & 2126 \\
\hline Otu67 & 1 & 0 & 16 & 0 & 9 & 48 & 71 & 800 & 0 & 0 & 8 & 44 & 80 & 234 & 638 & 63 & 23 & 21 & 0 & 0 & 2056 \\
\hline Otu71 & 0 & 9 & 203 & 0 & 6 & 0 & 34 & 35 & 440 & 290 & 162 & 125 & 207 & 146 & 38 & 195 & 4 & 107 & 0 & 0 & 2001 \\
\hline Otu45 & 0 & 1 & 1189 & 1 & 0 & 0 & 710 & 71 & 0 & 0 & 0 & 0 & 0 & 0 & 0 & 0 & 0 & 0 & 0 & 0 & 1972 \\
\hline Otu280 & 475 & 213 & 72 & 97 & 30 & 69 & 64 & 148 & 34 & 35 & 41 & 89 & 28 & 201 & 188 & 42 & 10 & 14 & 28 & 30 & 1908 \\
\hline Otu274 & 459 & 125 & 33 & 3 & 43 & 184 & 252 & 194 & 93 & 5 & 66 & 4 & 269 & 29 & 19 & 29 & 52 & 25 & 15 & 5 & 1904 \\
\hline Otu108 & 1 & 94 & 204 & 65 & 28 & 82 & 58 & 184 & 51 & 41 & 27 & 80 & 181 & 241 & 158 & 188 & 83 & 78 & 33 & 25 & 1902 \\
\hline Otu117 & 0 & 40 & 308 & 111 & 11 & 70 & 88 & 106 & 174 & 109 & 63 & 46 & 233 & 29 & 12 & 140 & 111 & 140 & 57 & 19 & 1867 \\
\hline Otu90 & 28 & 7 & 30 & 213 & 217 & 53 & 98 & 41 & 84 & 45 & 68 & 86 & 66 & 71 & 65 & 127 & 88 & 65 & 199 & 213 & 1864 \\
\hline Otu72 & 145 & 386 & 30 & 59 & 15 & 144 & 49 & 227 & 71 & 62 & 49 & 75 & 62 & 69 & 142 & 55 & 9 & 55 & 92 & 38 & 1834 \\
\hline Otu100 & 18 & 223 & 81 & 28 & 19 & 99 & 14 & 79 & 53 & 26 & 31 & 24 & 701 & 164 & 22 & 131 & 28 & 75 & 5 & 6 & 1827 \\
\hline Otu78 & 0 & 260 & 21 & 12 & 2 & 48 & 49 & 475 & 4 & 4 & 80 & 48 & 144 & 200 & 315 & 60 & 14 & 71 & 5 & 11 & 1823 \\
\hline Otu146 & 13 & 84 & 55 & 137 & 7 & 134 & 192 & 78 & 29 & 6 & 105 & 59 & 228 & 33 & 19 & 283 & 67 & 140 & 46 & 79 & 1794 \\
\hline Otu44 & 0 & 6 & 9 & 23 & 54 & 169 & 5 & 80 & 19 & 14 & 806 & 249 & 15 & 4 & 22 & 48 & 74 & 112 & 12 & 67 & 1788 \\
\hline Otu46 & 0 & 0 & 421 & 0 & 0 & 0 & 52 & 19 & 815 & 0 & 97 & 166 & 0 & 7 & 5 & 0 & 23 & 94 & 1 & 2 & 1702 \\
\hline Otu105 & 135 & 311 & 82 & 27 & 25 & 114 & 12 & 56 & 121 & 27 & 155 & 117 & 98 & 28 & 16 & 77 & 25 & 186 & 41 & 12 & 1665 \\
\hline Otu58 & 38 & 328 & 22 & 18 & 15 & 70 & 58 & 709 & 160 & 53 & 57 & 26 & 24 & 11 & 9 & 26 & 1 & 19 & 0 & 1 & 1645 \\
\hline Otu30 & 0 & 1 & 0 & 0 & 0 & 0 & 1416 & 221 & 0 & 0 & 0 & 0 & 0 & 0 & 0 & 0 & 0 & 0 & 0 & 0 & 1638 \\
\hline Otu79 & 104 & 1 & 52 & 23 & 27 & 451 & 31 & 235 & 1 & 2 & 18 & 122 & 40 & 136 & 120 & 64 & 60 & 80 & 6 & 4 & 1577 \\
\hline Otu56 & 0 & 63 & 32 & 21 & 14 & 52 & 88 & 66 & 35 & 29 & 30 & 38 & 770 & 75 & 23 & 72 & 60 & 55 & 1 & 10 & 1534 \\
\hline Otu124 & 98 & 53 & 157 & 123 & 125 & 123 & 35 & 9 & 83 & 12 & 52 & 23 & 223 & 35 & 6 & 148 & 70 & 111 & 18 & 1 & 1505 \\
\hline Otu140 & 301 & 115 & 205 & 5 & 17 & 108 & 78 & 144 & 32 & 5 & 45 & 13 & 263 & 14 & 3 & 100 & 24 & 20 & 5 & 1 & 1498 \\
\hline Otu115 & 131 & 187 & 62 & 38 & 4 & 60 & 21 & 209 & 79 & 45 & 32 & 113 & 61 & 35 & 104 & 21 & 20 & 31 & 36 & 6 & 1295 \\
\hline Otu43 & 0 & 156 & 0 & 0 & 1 & 0 & 1 & 0 & 0 & 0 & 3 & 117 & 5 & 88 & 727 & 1 & 33 & 0 & 38 & 14 & 1184 \\
\hline Otu125 & 17 & 1 & 65 & 20 & 96 & 201 & 9 & 91 & 1 & 3 & 6 & 47 & 154 & 143 & 142 & 87 & 17 & 19 & 9 & 6 & 1134 \\
\hline Otu114 & 77 & 75 & 131 & 15 & 26 & 163 & 59 & 46 & 34 & 18 & 47 & 38 & 44 & 180 & 49 & 31 & 71 & 19 & 10 & 0 & 1133 \\
\hline Otu103 & 0 & 3 & 144 & 0 & 23 & 2 & 9 & 3 & 1 & 9 & 0 & 46 & 123 & 222 & 141 & 192 & 83 & 102 & 1 & 4 & 1108 \\
\hline Otu82 & 0 & 16 & 22 & 53 & 150 & 15 & 1 & 13 & 9 & 11 & 71 & 36 & 10 & 12 & 39 & 47 & 288 & 84 & 155 & 72 & 1104 \\
\hline Otu144 & 0 & 0 & 273 & 23 & 0 & 0 & 151 & 53 & 149 & 111 & 18 & 28 & 64 & 7 & 0 & 76 & 26 & 94 & 9 & 5 & 1087 \\
\hline Otu134 & 27 & 52 & 75 & 57 & 27 & 44 & 57 & 24 & 45 & 27 & 32 & 72 & 48 & 74 & 25 & 253 & 25 & 91 & 15 & 7 & 1077 \\
\hline Otu106 & 3 & 13 & 57 & 53 & 7 & 19 & 35 & 58 & 28 & 25 & 56 & 62 & 77 & 66 & 36 & 116 & 77 & 44 & 134 & 101 & 1067 \\
\hline Otu151 & 11 & 9 & 10 & 33 & 24 & 35 & 34 & 48 & 56 & 18 & 195 & 31 & 42 & 4 & 9 & 56 & 71 & 66 & 159 & 53 & 964 \\
\hline
\end{tabular}

APPLIED ECOLOGY AND ENVIRONMENTAL RESEARCH 18(5):7089-7138. http://www.aloki.hu • ISSN 15891623 (Print) • ISSN 17850037 (Online)

DOI: http://dx.doi.org/10.15666/aeer/1805_70897138 


\begin{tabular}{|c|c|c|c|c|c|c|c|c|c|c|c|c|c|c|c|c|c|c|c|c|c|}
\hline & BEF2 & AF2 & BEF6 & AF6 & BEF8 & AF8 & BEF9 & AF9 & BEF10 & AF10 & \begin{tabular}{|l|} 
BEF12 \\
\end{tabular} & AF12 & BEF14 & AF14 & BEF15 & AF15 & BEF19 & AF19 & BEF20 & AF20 & Total \\
\hline Otu85 & 2 & 3 & 0 & 1 & 0 & 0 & 474 & 311 & 0 & 2 & 57 & 37 & 10 & 41 & 12 & 2 & 0 & 0 & 0 & 1 & 953 \\
\hline Otu92 & 326 & 33 & 58 & 4 & 11 & 36 & 17 & 14 & 54 & 15 & 36 & 11 & 138 & 3 & 8 & 29 & 83 & 51 & 21 & 4 & 952 \\
\hline Otu54 & 0 & 1 & 35 & 6 & 55 & 94 & 22 & 7 & 5 & 0 & 17 & 5 & 568 & 20 & 15 & 89 & 0 & 0 & 0 & 0 & 939 \\
\hline Otu97 & 41 & 10 & 15 & 3 & 0 & 14 & 59 & 55 & 0 & 0 & 8 & 20 & 66 & 105 & 44 & 59 & 10 & 9 & 94 & 292 & 904 \\
\hline Otu63 & 0 & 0 & 381 & 0 & 0 & 0 & 407 & 96 & 0 & 0 & 0 & 0 & 0 & 0 & 0 & 0 & 0 & 0 & 0 & 0 & 884 \\
\hline Otu239 & 3 & 43 & 24 & 5 & 16 & 26 & 57 & 261 & 40 & 4 & 55 & 20 & 18 & 49 & 45 & 38 & 0 & 0 & 56 & 66 & 826 \\
\hline Otu91 & 6 & 1 & 46 & 76 & 13 & 21 & 15 & 13 & 72 & 33 & 193 & 108 & 2 & 13 & 8 & 22 & 14 & 28 & 84 & 56 & 824 \\
\hline Otu219 & 10 & 81 & 7 & 22 & 5 & 48 & 15 & 30 & 6 & 12 & 119 & 55 & 184 & 10 & 12 & 96 & 22 & 36 & 10 & 27 & 807 \\
\hline Otu94 & 0 & 0 & 14 & 19 & 0 & 0 & 24 & 24 & 174 & 55 & 76 & 31 & 44 & 18 & 6 & 51 & 26 & 200 & 26 & 15 & 803 \\
\hline Otu276 & 31 & 85 & 80 & 6 & 16 & 112 & 25 & 25 & 60 & 41 & 4 & 22 & 95 & 6 & 5 & 32 & 22 & 68 & 23 & 18 & 776 \\
\hline Otu73 & 0 & 0 & 109 & 0 & 0 & 0 & 8 & 195 & 11 & 19 & 0 & 0 & 368 & 0 & 0 & 63 & 0 & 0 & 0 & 0 & 773 \\
\hline Otu122 & 39 & 223 & 13 & 15 & 6 & 90 & 22 & 163 & 24 & 5 & 37 & 25 & 4 & 15 & 9 & 26 & 2 & 12 & 6 & 3 & 739 \\
\hline Otu129 & 5 & 15 & 26 & 36 & 9 & 31 & 50 & 64 & 24 & 30 & 40 & 72 & 68 & 15 & 8 & 50 & 92 & 67 & 4 & 5 & 711 \\
\hline Otu169 & 0 & 3 & 112 & 18 & 0 & 0 & 331 & 24 & 31 & 31 & 10 & 13 & 0 & 26 & 0 & 0 & 17 & 89 & 0 & 0 & 705 \\
\hline Otu145 & 11 & 125 & 71 & 31 & 1 & 0 & 6 & 6 & 40 & 42 & 36 & 52 & 61 & 77 & 32 & 10 & 26 & 60 & 2 & 9 & 698 \\
\hline Otu131 & 0 & 0 & 0 & 20 & 0 & 0 & 138 & 393 & 19 & 100 & 2 & 0 & 3 & 8 & 5 & 0 & 0 & 0 & 0 & 0 & 688 \\
\hline Otu99 & 0 & 0 & 2 & 0 & 0 & 0 & 33 & 4 & 1 & 0 & 6 & 0 & 153 & 1 & 0 & 6 & 98 & 293 & 0 & 22 & 619 \\
\hline Otu120 & 0 & 1 & 108 & 18 & 7 & 12 & 81 & 13 & 1 & 4 & 15 & 11 & 60 & 22 & 6 & 123 & 2 & 3 & 41 & 83 & 611 \\
\hline Otu287 & 2 & 1 & 47 & 4 & 0 & 8 & 8 & 31 & 21 & 0 & 20 & 146 & 25 & 10 & 9 & 19 & 50 & 12 & 6 & 189 & 608 \\
\hline Otu154 & 16 & 21 & 57 & 30 & 6 & 47 & 100 & 40 & 25 & 2 & 59 & 12 & 71 & 10 & 4 & 33 & 27 & 13 & 27 & 7 & 607 \\
\hline Otu143 & 103 & 56 & 6 & 11 & 8 & 49 & 13 & 40 & 40 & 6 & 48 & 52 & 68 & 17 & 11 & 32 & 14 & 28 & 2 & 0 & 604 \\
\hline Otu217 & 12 & 20 & 3 & 6 & 2 & 50 & 10 & 93 & 39 & 13 & 3 & 0 & 256 & 0 & 3 & 7 & 10 & 22 & 6 & 1 & 556 \\
\hline Otu268 & 11 & 6 & 9 & 66 & 53 & 26 & 3 & 3 & 17 & 6 & 65 & 16 & 23 & 4 & 7 & 30 & 69 & 33 & 92 & 17 & 556 \\
\hline Otu102 & 0 & 0 & 0 & 0 & 0 & 0 & 371 & 89 & 83 & 0 & 8 & 0 & 0 & 0 & 0 & 0 & 0 & 0 & 0 & 0 & 551 \\
\hline Otu107 & 0 & 0 & 86 & 0 & 1 & 11 & 98 & 28 & 32 & 16 & 2 & 18 & 145 & 21 & 4 & 34 & 18 & 32 & 2 & 0 & 548 \\
\hline Otu139 & 0 & 62 & 9 & 47 & 10 & 40 & 46 & 49 & 49 & 13 & 39 & 39 & 51 & 5 & 0 & 18 & 5 & 23 & 22 & 19 & 546 \\
\hline Otu192 & 1 & 34 & 34 & 17 & 7 & 49 & 44 & 10 & 35 & 16 & 31 & 15 & 108 & 27 & 2 & 27 & 27 & 49 & 3 & 4 & 540 \\
\hline Otu60 & 3 & 1 & 0 & 3 & 4 & 0 & 0 & 2 & 4 & 0 & 1 & 2 & 0 & 85 & 12 & 0 & 6 & 416 & 0 & 0 & 539 \\
\hline Otu133 & 0 & 115 & 37 & 14 & 8 & 27 & 48 & 26 & 20 & 12 & 10 & 15 & 30 & 33 & 5 & 42 & 10 & 37 & 7 & 6 & 502 \\
\hline Otu74 & 0 & 0 & 9 & 0 & 0 & 0 & 260 & 41 & 0 & 0 & 11 & 7 & 0 & 0 & 0 & 0 & 2 & 161 & 0 & 0 & 491 \\
\hline Otu111 & 0 & 74 & 39 & 25 & 10 & 43 & 7 & 3 & 29 & 7 & 89 & 20 & 13 & 14 & 1 & 5 & 44 & 51 & 0 & 0 & 474 \\
\hline Otu89 & 0 & 0 & 0 & 0 & 0 & 0 & 10 & 29 & 13 & 63 & 0 & 0 & 36 & 0 & 0 & 47 & 42 & 234 & 0 & 0 & 474 \\
\hline Otu136 & 12 & 93 & 6 & 7 & 8 & 116 & 21 & 28 & 7 & 4 & 43 & 15 & 45 & 9 & 3 & 13 & 11 & 17 & 4 & 5 & 467 \\
\hline Otu194 & 16 & 1 & 50 & 0 & 18 & 20 & 54 & 110 & 16 & 1 & 3 & 0 & 83 & 15 & 15 & 25 & 10 & 11 & 4 & 0 & 452 \\
\hline
\end{tabular}

APPLIED ECOLOGY AND ENVIRONMENTAL RESEARCH 18(5):7089-7138. http://www.aloki.hu • ISSN 15891623 (Print) • ISSN 17850037 (Online)

DOI: http://dx.doi.org/10.15666/aeer/1805_70897138 


\begin{tabular}{|c|c|c|c|c|c|c|c|c|c|c|c|c|c|c|c|c|c|c|c|c|c|}
\hline & BEF2 & AF2 & BEF6 & AF6 & BEF8 & AF8 & BEF9 & AF9 & BEF10 & AF10 & \begin{tabular}{|l|} 
BEF12 \\
\end{tabular} & AF12 & BEF14 & AF14 & BEF15 & AF15 & BEF19 & AF19 & BEF20 & AF20 & Total \\
\hline Otu186 & 0 & 3 & 91 & 8 & 0 & 10 & 63 & 18 & 42 & 12 & 14 & 3 & 27 & 9 & 3 & 28 & 26 & 67 & 6 & 5 & 435 \\
\hline Otu119 & 26 & 9 & 33 & 26 & 1 & 19 & 27 & 35 & 10 & 10 & 7 & 12 & 4 & 25 & 130 & 13 & 11 & 22 & 11 & 2 & 433 \\
\hline Otu104 & 0 & 0 & 162 & 0 & 0 & 0 & 186 & 61 & 0 & 0 & 0 & 0 & 0 & 3 & 7 & 0 & 0 & 0 & 0 & 0 & 419 \\
\hline Otu159 & 15 & 30 & 10 & 25 & 2 & 31 & 24 & 83 & 92 & 2 & 0 & 8 & 48 & 7 & 1 & 14 & 9 & 9 & 1 & 1 & 412 \\
\hline Otu285 & 18 & 6 & 19 & 11 & 106 & 25 & 1 & 1 & 17 & 19 & 1 & 22 & 8 & 16 & 0 & 4 & 112 & 8 & 1 & 11 & 406 \\
\hline Otu189 & 0 & 25 & 51 & 25 & 9 & 25 & 2 & 10 & 65 & 17 & 74 & 8 & 8 & 0 & 0 & 18 & 24 & 37 & 0 & 0 & 398 \\
\hline Otu96 & 0 & 0 & 52 & 7 & 0 & 0 & 199 & 57 & 0 & 0 & 0 & 0 & 21 & 13 & 6 & 31 & 0 & 1 & 0 & 0 & 387 \\
\hline Otu156 & 0 & 62 & 40 & 5 & 4 & 15 & 16 & 57 & 101 & 11 & 13 & 11 & 9 & 0 & 0 & 9 & 1 & 26 & 0 & 0 & 380 \\
\hline Otu101 & 0 & 0 & 30 & 26 & 1 & 0 & 24 & 2 & 0 & 0 & 15 & 10 & 143 & 10 & 0 & 62 & 2 & 33 & 5 & 10 & 373 \\
\hline Otu168 & 5 & 17 & 50 & 11 & 0 & 0 & 51 & 34 & 20 & 2 & 58 & 2 & 19 & 13 & 6 & 51 & 12 & 16 & 0 & 1 & 368 \\
\hline Otu113 & 0 & 31 & 26 & 0 & 0 & 2 & 7 & 229 & 0 & 24 & 0 & 3 & 0 & 0 & 0 & 11 & 0 & 11 & 1 & 3 & 348 \\
\hline Otu123 & 0 & 0 & 78 & 7 & 0 & 0 & 25 & 14 & 56 & 26 & 15 & 5 & 25 & 9 & 2 & 33 & 0 & 52 & 0 & 0 & 347 \\
\hline Otu118 & 11 & 7 & 3 & 1 & 5 & 1 & 0 & 5 & 0 & 4 & 4 & 5 & 47 & 154 & 44 & 13 & 8 & 10 & 1 & 0 & 323 \\
\hline Otu110 & 35 & 41 & 0 & 0 & 31 & 27 & 4 & 2 & 0 & 0 & 4 & 2 & 1 & 58 & 114 & 2 & 0 & 0 & 0 & 0 & 321 \\
\hline Otu121 & 0 & 8 & 28 & 35 & 0 & 0 & 9 & 5 & 78 & 42 & 18 & 32 & 0 & 19 & 3 & 0 & 5 & 27 & 0 & 0 & 309 \\
\hline Otu83 & 2 & 2 & 0 & 5 & 4 & 3 & 22 & 13 & 0 & 0 & 10 & 4 & 5 & 0 & 2 & 19 & 10 & 3 & 152 & 51 & 307 \\
\hline Otu184 & 9 & 13 & 34 & 8 & 0 & 15 & 44 & 41 & 4 & 3 & 14 & 2 & 46 & 2 & 0 & 15 & 29 & 18 & 2 & 6 & 305 \\
\hline Otu132 & 0 & 1 & 3 & 5 & 3 & 10 & 6 & 5 & 23 & 5 & 19 & 4 & 32 & 4 & 1 & 14 & 3 & 23 & 89 & 38 & 288 \\
\hline Otu112 & 0 & 0 & 49 & 0 & 0 & 0 & 13 & 3 & 124 & 38 & 8 & 0 & 0 & 0 & 0 & 0 & 2 & 38 & 0 & 0 & 275 \\
\hline Otu177 & 14 & 5 & 14 & 1 & 0 & 1 & 26 & 15 & 2 & 0 & 4 & 11 & 7 & 135 & 11 & 5 & 4 & 5 & 2 & 2 & 264 \\
\hline Otu95 & 0 & 0 & 0 & 0 & 1 & 34 & 20 & 165 & 0 & 0 & 0 & 4 & 7 & 4 & 26 & 0 & 0 & 0 & 0 & 0 & 261 \\
\hline Otu164 & 0 & 39 & 9 & 22 & 5 & 28 & 5 & 0 & 3 & 0 & 7 & 4 & 54 & 16 & 3 & 19 & 9 & 17 & 0 & 1 & 241 \\
\hline Otu176 & 0 & 2 & 0 & 6 & 5 & 2 & 6 & 10 & 23 & 7 & 3 & 12 & 14 & 29 & 8 & 41 & 4 & 14 & 27 & 20 & 233 \\
\hline Otu183 & 0 & 0 & 22 & 0 & 0 & 0 & 11 & 0 & 15 & 1 & 0 & 0 & 107 & 11 & 8 & 44 & 3 & 9 & 0 & 0 & 231 \\
\hline Otu153 & 0 & 0 & 65 & 1 & 1 & 9 & 1 & 6 & 13 & 11 & 18 & 19 & 10 & 21 & 5 & 24 & 1 & 15 & 4 & 1 & 225 \\
\hline Otu221 & 54 & 14 & 14 & 1 & 11 & 2 & 13 & 0 & 0 & 0 & 4 & 4 & 54 & 2 & 0 & 29 & 20 & 2 & 0 & 0 & 224 \\
\hline Otu170 & 1 & 14 & 17 & 3 & 2 & 15 & 26 & 53 & 0 & 0 & 2 & 1 & 42 & 11 & 1 & 16 & 9 & 5 & 0 & 0 & 218 \\
\hline Otu165 & 47 & 36 & 3 & 3 & 2 & 22 & 2 & 0 & 3 & 0 & 7 & 9 & 21 & 9 & 7 & 29 & 7 & 8 & 0 & 0 & 215 \\
\hline Otu172 & 0 & 0 & 29 & 24 & 0 & 0 & 21 & 2 & 37 & 15 & 16 & 5 & 22 & 6 & 1 & 19 & 2 & 11 & 3 & 0 & 213 \\
\hline Otu162 & 1 & 2 & 11 & 8 & 0 & 4 & 32 & 20 & 3 & 0 & 48 & 18 & 8 & 1 & 1 & 32 & 9 & 6 & 1 & 6 & 211 \\
\hline Otu147 & 0 & 0 & 23 & 7 & 5 & 7 & 2 & 7 & 8 & 1 & 1 & 0 & 107 & 14 & 0 & 12 & 6 & 7 & 0 & 0 & 207 \\
\hline Otu202 & 6 & 2 & 15 & 2 & 6 & 21 & 30 & 6 & 0 & 8 & 0 & 3 & 26 & 17 & 4 & 38 & 15 & 3 & 2 & 3 & 207 \\
\hline Otu180 & 1 & 10 & 29 & 5 & 0 & 3 & 6 & 4 & 4 & 4 & 9 & 7 & 22 & 1 & 3 & 41 & 12 & 31 & 6 & 4 & 202 \\
\hline Otu148 & 0 & 0 & 0 & 0 & 0 & 0 & 13 & 22 & 42 & 52 & 11 & 12 & 0 & 0 & 0 & 0 & 16 & 30 & 0 & 0 & 198 \\
\hline
\end{tabular}

APPLIED ECOLOGY AND ENVIRONMENTAL RESEARCH 18(5):7089-7138. http://www.aloki.hu • ISSN 15891623 (Print) • ISSN 17850037 (Online)

DOI: http://dx.doi.org/10.15666/aeer/1805_70897138 


\begin{tabular}{|c|c|c|c|c|c|c|c|c|c|c|c|c|c|c|c|c|c|c|c|c|c|}
\hline & BEF2 & AF2 & BEF6 & AF6 & BEF8 & AF8 & BEF9 & AF9 & BEF10 & AF10 & BEF12 & AF12 & \begin{tabular}{|l|} 
BEF14 \\
\end{tabular} & AF14 & BEF15 & AF15 & BEF19 & AF19 & BEF20 & AF20 & Tota \\
\hline Otu187 & 1 & 7 & 2 & 1 & 3 & 9 & 26 & 63 & 11 & 0 & 3 & 3 & 14 & 1 & 0 & 9 & 4 & 4 & 17 & 11 & 189 \\
\hline Otu182 & 0 & 5 & 111 & 28 & 1 & 2 & 0 & 1 & 2 & 3 & 3 & 3 & 0 & 14 & 0 & 3 & 1 & 11 & 0 & 0 & 188 \\
\hline Otu163 & 0 & 27 & 36 & 5 & 1 & 4 & 2 & 6 & 12 & 4 & 6 & 12 & 17 & 3 & 4 & 5 & 23 & 11 & 5 & 4 & 187 \\
\hline Otu141 & 0 & 1 & 3 & 5 & 0 & 12 & 3 & 2 & 15 & 16 & 0 & 1 & 64 & 0 & 6 & 49 & 2 & 5 & 0 & 0 & 184 \\
\hline Otu130 & 0 & 0 & 0 & 16 & 0 & 0 & 1 & 0 & 0 & 0 & 0 & 0 & 25 & 25 & 15 & 10 & 10 & 81 & 0 & 0 & 183 \\
\hline Otu149 & 0 & 6 & 3 & 0 & 5 & 5 & 0 & 7 & 6 & 0 & 3 & 6 & 97 & 4 & 5 & 27 & 0 & 4 & 0 & 0 & 178 \\
\hline Otu281 & 0 & 1 & 3 & 0 & 2 & 7 & 43 & 80 & 4 & 12 & 0 & 0 & 1 & 6 & 5 & 1 & 1 & 7 & 1 & 0 & 174 \\
\hline Otu142 & 0 & 0 & 71 & 0 & 0 & 0 & 33 & 7 & 0 & 0 & 0 & 0 & 14 & 4 & 0 & 15 & 6 & 19 & 0 & 0 & 169 \\
\hline Otu116 & 0 & 0 & 0 & 0 & 0 & 0 & 0 & 0 & 0 & 0 & 0 & 0 & 126 & 4 & 4 & 21 & 0 & 0 & 0 & 0 & 155 \\
\hline Otu174 & 0 & 8 & 4 & 11 & 1 & 7 & 1 & 1 & 8 & 14 & 15 & 17 & 33 & 0 & 1 & 7 & 3 & 17 & 0 & 0 & 148 \\
\hline Otu191 & 0 & 0 & 5 & 0 & 0 & 0 & 97 & 9 & 28 & 0 & 2 & 3 & 0 & 0 & 0 & 0 & 0 & 0 & 0 & 0 & 144 \\
\hline Otu150 & 0 & 0 & 34 & 0 & 0 & 0 & 40 & 4 & 0 & 0 & 6 & 5 & 1 & 1 & 2 & 0 & 1 & 39 & 10 & 0 & 143 \\
\hline Otu152 & 0 & 0 & 22 & 2 & 0 & 0 & 14 & 73 & 0 & 0 & 4 & 1 & 0 & 0 & 0 & 14 & 2 & 9 & 0 & 2 & 143 \\
\hline Otu179 & 0 & 4 & 2 & 14 & 2 & 37 & 3 & 11 & 11 & 5 & 6 & 14 & 0 & 1 & 18 & 3 & 1 & 7 & 0 & 1 & 140 \\
\hline Otu171 & 1 & 1 & 26 & 6 & 0 & 2 & 29 & 5 & 5 & 1 & 1 & 2 & 15 & 2 & 1 & 6 & 7 & 2 & 5 & 22 & 139 \\
\hline Otu185 & 8 & 0 & 18 & 0 & 1 & 6 & 2 & 0 & 3 & 1 & 2 & 0 & 26 & 2 & 0 & 10 & 29 & 24 & 0 & 1 & 133 \\
\hline Otu160 & 0 & 0 & 37 & 0 & 0 & 0 & 0 & 0 & 47 & 22 & 0 & 0 & 0 & 1 & 1 & 0 & 4 & 19 & 0 & 0 & 131 \\
\hline Otu196 & 0 & 22 & 3 & 6 & 3 & 38 & 1 & 1 & 5 & 4 & 0 & 0 & 22 & 2 & 0 & 6 & 3 & 9 & 0 & 3 & 128 \\
\hline Otu216 & 33 & 8 & 9 & 2 & 0 & 2 & 7 & 10 & 9 & 0 & 1 & 3 & 28 & 0 & 2 & 9 & 1 & 2 & 0 & 0 & 126 \\
\hline Otu251 & 14 & 0 & 12 & 1 & 11 & 7 & 11 & 6 & 0 & 1 & 0 & 1 & 0 & 18 & 8 & 18 & 13 & 0 & 2 & 2 & 125 \\
\hline Otu128 & 0 & 5 & 0 & 4 & 0 & 1 & 2 & 11 & 5 & 0 & 0 & 0 & 6 & 0 & 0 & 1 & 0 & 0 & 45 & 42 & 122 \\
\hline Otu228 & 0 & 16 & 4 & 0 & 0 & 1 & 3 & 25 & 4 & 3 & 14 & 6 & 4 & 15 & 3 & 8 & 1 & 13 & 0 & 2 & 122 \\
\hline Otu238 & 0 & 4 & 5 & 4 & 1 & 6 & 5 & 6 & 0 & 0 & 3 & 15 & 28 & 0 & 1 & 5 & 1 & 5 & 10 & 12 & 111 \\
\hline Otu250 & 0 & 2 & 12 & 1 & 0 & 0 & 7 & 12 & 3 & 0 & 5 & 5 & 25 & 1 & 0 & 24 & 2 & 8 & 0 & 4 & 111 \\
\hline Otu188 & 0 & 0 & 20 & 0 & 5 & 23 & 1 & 0 & 0 & 0 & 10 & 11 & 1 & 5 & 0 & 0 & 3 & 24 & 0 & 0 & 103 \\
\hline Otu209 & 1 & 4 & 22 & 0 & 0 & 12 & 26 & 12 & 0 & 0 & 2 & 7 & 1 & 0 & 2 & 1 & 1 & 9 & 1 & 0 & 101 \\
\hline Otu190 & 0 & 0 & 2 & 0 & 0 & 5 & 2 & 0 & 10 & 1 & 9 & 1 & 0 & 0 & 11 & 0 & 27 & 32 & 0 & 0 & 100 \\
\hline Otu201 & 0 & 1 & 0 & 0 & 0 & 0 & 6 & 10 & 0 & 1 & 0 & 0 & 14 & 20 & 22 & 11 & 0 & 3 & 5 & 7 & 100 \\
\hline Otu207 & 5 & 14 & 8 & 4 & 0 & 0 & 7 & 2 & 0 & 0 & 12 & 1 & 17 & 0 & 0 & 22 & 2 & 5 & 0 & 0 & 99 \\
\hline Otu204 & 0 & 0 & 10 & 5 & 1 & 8 & 0 & 0 & 5 & 3 & 0 & 0 & 15 & 3 & 0 & 29 & 17 & 0 & 0 & 0 & 96 \\
\hline Otu205 & 0 & 2 & 9 & 1 & 4 & 3 & 5 & 6 & 7 & 2 & 1 & 2 & 24 & 8 & 2 & 4 & 11 & 4 & 0 & 1 & 96 \\
\hline Otu135 & 0 & 0 & 36 & 0 & 0 & 0 & 41 & 5 & 0 & 0 & 0 & 0 & 12 & 0 & 0 & 1 & 0 & 0 & 0 & 0 & 95 \\
\hline Otu227 & 0 & 0 & 15 & 3 & 0 & 2 & 20 & 3 & 6 & 13 & 4 & 0 & 1 & 1 & 0 & 23 & 0 & 0 & 4 & 0 & 95 \\
\hline Otu167 & 0 & 0 & 0 & 0 & 0 & 0 & 3 & 0 & 0 & 0 & 0 & 1 & 58 & 0 & 0 & 0 & 20 & 9 & 0 & 2 & 93 \\
\hline
\end{tabular}

APPLIED ECOLOGY AND ENVIRONMENTAL RESEARCH 18(5):7089-7138. http://www.aloki.hu • ISSN 15891623 (Print) • ISSN 17850037 (Online)

DOI: http://dx.doi.org/10.15666/aeer/1805_70897138 


\begin{tabular}{|c|c|c|c|c|c|c|c|c|c|c|c|c|c|c|c|c|c|c|c|c|c|}
\hline & BEF2 & AF2 & BEF6 & AF6 & BEF8 & AF8 & BEF9 & AF9 & BEF10 & AF10 & BEF12 & AF12 & BEF14 & AF14 & BEF15 & AF15 & BEF19 & AF19 & BEF20 & AF20 & Total \\
\hline Otu225 & 0 & 2 & 8 & 1 & 0 & 0 & 6 & 1 & 0 & 0 & 5 & 3 & 47 & 1 & 0 & 19 & 0 & 0 & 0 & 0 & 93 \\
\hline Otu279 & 11 & 14 & 1 & 4 & 1 & 2 & 1 & 7 & 4 & 5 & 9 & 1 & 0 & 8 & 4 & 1 & 1 & 3 & 4 & 12 & 93 \\
\hline Otu197 & 0 & 0 & 4 & 0 & 5 & 4 & 17 & 7 & 5 & 3 & 1 & 0 & 6 & 0 & 0 & 7 & 3 & 30 & 0 & 0 & 92 \\
\hline Otu214 & 7 & 6 & 0 & 2 & 2 & 5 & 2 & 4 & 8 & 3 & 0 & 5 & 18 & 8 & 4 & 5 & 0 & 8 & 2 & 0 & 89 \\
\hline Otu240 & 0 & 0 & 21 & 5 & 7 & 10 & 4 & 5 & 6 & 3 & 2 & 0 & 1 & 8 & 1 & 13 & 0 & 0 & 0 & 0 & 86 \\
\hline Otu158 & 0 & 2 & 3 & 0 & 1 & 1 & 0 & 2 & 1 & 1 & 1 & 0 & 59 & 0 & 2 & 11 & 0 & 1 & 0 & 0 & 85 \\
\hline Otu237 & 0 & 0 & 43 & 3 & 9 & 11 & 0 & 1 & 7 & 7 & 0 & 0 & 1 & 2 & 0 & 1 & 0 & 0 & 0 & 0 & 85 \\
\hline Otu291 & 0 & 26 & 0 & 0 & 4 & 4 & 2 & 15 & 0 & 1 & 0 & 0 & 10 & 13 & 10 & 0 & 0 & 0 & 0 & 0 & 85 \\
\hline Otu223 & 2 & 4 & 8 & 0 & 2 & 8 & 2 & 0 & 3 & 0 & 15 & 4 & 17 & 2 & 1 & 2 & 2 & 12 & 0 & 0 & 84 \\
\hline Otu127 & 0 & 0 & 0 & 0 & 0 & 0 & 0 & 0 & 0 & 0 & 0 & 0 & 0 & 0 & 0 & 82 & 0 & 0 & 0 & 0 & 82 \\
\hline Otu203 & 0 & 0 & 0 & 0 & 0 & 0 & 51 & 24 & 0 & 0 & 0 & 0 & 0 & 0 & 0 & 6 & 0 & 0 & 0 & 0 & 81 \\
\hline Otu226 & 2 & 0 & 4 & 6 & 1 & 2 & 16 & 8 & 8 & 6 & 2 & 1 & 2 & 1 & 0 & 5 & 0 & 0 & 1 & 0 & 65 \\
\hline Otu215 & 0 & 0 & 0 & 0 & 0 & 0 & 23 & 0 & 0 & 0 & 0 & 0 & 31 & 0 & 0 & 0 & 16 & 5 & 0 & 0 & 75 \\
\hline Otu233 & 0 & 0 & 1 & 0 & 0 & 0 & 3 & 2 & 0 & 0 & 2 & 3 & 41 & 0 & 0 & 23 & 0 & 0 & 0 & 0 & 75 \\
\hline Otu157 & 0 & 0 & 0 & 0 & 0 & 0 & 3 & 17 & 12 & 35 & 3 & 3 & 0 & 0 & 0 & 0 & 0 & 0 & 0 & 0 & 73 \\
\hline Otu138 & 1 & 0 & 0 & 0 & 1 & 0 & 2 & 0 & 1 & 0 & 0 & 0 & 67 & 0 & 0 & 0 & 0 & 0 & 0 & 0 & 72 \\
\hline Otu242 & 0 & 13 & 7 & 2 & 0 & 0 & 0 & 0 & 0 & 0 & 4 & 0 & 20 & 3 & 1 & 15 & 0 & 6 & 0 & 0 & 71 \\
\hline Otu210 & 0 & 0 & 15 & 4 & 1 & 2 & 3 & 3 & 4 & 0 & 2 & 1 & 14 & 1 & 1 & 4 & 0 & 7 & 2 & 5 & 69 \\
\hline Otu222 & 0 & 0 & 2 & 1 & 0 & 1 & 1 & 2 & 1 & 2 & 0 & 0 & 34 & 1 & 1 & 13 & 0 & 7 & 1 & 0 & 67 \\
\hline Otu270 & 0 & 0 & 7 & 0 & 0 & 0 & 13 & 0 & 5 & 4 & 12 & 1 & 1 & 2 & 2 & 9 & 0 & 11 & 0 & 0 & 67 \\
\hline Otu256 & 9 & 11 & 0 & 2 & 0 & 1 & 1 & 0 & 7 & 1 & 2 & 2 & 1 & 8 & 1 & 2 & 2 & 11 & 3 & 2 & 66 \\
\hline Otu272 & 0 & 0 & 10 & 0 & 2 & 0 & 0 & 2 & 3 & 1 & 0 & 1 & 31 & 4 & 0 & 12 & 0 & 0 & 0 & 0 & 66 \\
\hline Otu289 & 0 & 0 & 6 & 0 & 0 & 0 & 3 & 10 & 0 & 3 & 0 & 0 & 19 & 0 & 0 & 0 & 24 & 0 & 0 & 0 & 65 \\
\hline Otu195 & 0 & 0 & 0 & 0 & 0 & 0 & 1 & 0 & 0 & 0 & 2 & 4 & 21 & 0 & 2 & 33 & 0 & 0 & 0 & 0 & 63 \\
\hline Otu235 & 1 & 0 & 0 & 2 & 0 & 8 & 5 & 1 & 4 & 1 & 9 & 1 & 12 & 0 & 0 & 11 & 3 & 3 & 0 & 0 & 61 \\
\hline Otu263 & 3 & 4 & 0 & 1 & 1 & 5 & 1 & 2 & 5 & 1 & 1 & 1 & 7 & 2 & 1 & 11 & 3 & 8 & 2 & 2 & 61 \\
\hline Otu255 & 0 & 0 & 8 & 1 & 0 & 0 & 11 & 0 & 5 & 2 & 4 & 3 & 17 & 0 & 2 & 4 & 0 & 3 & 0 & 0 & 60 \\
\hline Otu166 & 0 & 0 & 1 & 0 & 0 & 0 & 0 & 0 & 0 & 0 & 1 & 0 & 1 & 0 & 0 & 0 & 0 & 1 & 36 & 19 & 59 \\
\hline Otu234 & 0 & 0 & 5 & 2 & 0 & 0 & 11 & 2 & 10 & 7 & 0 & 0 & 0 & 2 & 1 & 0 & 0 & 15 & 2 & 2 & 59 \\
\hline Otu246 & 0 & 5 & 0 & 7 & 0 & 4 & 3 & 1 & 0 & 2 & 1 & 0 & 21 & 2 & 2 & 1 & 4 & 4 & 1 & 0 & 58 \\
\hline Otu175 & 3 & 1 & 0 & 0 & 0 & 0 & 2 & 0 & 4 & 0 & 0 & 0 & 0 & 0 & 1 & 0 & 0 & 43 & 1 & 0 & 55 \\
\hline Otu231 & 1 & 5 & 13 & 3 & 0 & 1 & 1 & 2 & 1 & 1 & 2 & 0 & 7 & 3 & 2 & 4 & 4 & 2 & 0 & 1 & 53 \\
\hline Otu252 & 0 & 0 & 8 & 1 & 0 & 3 & 1 & 2 & 12 & 1 & 5 & 0 & 17 & 0 & 1 & 0 & 0 & 2 & 0 & 0 & 53 \\
\hline Otu253 & 0 & 1 & 28 & 0 & 0 & 1 & 9 & 11 & 0 & 0 & 0 & 0 & 2 & 0 & 0 & 0 & 0 & 0 & 0 & 0 & 52 \\
\hline
\end{tabular}

APPLIED ECOLOGY AND ENVIRONMENTAL RESEARCH 18(5):7089-7138. http://www.aloki.hu • ISSN 15891623 (Print) • ISSN 17850037 (Online)

DOI: http://dx.doi.org/10.15666/aeer/1805_70897138 


\begin{tabular}{|c|c|c|c|c|c|c|c|c|c|c|c|c|c|c|c|c|c|c|c|c|c|}
\hline & BEF2 & AF2 & BEF6 & AF6 & BEF8 & AF8 & BEF9 & AF9 & BEF10 & AF10 & BEF12 & AF12 & BEF14 & AF14 & BEF15 & AF15 & \begin{tabular}{|l|} 
BEF19 \\
\end{tabular} & AF19 & BEF20 & AF20 & Total \\
\hline Otu181 & 0 & 0 & 0 & 0 & 0 & 0 & 50 & 0 & 0 & 0 & 0 & 0 & 0 & 0 & 0 & 0 & 0 & 0 & 0 & 0 & 50 \\
\hline Otu218 & 0 & 2 & 0 & 0 & 1 & 0 & 0 & 2 & 0 & 16 & 2 & 0 & 1 & 1 & 0 & 2 & 21 & 1 & 0 & 1 & 50 \\
\hline Otu244 & 0 & 1 & 2 & 6 & 1 & 0 & 0 & 0 & 7 & 2 & 4 & 5 & 7 & 0 & 0 & 2 & 2 & 5 & 3 & 2 & 49 \\
\hline Otu229 & 0 & 0 & 0 & 2 & 0 & 0 & 0 & 0 & 0 & 2 & 0 & 1 & 39 & 1 & 0 & 2 & 0 & 1 & 0 & 0 & 48 \\
\hline Otu200 & 0 & 0 & 0 & 0 & 0 & 0 & 44 & 2 & 0 & 0 & 0 & 0 & 0 & 0 & 0 & 0 & 0 & 0 & 0 & 0 & 46 \\
\hline Otu248 & 0 & 2 & 15 & 1 & 0 & 0 & 3 & 2 & 5 & 0 & 5 & 3 & 0 & 0 & 1 & 1 & 1 & 7 & 0 & 0 & 46 \\
\hline Otu273 & 0 & 0 & 9 & 0 & 0 & 5 & 0 & 0 & 5 & 0 & 1 & 0 & 0 & 5 & 5 & 0 & 11 & 5 & 0 & 0 & 46 \\
\hline Otu224 & 0 & 0 & 44 & 0 & 0 & 0 & 0 & 0 & 0 & 0 & 0 & 0 & 0 & 0 & 0 & 0 & 0 & 0 & 0 & 0 & 44 \\
\hline Otu208 & 1 & 0 & 0 & 0 & 0 & 0 & 0 & 0 & 0 & 0 & 0 & 0 & 13 & 0 & 0 & 1 & 4 & 23 & 0 & 0 & 42 \\
\hline Otu264 & 0 & 0 & 2 & 0 & 0 & 0 & 3 & 0 & 2 & 0 & 0 & 0 & 21 & 4 & 2 & 5 & 1 & 2 & 0 & 0 & 42 \\
\hline Otu247 & 0 & 0 & 0 & 0 & 0 & 0 & 2 & 2 & 0 & 0 & 0 & 0 & 16 & 0 & 0 & 17 & 0 & 0 & 4 & 0 & 41 \\
\hline Otu236 & 0 & 1 & 0 & 5 & 0 & 0 & 2 & 3 & 0 & 0 & 1 & 1 & 2 & 1 & 2 & 9 & 1 & 8 & 3 & 1 & 40 \\
\hline Otu211 & 0 & 0 & 22 & 3 & 0 & 0 & 0 & 2 & 0 & 9 & 1 & 0 & 0 & 1 & 0 & 0 & 0 & 0 & 0 & 0 & 38 \\
\hline Otu290 & 0 & 0 & 19 & 0 & 0 & 0 & 3 & 3 & 0 & 0 & 0 & 0 & 3 & 0 & 5 & 5 & 0 & 0 & 0 & 0 & 38 \\
\hline Otu178 & 0 & 0 & 0 & 0 & 0 & 0 & 5 & 30 & 0 & 0 & 0 & 0 & 0 & 0 & 0 & 0 & 0 & 0 & 0 & 0 & 35 \\
\hline Otu212 & 0 & 0 & 0 & 30 & 0 & 0 & 0 & 0 & 0 & 0 & 1 & 0 & 0 & 1 & 0 & 0 & 1 & 2 & 0 & 0 & 35 \\
\hline Otu220 & 0 & 0 & 11 & 0 & 0 & 0 & 1 & 0 & 3 & 0 & 2 & 4 & 6 & 1 & 0 & 6 & 0 & 1 & 0 & 0 & 35 \\
\hline Otu265 & 0 & 0 & 0 & 0 & 0 & 0 & 3 & 1 & 7 & 5 & 5 & 7 & 0 & 0 & 0 & 0 & 3 & 4 & 0 & 0 & 35 \\
\hline Otu230 & 0 & 0 & 0 & 0 & 0 & 0 & 14 & 18 & 0 & 0 & 0 & 0 & 0 & 2 & 0 & 0 & 0 & 0 & 0 & 0 & 34 \\
\hline Otu199 & 0 & 0 & 0 & 0 & 0 & 0 & 30 & 1 & 0 & 0 & 0 & 0 & 0 & 0 & 1 & 0 & 0 & 0 & 0 & 0 & 32 \\
\hline Otu198 & 0 & 0 & 0 & 0 & 0 & 0 & 5 & 26 & 0 & 0 & 0 & 0 & 0 & 0 & 0 & 0 & 0 & 0 & 0 & 0 & 31 \\
\hline Otu241 & 0 & 2 & 1 & 0 & 0 & 0 & 3 & 7 & 8 & 0 & 0 & 0 & 0 & 0 & 0 & 1 & 0 & 1 & 8 & 0 & 31 \\
\hline Otu288 & 0 & 0 & 0 & 1 & 0 & 0 & 4 & 2 & 0 & 0 & 0 & 0 & 17 & 0 & 1 & 5 & 0 & 0 & 0 & 0 & 30 \\
\hline Otu249 & 0 & 0 & 0 & 2 & 0 & 0 & 0 & 10 & 3 & 1 & 0 & 0 & 0 & 0 & 0 & 0 & 0 & 11 & 0 & 2 & 29 \\
\hline Otu173 & 0 & 0 & 0 & 0 & 0 & 0 & 24 & 4 & 0 & 0 & 0 & 0 & 0 & 0 & 0 & 0 & 0 & 0 & 0 & 0 & 28 \\
\hline Otu232 & 0 & 0 & 0 & 0 & 0 & 0 & 0 & 0 & 0 & 0 & 7 & 0 & 13 & 0 & 0 & 0 & 8 & 0 & 0 & 0 & 28 \\
\hline Otu213 & 0 & 1 & 0 & 0 & 1 & 0 & 3 & 15 & 0 & 0 & 0 & 0 & 0 & 0 & 0 & 1 & 1 & 4 & 0 & 0 & 26 \\
\hline Otu286 & 0 & 0 & 17 & 0 & 0 & 0 & 0 & 0 & 0 & 0 & 2 & 3 & 0 & 2 & 1 & 0 & 0 & 0 & 0 & 0 & 25 \\
\hline Otu161 & 0 & 0 & 16 & 0 & 0 & 0 & 2 & 3 & 0 & 0 & 0 & 0 & 0 & 0 & 0 & 0 & 0 & 0 & 0 & 0 & 21 \\
\hline Otu258 & 0 & 0 & 0 & 0 & 0 & 0 & 1 & 1 & 0 & 0 & 0 & 0 & 0 & 1 & 4 & 14 & 0 & 0 & 0 & 0 & 21 \\
\hline Otu269 & 0 & 0 & 0 & 6 & 0 & 0 & 0 & 14 & 0 & 0 & 0 & 0 & 0 & 0 & 0 & 0 & 0 & 0 & 0 & 0 & 20 \\
\hline Otu262 & 0 & 0 & 0 & 0 & 0 & 0 & 3 & 0 & 0 & 0 & 0 & 0 & 3 & 0 & 0 & 5 & 1 & 5 & 0 & 0 & 17 \\
\hline Otu284 & 0 & 0 & 0 & 0 & 0 & 0 & 0 & 0 & 11 & 3 & 0 & 0 & 0 & 0 & 0 & 0 & 1 & 0 & 0 & 0 & 15 \\
\hline Otu259 & 0 & 0 & 0 & 0 & 0 & 0 & 0 & 2 & 0 & 0 & 0 & 0 & 6 & 0 & 0 & 0 & 3 & 0 & 0 & 0 & 11 \\
\hline
\end{tabular}

APPLIED ECOLOGY AND ENVIRONMENTAL RESEARCH 18(5):7089-7138. http://www.aloki.hu • ISSN 15891623 (Print) • ISSN 17850037 (Online)

DOI: http://dx.doi.org/10.15666/aeer/1805_70897138 


\begin{tabular}{|c|c|c|c|c|c|c|c|c|c|c|c|c|c|c|c|c|c|c|c|c|c|}
\hline & BEF2 & AF2 & BEF6 & AF6 & BEF8 & AF8 & BEF9 & AF9 & BEF10 & AF10 & BEF12 & AF12 & \begin{tabular}{|l|} 
BEF14 \\
\end{tabular} & AF14 & BEF15 & AF15 & \begin{tabular}{|l|} 
BEF19 \\
\end{tabular} & AF19 & BEF20 & AF20 & Tota \\
\hline Otu278 & 0 & 0 & 0 & 0 & 0 & 0 & 0 & 7 & 0 & 1 & 0 & 0 & 0 & 0 & 0 & 0 & 1 & 2 & 0 & 0 & 11 \\
\hline Otu266 & 0 & 0 & 10 & 0 & 0 & 0 & 0 & 0 & 0 & 0 & 0 & 0 & 0 & 0 & 0 & 0 & 0 & 0 & 0 & 0 & 10 \\
\hline Otu243 & 0 & 0 & 0 & 0 & 0 & 0 & 9 & 0 & 0 & 0 & 0 & 0 & 0 & 0 & 0 & 0 & 0 & 0 & 0 & 0 & 9 \\
\hline Otu282 & 0 & 0 & 4 & 2 & 0 & 0 & 1 & 2 & 0 & 0 & 0 & 0 & 0 & 0 & 0 & 0 & 0 & 0 & 0 & 0 & 9 \\
\hline Otu283 & 0 & 0 & 0 & 0 & 2 & 0 & 0 & 3 & 0 & 0 & 2 & 1 & 0 & 0 & 0 & 0 & 0 & 0 & 0 & 1 & 9 \\
\hline Otu254 & 0 & 0 & 0 & 0 & 0 & 0 & 0 & 0 & 0 & 0 & 1 & 0 & 3 & 0 & 0 & 0 & 2 & 1 & 0 & 1 & 8 \\
\hline Otu275 & 0 & 0 & 6 & 0 & 0 & 1 & 0 & 0 & 0 & 0 & 0 & 0 & 0 & 0 & 0 & 0 & 0 & 0 & 0 & 0 & 7 \\
\hline Otu260 & 0 & 0 & 4 & 0 & 0 & 0 & 0 & 0 & 0 & 0 & 0 & 0 & 0 & 0 & 1 & 0 & 0 & 0 & 0 & 0 & 5 \\
\hline Otu267 & 0 & 0 & 0 & 0 & 0 & 0 & 1 & 0 & 0 & 0 & 0 & 0 & 4 & 0 & 0 & 0 & 0 & 0 & 0 & 0 & 5 \\
\hline Otu257 & 0 & 0 & 0 & 0 & 0 & 0 & 0 & 0 & 0 & 0 & 0 & 0 & 0 & 0 & 0 & 0 & 4 & 0 & 0 & 0 & 4 \\
\hline
\end{tabular}

Table A3. Taxonomy and description of the highly abundant OTUs recovered from oral microbiomes of children regardless of swaking

\begin{tabular}{|c|c|c|c|}
\hline Phylum & Genus/Species & Description & OTUs \\
\hline \multirow{6}{*}{ Bacteroidetes } & Prevotella spp. & $\begin{array}{c}\text { A genus of gram negative anaerobic bacteria. Some strains are present in humans, including Prevotella denticola. They are predominantly } \\
\text { oral and can be opportunistic pathogens [1]. }\end{array}$ & $15,21,33$ \\
\hline & Prevotella melaninogenica & $\begin{array}{l}\text { A species of bacterium in the normal flora of the upper respiratory tract. It is formerly called Bacteroides melaninogenicus, is a gram- } \\
\text { negative, anaerobic, rod-shaped bacterium that inhabits the oral cavity. It is an important human pathogen in various anaerobic infections [2]. }\end{array}$ & 1 \\
\hline & Prevotella pallens & $\begin{array}{l}\text { A genus of gram-negative bacteria. Prevotella spp. are members of the oral, vaginal, and gut microbiota and are often recovered from } \\
\text { anaerobic infections of the respiratory tract [3]. }\end{array}$ & 17 \\
\hline & Prevotella tannerae & $\begin{array}{c}\text { An obligately anaerobic, non-spore-forming, nonmotile, gram-negative, rod-shaped bacterium that was isolated from the human gingival } \\
\text { crevice [4]. }\end{array}$ & 28 \\
\hline & Prevotella nanceiensis & $\begin{array}{l}\text { A novel species isolated from human clinical samples, e.g., blood cultures, lung abscess pus, broncho-alveolar lavage fluid, obligately } \\
\text { anaerobic, non-spore-forming, non-motile, gram-negative coccoid and short rods [5]. }\end{array}$ & 26 \\
\hline & Porphyromonas spp. & $\begin{array}{l}\text { Associated with severe and chronic periodontal (tissues surrounding and supporting the tooth) diseases. Progression of the disease is caused } \\
\text { by colonization by this organism in an anaerobic environment in host tissues and severe progression results in loss of the tissues supporting } \\
\text { the tooth and eventually loss of the tooth itself [6]. }\end{array}$ & 25 \\
\hline \multirow{3}{*}{ Firmicutes } & Streptococcus spp. & $\begin{array}{l}\text { First isolated in } 1924 \text { from human carious (cavities) lesions and is the main cause of tooth decay. This organism thrives in a bacterial } \\
\text { community known as a dental plaque which forms on the surface of teeth. This organism has also been implicated in cases of infective } \\
\text { endocarditis [7]. }\end{array}$ & 12 \\
\hline & Streptococcus infantis & A species of alpha-haemolytic streptococci. It has been isolated from human tooth surfaces and pharynx [8]. & 2 \\
\hline & Veillonella spp. & $\begin{array}{l}\text { Well known for its lactate fermenting abilities. They are a normal bacterium in the intestines and oral mucosa of mammals. In humans they } \\
\text { have been rarely implicated in cases of osteomyelitis and endocarditis [9]. }\end{array}$ & 40 \\
\hline
\end{tabular}




\begin{tabular}{|c|c|c|c|}
\hline Phylum & Genus/Species & Description & OTUs \\
\hline & Veillonella dispar & A member of the normal human oral microbial community [10]. & 3,32 \\
\hline & Gemella morbillorum & $\begin{array}{l}\text { Previously known as Streptococcus morbillorum, is an anaerobic, gram-positive coccus which is a component of the normal flora of the } \\
\text { human gastrointestinal tract and the human oral microflora [11]. }\end{array}$ & 14 \\
\hline & Megasphaera spp. & $\begin{array}{l}\text { A commensal genus of Firmicutes classified within the class Negativicutes as a member of the Clostridia. Megasphaera spp. reside in the } \\
\text { human genitourinary tract. It has not yet been characterized using traditional methods, or the species name has not yet been validly published } \\
\text { [12]. }\end{array}$ & 37 \\
\hline & Clostridium spp. & Distinguished from the Bacilli by lacking aerobic respiration. They are obligate anaerobes and oxygen is toxic to them [13]. & 23 \\
\hline & Granulicatella spp. & $\begin{array}{l}\text { A facultatively anaerobic gram-positive, non-motile, non-sporulating bacterium. It is part of normal human oral flora and is thought to be a } \\
\text { cause of endocarditis [14]. }\end{array}$ & 7 \\
\hline & Granulicatella adjacens & $\begin{array}{c}\text { Formerly called Streptococcus adjacens or Abiotrophia adiacens, a species of gram-positive, non-motile, non-sporulating cocci isolated from } \\
\text { the throat flora, urine and blood of patients with endocarditis [15]. }\end{array}$ & 27 \\
\hline \multirow{7}{*}{ Proteobacteria } & Haemophilus parainfluenzae & A slow-growing gram negative bacteria that is a normal part of the human oropharyngeal flora. It is a cause of endocarditis in children [16]. & 4 \\
\hline & Campylobacter spp. & $\begin{array}{l}\text { The leading cause of bacterial food poisoning (campylobacteriosis) in the world, and is more prevalent than Salmonella enteritis } \\
\text { (salmonellosis). Severe health and economic problems are a result of widespread infections that affect up to } 1 \% \text { of the population [17]. }\end{array}$ & 5 \\
\hline & Neisseria spp. & $\begin{array}{l}\text { A nonpathogenic, commensal bacterium closely related to the pathogenic Neisseria meningitidis. Of the } 11 \text { species that colonize humans, } \\
\text { only two are pathogens, N. meningitidis and N. gonorrhoeae [18]. }\end{array}$ & 29 \\
\hline & Neisseria subflava & $\begin{array}{c}\text { Commonly isolated from the oral and respiratory tract of humans. This bacterium can be an opportunistic pathogen and has occasionally } \\
\text { been isolated from cases of endocarditis or bacteremia [19]. }\end{array}$ & 6 \\
\hline & Neisseria cinerea & Isolated in Germany from the nasopharyngeal mucosa of a healthy human [20]. & 261 \\
\hline & Moraxella spp. & $\begin{array}{l}\text { Part of the commensal flora of the upper respiratory tract. It is also recognized as the cause of a variety of human infectious diseases } \\
\text { including acute otitis media and sinusitis, which occur primarily in infants and young children [21]. }\end{array}$ & 9 \\
\hline & Pasteurella spp. & $\begin{array}{l}\text { One of the first pathogens ever studied, and is named after Louis Pasteur, who used it in his vaccination studies in the 1880s. This organism } \\
\text { usually resides in the mucous membranes of the intestinal, genital, and respiratory tissues and is an opportunistic pathogen [22]. }\end{array}$ & 193 \\
\hline \multirow[t]{2}{*}{ Fusobacteria } & Fusobacterium spp. & $\begin{array}{l}\text { Belongs to the normal microflora of the human oral and gastrointestinal tracts. It is a very long and slender spindle-shaped bacillus with } \\
\text { sharply pointed ends that is characterized by the ability to invade soft tissues. Although not considered a major dental pathogen on its own, } \\
\text { this anaerobe facilitates the aggregation and establishment of several other species including the dental pathogens Porphyromonas gingivalis } \\
\text { and Bacteroides forsythus [23]. }\end{array}$ & 11 \\
\hline & Leptotrichia spp. & $\begin{array}{c}\text { An anaerobic, gram-negative rod bacteria. It is a constituent of normal oral flora. Leptotrichiabuccalis can be clearly identified using live } \\
\text { blood analysis in dark field. They have a distinct form, which separates them from other rod forms [24]. }\end{array}$ & 20 \\
\hline Actinobacteria & Rothia mucilaginosa & $\begin{array}{l}\text { A gram-positive, cocci-shaped bacterium that inhabits the oral cavity. The bacterium is considered an opportunistic pathogen and has been } \\
\text { associated with endocarditis, meningitis, and peritonitis [25]. }\end{array}$ & 8 \\
\hline $\begin{array}{l}\text { Saccharibacteria } \\
\quad(\text { TM7-3) }\end{array}$ & N/A & $\begin{array}{l}\text { A major lineage of Bacteria, or a candidate phylum known solely through environmental } 16 \mathrm{~S} \text { rRNA sequences as no species had been grown } \\
\text { in the lab [26]. }\end{array}$ & 10 \\
\hline
\end{tabular}


Table A4. Statistical analysis across subjects of the highly abundant OTUs recovered from oral microbiomes of children due to swaking

\begin{tabular}{|c|c|c|c|c|c|c|c|c|c|c|c|c|c|c|c|c|c|c|c|c|c|c|c|c|c|}
\hline OTU no. & $\begin{array}{c}\begin{array}{c}\text { OTU } \\
\text { abundance }\end{array} \\
\end{array}$ & Taxonomy & BEF2 & AF2 & BEF6 & AF6 & BEF8 & AF8 & BEF9 & AF9 & BEF10 & AF10 & BEF12 & AF12 & BEF14 & AF14 & BEF15 & AF15 & BEF19 & AF19 $\mathrm{I}$ & BEF20 & AF20 & $\begin{array}{c}\text { Mean } \\
\text { BEF }\end{array}$ & $\begin{array}{c}\text { Mean } \\
\text { AF }\end{array}$ & $\begin{array}{c}\mathbf{P} \\
\text { value } \\
\end{array}$ \\
\hline Otu2 & 235993 & \begin{tabular}{|c|} 
Bacteria; Firmicutes; Bacilli; \\
Lactobacillales; \\
Streptococcaceae; Streptococcus; \\
Streptococcus_infantis \\
\end{tabular} & 11062 & 11570 & 7278 & 9371 & 10372 & 16437 & 13938 & 14394 & 14000 & 16547 & \begin{tabular}{|l|l|}
6064 \\
\end{tabular} & 8382 & 6956 & 16884 & 18405 & 13464 & \begin{tabular}{|l|}
4544 \\
\end{tabular} & 13569 & 14256 & 8500 & $|10687.5|$ & 12911.8 & 0.208 \\
\hline Otu1 & 195394 & $\begin{array}{c}\text { Bacteria; Bacteroidetes; } \\
\text { Bacteroidia; Bacteroidales; } \\
\text { Prevotellaceae; Prevotella; } \\
\text { Prevotella_melaninogenica }\end{array}$ & 15251 & 2972 & 12398 & 10906 & 19902 & 6250 & 8512 & 4404 & 9177 & 17991 & 1640 & 5479 & 4465 & 12883 & 3700 & 11478 & 21756 & 5495 & 12085 & 8650 & $\mid 10888.6$ & 8659.8 & 0.474 \\
\hline Otu3 & 147490 & \begin{tabular}{|c|} 
Bacteria; Firmicutes; Clostridia; \\
Clostridiales; Veillonellaceae; \\
Veillonella; Veillonella_dispar \\
\end{tabular} & 8044 & 3356 & 9825 & 5142 & 13444 & 5971 & 10524 & 3200 & 9441 & 9744 & 5498 & 6325 & 5589 & 6824 & 2186 & 8438 & 13926 & 7560 & 10655 & 1798 & 8913.2 & 5835.8 & 0.08 \\
\hline Otu4 & 92051 & \begin{tabular}{|c|} 
Bacteria; Proteobacteria; \\
Gammaproteobacteria; \\
Pasteurellales; Pasteurellaceae; \\
Haemophilus; \\
Haemophilus_parainfluenzae \\
\end{tabular} & 12642 & 7845 & 842 & 1941 & 1587 & 2831 & 1634 & 7295 & 5771 & 3147 & $\mid 6416$ & 4897 & 1116 & 8691 & 6067 & 1646 & 619 & 1804 & 5901 & 9359 & 4259.5 & 4945.6 & 0.611 \\
\hline Otu11 & 58531 & \begin{tabular}{|c|} 
Bacteria; Fusobacteria; \\
Fusobacteriia; Fusobacteriales; \\
Fusobacteriaceae; Fusobacterium
\end{tabular} & 1690 & 2370 & 3060 & 4357 & $\mid 1089$ & 3688 & 3934 & 6327 & 1752 & 793 & 1498 & 1760 & 5147 & 1874 & 1641 & 4427 & 1395 & 1329 & 5658 & 4742 & 2686.4 & $\mid 3166.7$ & 0.446 \\
\hline Otu32 & 50183 & \begin{tabular}{|c|} 
Bacteria; Firmicutes; Clostridia; \\
Clostridiales; Veillonellaceae; \\
Veillonella; Veillonella_dispar \\
\end{tabular} & 3563 & 802 & 4934 & 5040 & 4315 & 2150 & 1399 & 816 & 2116 & 2866 & \begin{tabular}{|l|}
3997 \\
\end{tabular} & 2932 & 1420 & 1023 & 704 & 965 & 4818 & 2740 & 1990 & 1593 & 2925.6 & 2092.7 & 0.049 \\
\hline Otu8 & 49093 & $\begin{array}{l}\text { Bacteria; Actinobacteria; } \\
\text { Actinobacteria; } \\
\text { Actinomycetales; } \\
\text { Micrococcaceae; Rothia; } \\
\text { Rothia_mucilaginosa }\end{array}$ & 5378 & 948 & 458 & 419 & 1608 & 2198 & 4793 & 3265 & 4079 & 2346 & 2484 & 1503 & 959 & 830 & 5074 & 1636 & 2190 & 2268 & 4500 & 2157 & 3152.3 & 1757 & 0.025 \\
\hline Otu14 & 46624 & $\begin{array}{l}\text { Bacteria; Firmicutes; Bacilli; } \\
\text { Gemellales; Gemellaceae }\end{array}$ & 2425 & 5232 & 2153 & 2774 & 803 & 3783 & 951 & 1463 & 2915 & 2086 & 2246 & 5832 & 1170 & 4094 & 3432 & 1546 & 236 & 1448 & 1352 & 683 & 1768.3 & 2894.1 & 0.093 \\
\hline Otu6 & 40872 & \begin{tabular}{|c|} 
Bacteria; Proteobacteria; \\
Betaproteobacteria; Neisseriales; \\
Neisseriaceae; Neisseria; \\
Neisseria_subflava \\
\end{tabular} & 3818 & 4766 & 708 & 208 & 1158 & 3386 & 8793 & 2683 & 371 & 110 & 27 & 362 & 3432 & 2877 & 3156 & 501 & 392 & 946 & 1669 & 1509 & 2352.4 & 1734.8 & 0.417 \\
\hline Otu12 & 34029 & $\begin{array}{c}\text { Bacteria; Firmicutes; Bacilli; } \\
\text { Lactobacillales; } \\
\text { Streptococcaceae; Streptococcus }\end{array}$ & 487 & 1567 & 468 & 130 & 1323 & 1673 & 194 & 1306 & 1862 & 2852 & 1573 & 2972 & 570 & 1585 & 179 & 6526 & 2685 & 3759 & 1072 & 1246 & 1041.3 & 2361.6 & 0.05 \\
\hline Otu10 & 33068 & Bacteria; TM7; TM7-3 & 1 & 640 & 2043 & 969 & 284 & 488 & 1059 & 495 & 1233 & 517 & 3846 & 3684 & 679 & 222 & 515 & 397 & 4118 & 2307 & 3827 & 5744 & 1760.5 & 1546.3 & 0.519 \\
\hline Otu7 & 32641 & $\begin{array}{l}\text { Bacteria; Firmicutes; Bacilli; } \\
\text { Lactobacillales; } \\
\text { Carnobacteriaceae; } \\
\text { Granulicatella } \\
\end{array}$ & 3968 & 2096 & 1733 & 1851 & 393 & 1201 & 548 & 2721 & 284 & 438 & 385 & 2072 & 769 & 4233 & 6953 & 1337 & 133 & 844 & 534 & 148 & 1570 & 1694.1 & 0.878 \\
\hline Otu5 & 32092 & Bacteria; Proteobacteria; & 1896 & 864 & 2344 & 1265 & 3027 & 405 & 1494 & 853 & 1702 & 662 & 1462 & 739 & 3057 & 873 & 835 & 396 & 3641 & 1719 & 3626 & 1232 & 2308.4 & 900.8 & 0 \\
\hline
\end{tabular}




\begin{tabular}{|c|c|c|c|c|c|c|c|c|c|c|c|c|c|c|c|c|c|c|c|c|c|c|c|c|c|}
\hline OTU no. & $\begin{array}{c}\begin{array}{c}\text { OTU } \\
\text { abundance }\end{array} \\
\end{array}$ & Taxonomy & BEF2 & AF2 & BEF6 & AF6 & BEF8 & AF8 & BEF9 & AF9 & BEF10 & AF10 & BEF12 & AF12 & BEF14 & AF14 & BEF15 & AF15 & BEF19 & AF19 & BEF20 & AF 20 & \begin{tabular}{|c|} 
Mean \\
BEF
\end{tabular} & $\begin{array}{c}\text { Mean } \\
\mathbf{A F}\end{array}$ & $\begin{array}{c}P \\
\text { value }\end{array}$ \\
\hline & & $\begin{array}{c}\text { Epsilonproteobacteria; } \\
\text { Campylobacterales; } \\
\text { Campylobacteraceae; } \\
\text { Campylobacter } \\
\end{array}$ & & & & & & & & & & & & & & & & & & & & & & & \\
\hline Otu261 & 27911 & \begin{tabular}{|c|} 
Bacteria; Proteobacteria; \\
Betaproteobacteria; Neisseriales; \\
Neisseriaceae; Neisseria; \\
Neisseria_cinerea
\end{tabular} & 1318 & 2960 & 1512 & 173 & 1817 & 1428 & 1695 & 4513 & 10 & 94 & 348 & 40 & 2661 & 1374 & 7146 & 241 & 141 & 193 & 196 & 51 & 1684.4 & 1106.7 & 0.493 \\
\hline Otu29 & 24893 & $\begin{array}{c}\text { Bacteria; Proteobacteria; } \\
\text { Betaproteobacteria; Neisseriales; } \\
\text { Neisseriaceae; Neisseria }\end{array}$ & 1204 & 4196 & 1753 & 151 & 291 & 1799 & $\mid 1931$ & 2459 & 276 & 1394 & 938 & 2197 & 1258 & 1718 & 495 & 1368 & 933 & 351 & 27 & 154 & 910.6 & 1578.7 & 0.122 \\
\hline Otu17 & 23783 & $\begin{array}{c}\text { Bacteria; Bacteroidetes; } \\
\text { Bacteroidia; Bacteroidales; } \\
\text { Prevotellaceae; Prevotella; } \\
\text { Prevotella_pallens }\end{array}$ & 209 & 158 & 2811 & 1991 & 3170 & 1185 & 253 & 344 & 390 & 143 & 1413 & 1889 & 642 & 727 & 553 & 699 & 2042 & 790 & 2090 & 2284 & 1357.3 & 1021 & 0.204 \\
\hline Otu15 & 22697 & $\begin{array}{c}\text { Bacteria; Bacteroidetes; } \\
\text { Bacteroidia; Bacteroidales; } \\
\text { Prevotellaceae; Prevotella } \\
\end{array}$ & 792 & 455 & 2528 & 1294 & 3798 & 773 & 483 & 272 & 1072 & 1604 & 1043 & 2485 & 695 & 355 & 198 & 523 & 2114 & 674 & 255 & 1284 & 1297.8 & 971.9 & 0.452 \\
\hline Otu25 & 20994 & $\begin{array}{c}\text { Bacteria; Bacteroidetes; } \\
\text { Bacteroidia; Bacteroidales; } \\
\text { Porphyromonadaceae; } \\
\text { Porphyromonas } \\
\end{array}$ & 785 & 1237 & 597 & 596 & 331 & 1719 & 3075 & 1734 & 61 & 116 & 386 & 878 & 2679 & 1383 & 1222 & 760 & 952 & 311 & 1780 & 392 & 1186.8 & 912.9 & 0.372 \\
\hline Otu21 & 18426 & $\begin{array}{c}\text { Bacteria; Bacteroidetes; } \\
\text { Bacteroidia; Bacteroidales; } \\
\text { Paraprevotellaceae; Prevotella } \\
\end{array}$ & 622 & 119 & 1301 & 2576 & 1203 & 870 & 1530 & 523 & 1843 & 548 & 485 & 513 & 1291 & 273 & 882 & 220 & 1835 & 330 & 1130 & 332 & 1212.2 & 630.4 & 0.046 \\
\hline Otu20 & 17155 & $\begin{array}{c}\text { Bacteria; Fusobacteria; } \\
\text { Fusobacteriia; Fusobacteriales; } \\
\text { Leptotrichiaceae; Leptotrichia }\end{array}$ & 91 & 128 & 1132 & 460 & 105 & 1377 & 454 & 2226 & 941 & 247 & 2634 & 1290 & 584 & 277 & 166 & 373 & 1213 & 2217 & 595 & 645 & 791.5 & 924 & 0.676 \\
\hline Otu27 & 13910 & $\begin{array}{c}\text { Bacteria; Firmicutes; Bacilli; } \\
\text { Lactobacillales; } \\
\text { Carnobacteriaceae; } \\
\text { Granulicatella } \\
\end{array}$ & 745 & 527 & 229 & 314 & 364 & 487 & 694 & 1237 & 1869 & 513 & 809 & 661 & 251 & 619 & 413 & 638 & 442 & 1081 & 1215 & 802 & 703.1 & 687.9 & 0.935 \\
\hline Otu26 & 13468 & $\begin{array}{c}\text { Bacteria; Bacteroidetes; } \\
\text { Bacteroidia; Bacteroidales; } \\
\text { Prevotellaceae; Prevotella; } \\
\text { Prevotella_nanceiensis }\end{array}$ & 800 & 947 & $\mid 1297$ & 155 & 177 & 898 & 1172 & 1185 & 54 & 173 & 104 & 544 & 457 & 2199 & 556 & 751 & 212 & 338 & 822 & 627 & 565.1 & 781.7 & 0.368 \\
\hline Otu9 & 13242 & $\begin{array}{l}\text { Bacteria; Proteobacteria; } \\
\text { Gammaproteobacteria; } \\
\text { Pseudomonadales; } \\
\text { Moraxellaceae; Moraxella } \\
\end{array}$ & 1 & 6634 & 0 & 60 & 79 & 562 & 106 & 849 & 778 & 362 & 5 & 750 & 1575 & 1182 & 263 & 1 & 0 & 21 & 14 & 0 & 282.1 & 1042.1 & 0.283 \\
\hline Otu40 & 13051 & $\begin{array}{c}\begin{array}{c}\text { Bacteria; Firmicutes; Clostridia; } \\
\text { Clostridiales; Veillonellaceae; } \\
\text { Veillonella }\end{array} \\
\end{array}$ & 797 & 78 & 1525 & 386 & 445 & 1210 & 745 & 462 & 27 & 281 & 17 & 326 & 793 & 2069 & 718 & 1551 & 747 & 723 & 108 & 43 & 592.2 & 712.9 & 0.615 \\
\hline Otu33 & 12906 & $\begin{array}{c}\text { Bacteria; Bacteroidetes; } \\
\text { Bacteroidia; Bacteroidales; }\end{array}$ & 825 & 25 & 2041 & 579 & 244 & 1491 & 699 & 2294 & 0 & 43 & 63 & 283 & 390 & 574 & 1564 & 594 & 403 & 566 & 176 & 52 & 640.5 & 650.1 & 0.975 \\
\hline
\end{tabular}

APPLIED ECOLOGY AND ENVIRONMENTAL RESEARCH 18(5):7089-7138.

http://www.aloki.hu • ISSN 15891623 (Print) • ISSN 17850037 (Online)

DOI: http://dx.doi.org/10.15666/aeer/1805_70897138

(c) 2020, ALÖKI Kft., Budapest, Hungary 


\begin{tabular}{|c|c|c|c|c|c|c|c|c|c|c|c|c|c|c|c|c|c|c|c|c|c|c|c|c|c|}
\hline OTU no. & $\begin{array}{c}\text { OTU } \\
\text { abundance }\end{array}$ & Taxonomy & BEF2 & AF2 & BEF6 & AF6 & BEF8 & AF8 & BEF9 & AF9 & BEF10 & AF10 & BEF12 & AF12 & BEF14 & AF14 & BEF15 & AF15 & BEF19 & AF19 & BEF20 & AF20 & \begin{tabular}{|c|} 
Mean \\
BEF
\end{tabular} & $\begin{array}{c}\text { Mean } \\
\mathbf{A F}\end{array}$ & $\begin{array}{c}\mathbf{P} \\
\text { value }\end{array}$ \\
\hline & & Paraprevotellaceae; Prevotella & & & & & & & & & & & & & & & & & & & & & & & \\
\hline Otu37 & 12672 & $\begin{array}{c}\text { Bacteria; Firmicutes; Clostridia; } \\
\text { Clostridiales; Veillonellaceae; } \\
\text { Megasphaera }\end{array}$ & 171 & 37 & 1119 & 1683 & 977 & 798 & 672 & 748 & 111 & 376 & 299 & 929 & 73 & 907 & 16 & 180 & 417 & 1659 & 623 & 877 & 447.8 & 819.4 & 0.027 \\
\hline Otu23 & 11908 & $\begin{array}{c}\text { Bacteria; Firmicutes; Clostridia; } \\
\text { Clostridiales }\end{array}$ & 201 & 2117 & 328 & 924 & 24 & 606 & 214 & 2345 & 232 & 49 & 538 & 1131 & 744 & 209 & 241 & 83 & 798 & 673 & 149 & 302 & 346.9 & 843.9 & 0.112 \\
\hline Otu193 & 11315 & \begin{tabular}{|c|} 
Bacteria; Proteobacteria; \\
Gammaproteobacteria; \\
Pasteurellales; Pasteurellaceae \\
\end{tabular} & 2650 & 318 & 416 & 163 & 1426 & 515 & 1844 & 354 & 197 & 230 & 811 & 427 & 482 & 428 & 178 & 65 & 292 & 285 & 189 & 45 & 848.5 & 283 & 0.049 \\
\hline Otu28 & 10024 & \begin{tabular}{|c|} 
Bacteria; Bacteroidetes; \\
Bacteroidia; Bacteroidales; \\
Paraprevotellaceae; Prevotella; \\
Prevotella_tannerae \\
\end{tabular} & 10 & 185 & 639 & 3606 & 53 & 663 & 515 & 174 & 27 & 84 & 1015 & 193 & 1624 & 97 & 70 & 627 & 115 & 286 & 21 & 20 & 408.9 & 593.5 & 0.63 \\
\hline
\end{tabular}

